\title{
The Flow Regimes Associated with Hydraulic Fractured Horizontal Wells in Shale Formations
}

\author{
Saba J. Raeisi \\ West Virginia University
}

Follow this and additional works at: https://researchrepository.wvu.edu/etd

\section{Recommended Citation}

Raeisi, Saba J., "The Flow Regimes Associated with Hydraulic Fractured Horizontal Wells in Shale Formations" (2013). Graduate Theses, Dissertations, and Problem Reports. 4992.

https://researchrepository.wvu.edu/etd/4992

This Thesis is protected by copyright and/or related rights. It has been brought to you by the The Research Repository @ WVU with permission from the rights-holder(s). You are free to use this Thesis in any way that is permitted by the copyright and related rights legislation that applies to your use. For other uses you must obtain permission from the rights-holder(s) directly, unless additional rights are indicated by a Creative Commons license in the record and/ or on the work itself. This Thesis has been accepted for inclusion in WVU Graduate Theses, Dissertations, and Problem Reports collection by an authorized administrator of The Research Repository @ WVU. For more information, please contact researchrepository@mail.wvu.edu. 
The Flow Regimes Associated with Hydraulic Fractured Horizontal Wells in Shale Formations

By

Saba J. Raeisi

Thesis submitted to the College of Engineering and Mineral Resources at West Virginia University in partial fulfillment of the requirements for the degree of

\author{
Master of Science \\ In \\ Petroleum and Natural Gas Engineering \\ Approved by \\ Kashy Aminian, Ph.D., Chair \\ Sam Ameri, M.S. \\ Daniel E. Della-Guistina, Ph.D. \\ Department of Petroleum and Natural Gas Engineering \\ Morgantown, West Virginia \\ 2013
}

Keywords: Shale Gas, Horizontal well, Hydraulic fracture, Natural fracture

Copyright 2013 Saba J. Raeisi 


\section{ABSTRACT \\ The Flow Regimes Associated with Hydraulically Fractured Horizontal Wells in Shale Formations \\ Saba J. Raeisi}

Shale gas in the United States went from a practically invisible resource to massive reserves that challenge the largest conventional gas accumulations in the world. Shale gas success is directly the result of economically managed deployment of petroleum technology, namely horizontal wells .Horizontal drilling and multi-stage stimulation technologies are driving the successful development of shale plays.

The production performance of hydraulically fractured horizontal wells in naturally fractured ultra-low permeability shale formations is not well established since the interaction among the hydraulic fractures, natural fracture system, and the shale matrix leads to a complex production mechanism that has not been fully investigated. Modeling and simulation of shale gas reservoir is challenging due to the complex nature of the reservoir, the strong heterogeneous and anisotropic characteristics of the system, different reservoir behavior, multiple gas-storage mechanisms and unique attributes that control the production.

The objective of this study was to understand the impact of hydraulic fracture on the flow behavior of the horizontal wells completed in ultralow permeability shale formations such as Marcellus Shale. A synthetic numerical model was developed using a commercial reservoir simulator (Eclipse) with different realizations to identify the impact of number of hydraulic fractures and gas desorption on the flow regime. Diagnostic plots were used to identify the flow regimes. The diagnostic plots were also used to investigate the impact of hydraulic fractures and shale characteristics on the duration of the flow periods. The most dominant flow regimes included the "Early Linear Flow" and "Compounded Linear Flow." The detail investigation of the flow regimes revealed that as the number of hydraulic fracture increased, the duration of the "Early Linear Flow" became longer while the duration of the "Compounded Linear Flow" became shorter. Furthermore as the fracture half-length was reduced, the "Early Linear Flow" became shorter and the "Compounded Linear Flow became longer. Also as the fissure permeability increased, the linear flow diminished. 


\section{ACKNOWLEDGEMENTS}

I would like to show my gratitude and appreciation to my research advisor Dr. Kashy Aminian for his guidance, advices, and encouragements during the course of this research. His enthusiasm, humor and support helped me to accomplish my research study and encouraged me to achieve my goals toward my professional life.

My appreciation goes to Dr. Samuel Ameri for all of his supports in every way and I wouldn't be here without him. He is not just a professor to me but he made me feel like a family and thanks for all he has done for me and accepting to be a member of my committee. I express my thankfulness to the administrative associate of PNGE department, Beverly Matheny, for her kindness, friendship, and her presence to help the students. Dr. Daniel E. Della-Guistina who generously accepted to be a member of my committee as well. Also my appreciations goes to Dr. Shahab Mohaghegh and team pearl for giving me the opportunity to be part of the team and work on their projects and learn from their knowledge.

Special thanks to my family. Words cannot express how grateful I am to my mother, father and sister for all of the sacrifices that they have made for me and I wouldn't be here without them. I would also like to thank my amazing friends for being always supportive and understanding in every situation and keeping me motivated to pursue my education.

\section{$70 \mathrm{My}$ Z amily and Friends.}




\section{Table of Contents}

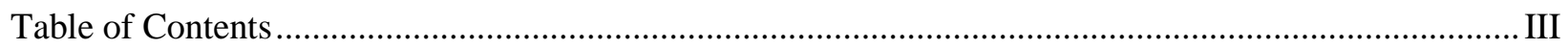

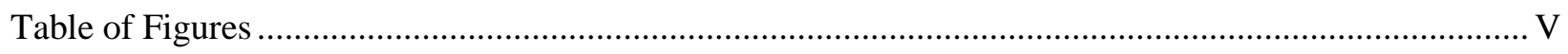

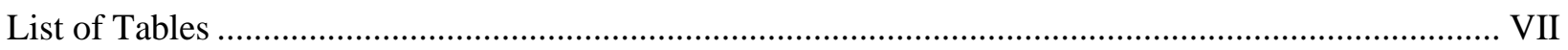

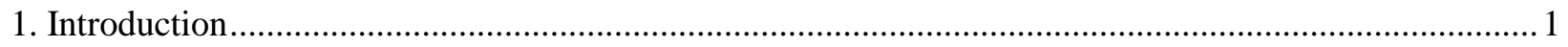

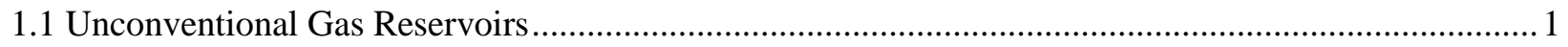

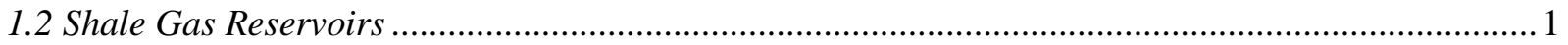

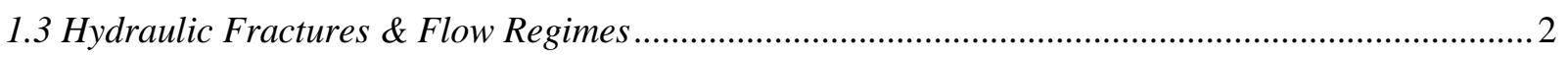

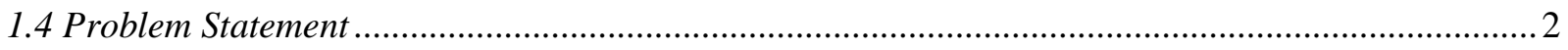

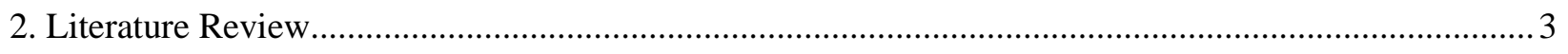

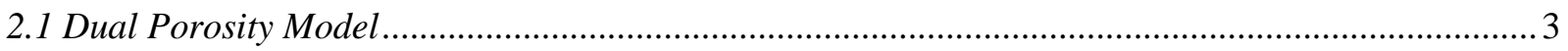

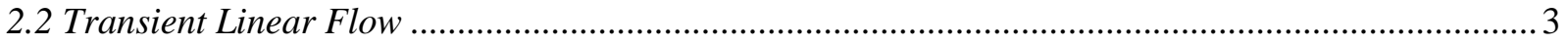

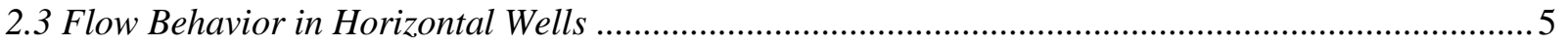

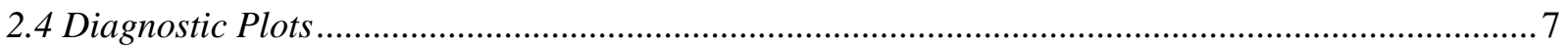

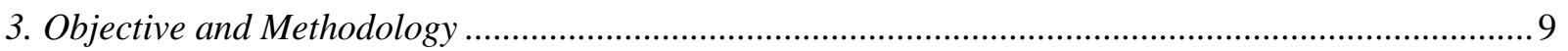

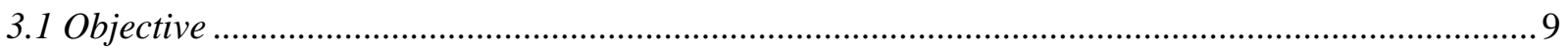

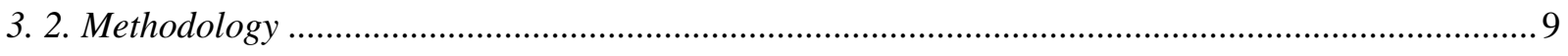

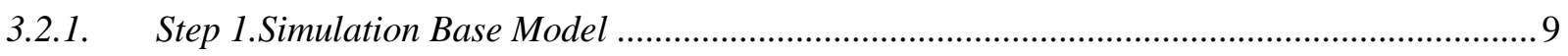

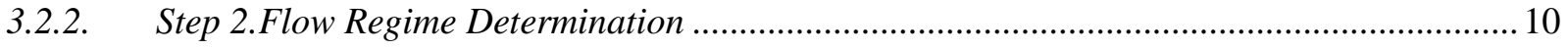

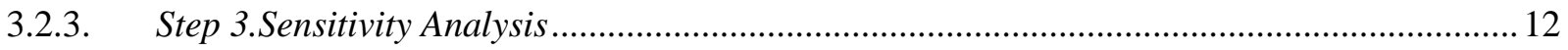

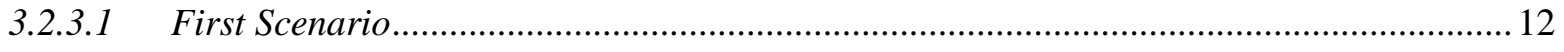

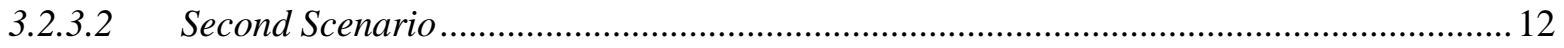

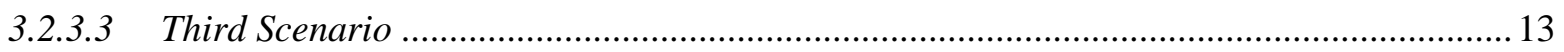

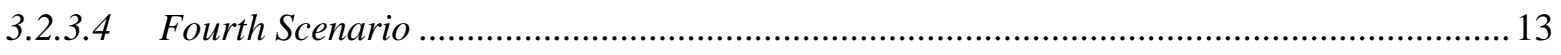

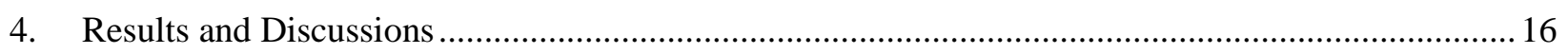

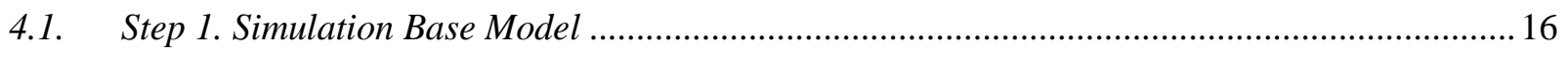

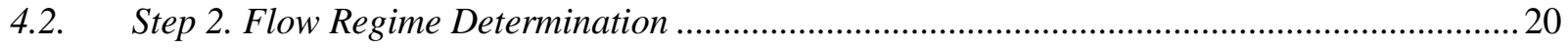

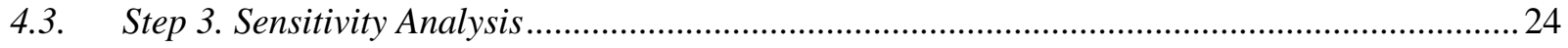

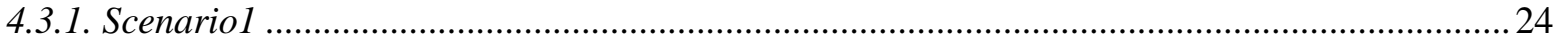

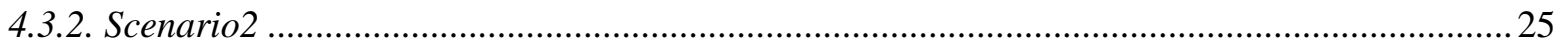

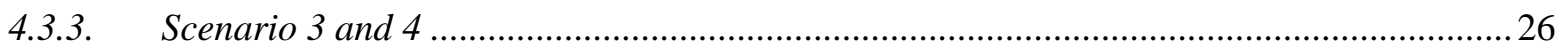

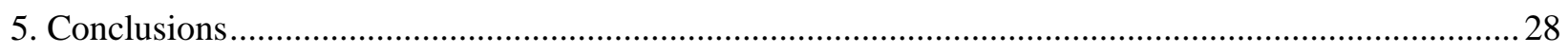

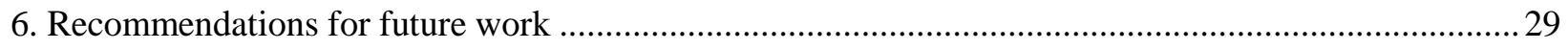




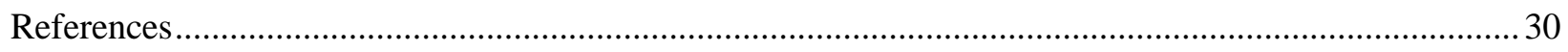

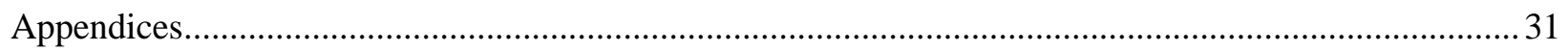

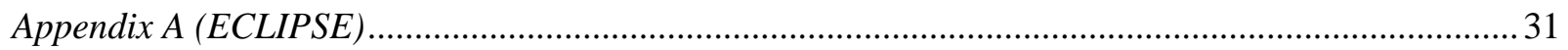

Appendix B (ECLIPSE Models Layouts) ……............................................................................ 44

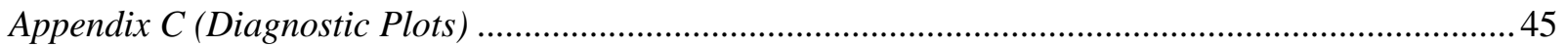




\section{Table of Figures}

Figure 1 - Illustration of the Five Flow Regions (Olusehun, 2009) ....................................................... 3

Figure 2 - Flow Behavior in Horizontal well (No Hydraulic Fractures) ................................................... 5

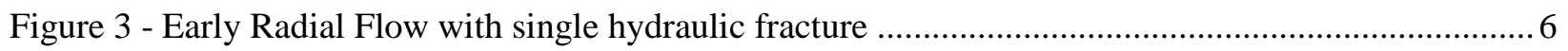

Figure 4 - Linear flow regimes with two hydraulic fractures ............................................................ 6

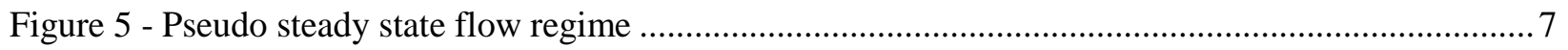

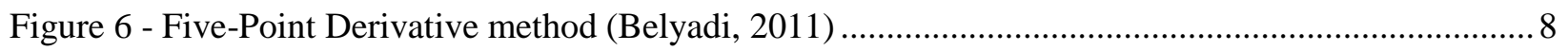

Figure 7 - Diagnostic Plot Illustrating Various Flow Regimes ......................................................... 13

Figure 8 - Diagnostic Plot Illustrating Various Flow Regimes ............................................................. 14

Figure 9 - Production profile of 3000 feet horizontal well with Desorption............................................. 16

Figure 10 - Production profile of 3000 feet horizontal well with No Desorption..................................... 17

Figure 11 - The impact of different number of hydraulic fractures on cumulative production.................. 18

Figure 12 - The impact of different number of hydraulic fractures on cumulative production .................. 19

Figure 13 - Diagnostic plot showing flow periods for all 4 cases.........................................................20

Figure 14 - Diagnostic plot showing flow periods for all 4 cases.........................................................2

Figure 15 - Diagnostic plot illustrating various flow periods (4 Fracs) ................................................22

Figure 16 - Diagnostic plot illustrating various flow periods (4 Fracs) ..................................................2

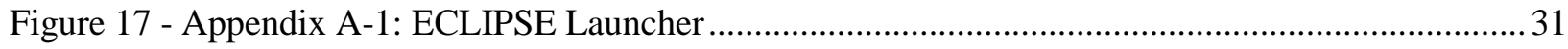

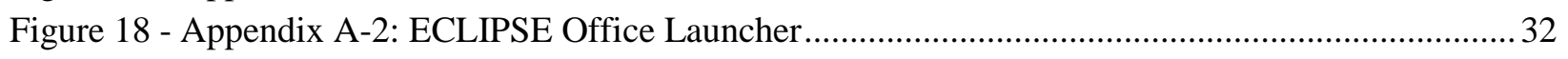

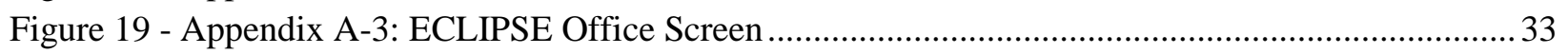

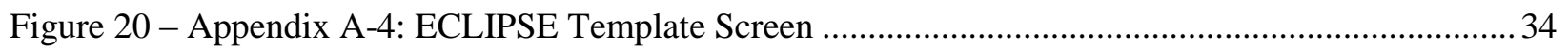

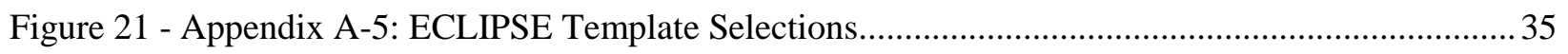

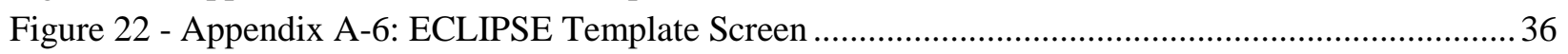

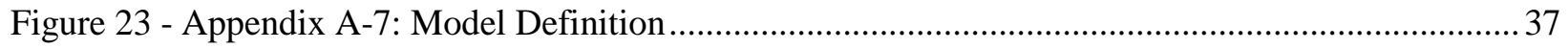

Figure 24 - Appendix A-8: Reservoir Layers Description .................................................................. 37

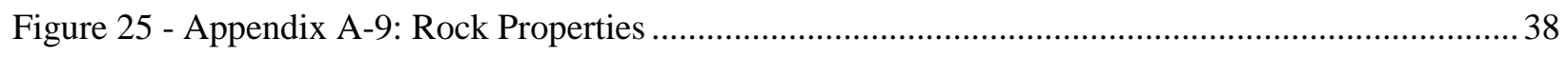

Figure 26 - Appendix A-10: Non-Equilibrium Initial Conditions ....................................................... 38

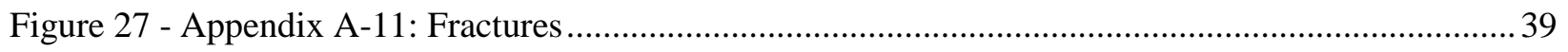

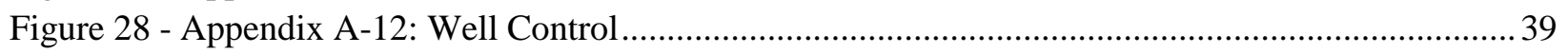

Figure 29 - Appendix A-13: Production Well Control ......................................................................... 40

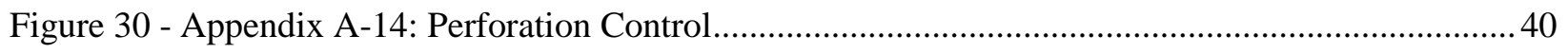

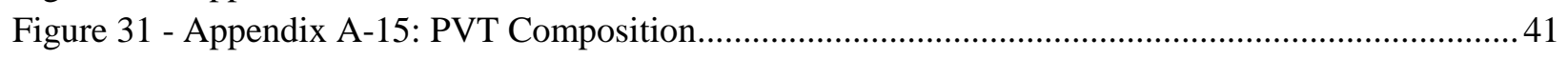

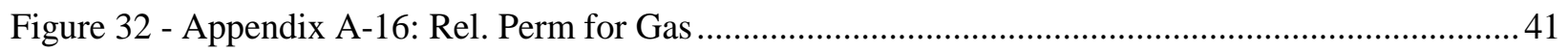

Figure 33 - Appendix A-17: Rel. Perm for Water ............................................................................ 42

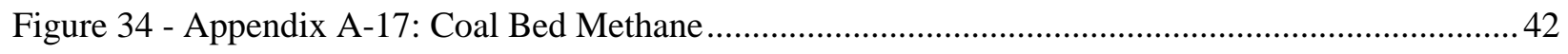

Figure 35 - Appendix A-18: Simulation Controls for Gridding Controls .................................................43

Figure 36 - Appendix A-19: Simulation Controls for Turning Controls ................................................ 43

Figure 37 - Appendix B-1: Model with 1 Hydraulic Fracture .............................................................. 44

Figure 38 - Appendix B-2: Model with 2 Hydraulic Fractures.......................................................... 44

Figure 39 - Appendix B-3: Model with 4 Hydraulic Fractures............................................................4 44

Figure 40 - Appendix C-1: Diagnostic Plot for the model w/ no desorption-250 ft Half-length (1HF) ..... 45

Figure 41 - Appendix C-2: Diagnostic Plot for the model w/ no desorption-250 ft Half-length (2HFs).... 45

Figure 42 - Appendix C-3: Diagnostic Plot for the model w/ no desorption-250 ft Half-length (4HFs).... 46 
Figure 43 - Appendix C-4: Diagnostic Plot for the model w/ no desorption-250 ft Half-length ................46

Figure 44 - Appendix C-5: Diagnostic plot for model for 2 hydraulic fractures w/ 0.001 permeability .... 47

Figure 45 - Appendix C-6: Diagnostic plot for model for 2 hydraulic fractures w/ 0.005 permeability .... 47

Figure 46 - Appendix C-7: Diagnostic plot for model for 2 hydraulic fractures w/ 0.01 permeability ...... 48

Figure 47 - Appendix C-8: Diagnostic plots for all scenarios for model with 2 hydraulic fractures.......... 48

Figure 48 - Appendix C-9: Diagnostic plots for all scenarios for model with 4 hydraulic fractures.......... 49 


\section{List of Tables}

Table 1 - Summary of Analysis Equations for the Constant $\boldsymbol{P} \boldsymbol{w} \boldsymbol{f}$ Inner Boundary Case (Slab Matrix) This case is the $\boldsymbol{m P \boldsymbol { i }}-\boldsymbol{m}(\boldsymbol{P} \boldsymbol{w} \boldsymbol{f}) \boldsymbol{q g}$ vs. $4 \boldsymbol{t} \quad$ (Olusehun, 2009) ............................................................... 4

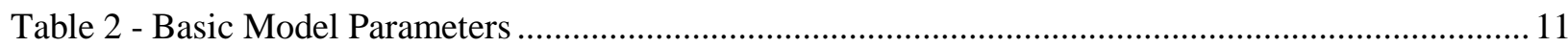

Table 3 - Constant Inputs for layers and Rock properties................................................................. 12

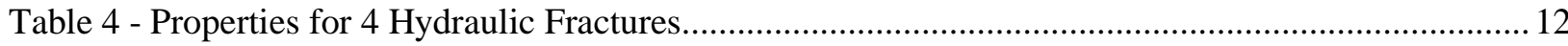

Table 5 - Variable Parameters for Each Case …................................................................................... 15

Table 6 - Hydraulic Fractures' Properties for 4 Fractures ........................................................................ 15

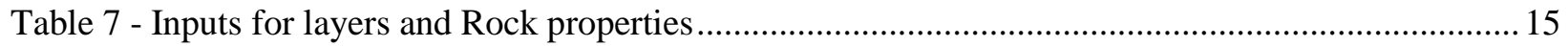

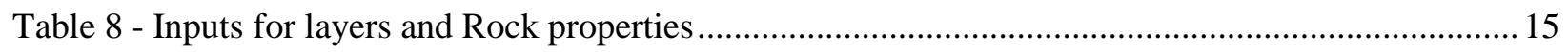

Table 9 - Inputs for layers and Rock properties ............................................................................... 15

Table 10 -Desorption w/ 500 feet Half Length \& 0.002 Permeability .....................................................22

Table 11 - No Desorption w/ 500 feet Half Length \& 0.002 Permeability ...............................................23

Table 12 - No Desorption w/ 250 feet Half Length \& 0.002 Perm.......................................................... 24

Table 13 - No Desorption Model w/ 500 feet Half Length and 0.001 Perm............................................25

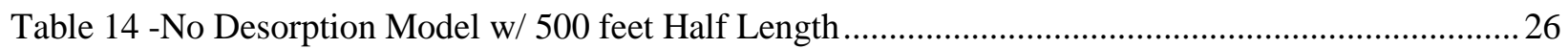




\section{Introduction}

\subsection{Unconventional Gas Reservoirs}

One of the fastest growing regions within the petroleum industry is Unconventional Gas Reservoirs, which includes Tight Gas Sand, Shale Gas, and Coal Bed Methane. These reservoirs have a large effect on hydrocarbon production in United States, and are categorized based on the geological and petrophysical systems of heterogeneities. Unconventional gas reservoirs naturally have good rock particle texture, display gas storage and flow characteristics and pore size spreading. The following are common characteristics of unconventional gas reservoirs:

1. They are difficult to develop due to their low permeability relative to conventional reservoirs

2. They have large volumes of hydrocarbons in place

3. They require advanced stimulation technologies

4. They are more expensive to drill into and complete compared to conventional gas reservoirs.

\subsection{Shale Gas Reservoirs}

Shale is a form of clay or mud that can easily split into layers, which were compressed by formation pressure or other geological conditions and turned into a fine-grained sedimentary rock. Shale gas reservoirs have been known as highly organic formations with ranges of permeability from $0.1 \mathrm{mD}$ to $10.7 \mathrm{mD}$. The influence of adsorbed gas to gas produced in shale is not as dominant as in coalbed methane reservoirs. Due to shale's ultra-low permeability, in order to produce gas at commercial rates and volumes from shale, horizontal drilling and hydraulic fracturing are required.

U.S shale gas production has been grown rapidly in recent years. (Kalantari, 2010) In 2008 the gas production from shale was 2.02 trillion cubic feet (57 billion cubic meters), which was a $71 \%$ increase over the previous year and later in 2009 the production increased an additional $51 \%$ to 3.11 trillion cubic feet ( 88 billion cubic meters) and by end of 2009 year production had reached 60.6 trillion cubic feet (1.72 trillion cubic meters). In 2007 the $13^{\text {th }}$ largest source of natural gas in U.S was the Antrim gas field with136 billion cubic feet (3.9 billion cubic meters) of gas production. In the same year, Barnett shale, which is located in the Ft. Worth Basin of North Central Texas, had 1.11 trillion cubic feet (31 billion cubic meters) of gas production and the formation has become a gas producer since the large success of the Barnett play (Anon., 2013). 


\subsection{Hydraulic Fractures \& Flow Regimes}

Hydraulic fracturing has significant effect on productivity of shale gas wells. This technique is a stimulation process of the well performed to maximize the extraction of underground resources including oil, natural gas, and water, fracturing occurs by injecting fluid into an underground formation at a high pressure to part of the formation. At this stage the injected fluid and proppants will pump into the created fracture to keep the fracture open and generate conductive flow path with large permeability toward the wellbore.

In 1988, Rosa and Carvalho were the first to extend the horizontal well solutions to dual porosity systems. Pressure transient in dual porosity systems have general solutions that are provided by log-log type curves, meanwhile the flow regimes are predicted by the model and rarely observed from field data. In 2009, Lu et al developed the direct synthesis method for horizontal wells, which concluded based on reservoir parameters that a number of flow regimes exist and one or more could be masked or missing. The flow regimes include the early radial flow in the vertical direction and it has short duration in thin or high vertical permeability reservoirs. Another flow regime is known as the intermediate linear flow regime and is developed because of greater length of horizontal well compared to the formation thickness. The transition period from short duration to intermediate linear becomes leading and the late radial flow period will be observed afterward (Belyadi, 2010).

\subsection{Problem Statement}

The production performance of hydraulically fractured horizontal wells in naturally fractured ultra-low permeability shale formations is not well established. The interaction among the hydraulic fracture, natural fracture systems, and the shale matrix, which contains both adsorbed and free gas, leads to a complex production mechanism that has not been fully investigated. Hydraulic fractures, which are high conductivity channels, have a significant impact on the flow geometry in the reservoir. 


\section{Literature Review}

\subsection{Dual Porosity Model}

Shale gas has naturally fractured reservoirs that have two distinct porosities, one in the matrix and one in the fractures. These types of reservoirs consist of irregular fractures that can be represented by homogeneous dual porosity model (Warren, 1963). This concept was formulated by Barenblatt et al based on limited derivation of the pressure in block sections and later extended to well test analysis by Warren and Root. Dual porosity has complex interface between the naturally fractured reservoir and rock matrix, also the volume of hydrocarbon stored within the natural fractures is much lower than is stored in the matrix. Once the natural fractures have been drained, the large volume of hydrocarbons contained within the bulk of the reservoir (matrix) begins flow (Olusehun, 2009).

\subsection{Transient Linear Flow}

Horizontal wells in hydraulically fractured shale gas have transient linear behavior. This behavior is characterized by a one-half slope on a log-log plot of rate against time, which caused by transient drainage of low permeability matrix blocks into adjoining fractures (Olusehun, 2009).

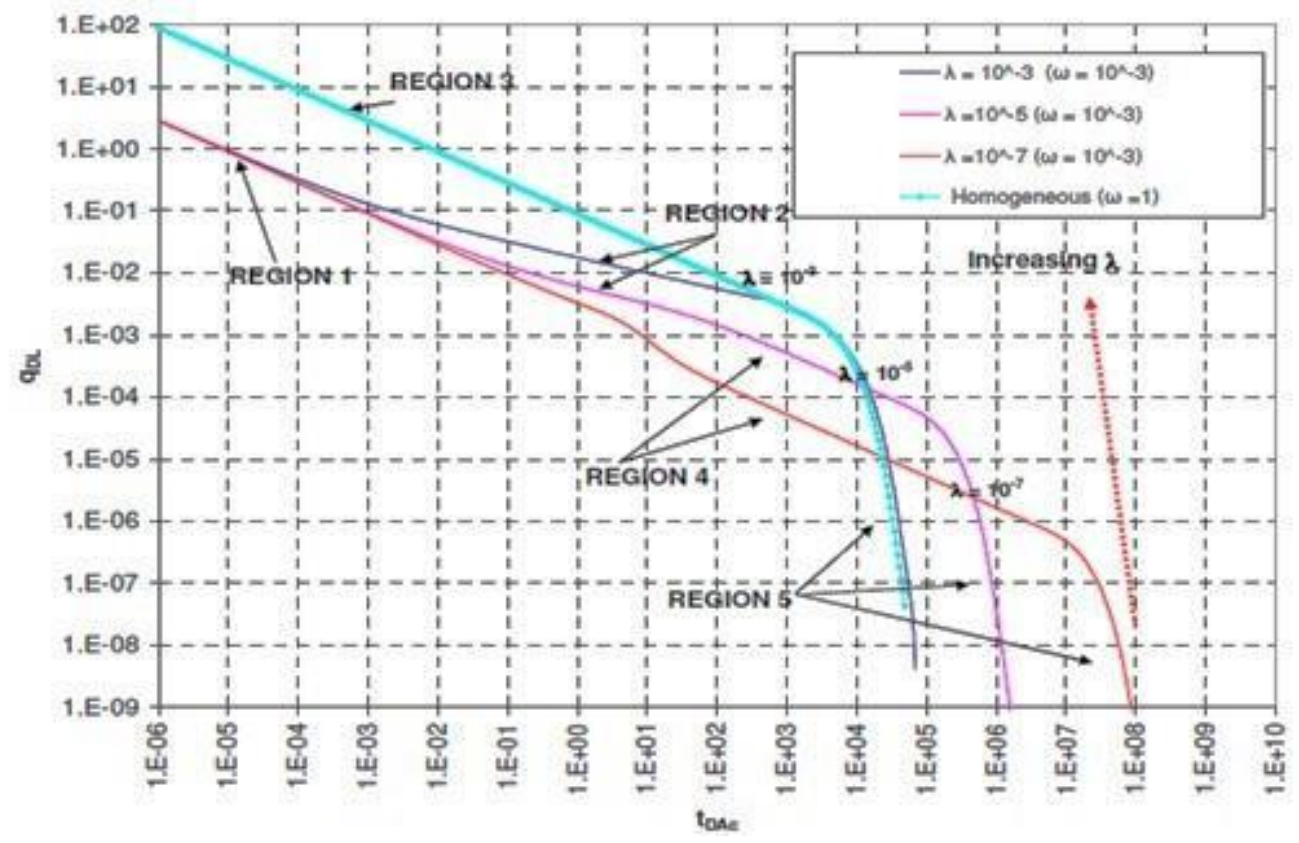

Figure 1 - Illustration of the Five Flow Regions (Olusehun, 2009)

Figure1 represents the effect of $\omega$ and $\lambda$ on linear model responses that Olusehun used for his thesis study. This figure shows the homogeneous response as a dual porosity response, which shows for $\omega=10^{-3}$, all the responses for $\lambda_{A C}=10^{-3}, 10^{-5}, 10^{-7}$ coverage to the same initial half-slope, which indicates the 
linear flow in the fractures, at early times and different half slopes at later times. The half slope at later times is indicative of linear flow in the matrix. Region 1 represents early transient linear from in the fracture, Region 2 represents bilinear flow caused by simultaneous transient flow in the fracture and matrix that is indicated by a one-quarter slope on a log-log plot. Region 3 represents the homogeneous reservoir; Region 4 represents the transient linear case, which is the purpose of the current study and Region 5 that represents the period when the reservoir boundary. Using a one-half slope line on a $\log$-log plot can indicate region 3 and 4 .

Table 1 - Summary of Analysis Equations for the Constant $\boldsymbol{P}_{w \boldsymbol{f}}$ Inner Boundary Case (Slab Matrix) This case is the $\frac{m(P i)-m\left(P_{w f}\right)}{q_{g}}$ vs. $\sqrt[4]{t} \quad$ (Olusehun, 2009)

\begin{tabular}{|c|c|c|}
\hline Region & Equation & $\begin{array}{l}\text { Analysis Equation } \\
\frac{m\left(p_{t}\right)-m\left(p_{s}\right)}{q_{s}} v s \sqrt{t}\end{array}$ \\
\hline 1- Early linear (fracture) & $q_{D C}=\frac{1}{2 \pi \sqrt{\pi I_{D A C} / \omega}}$ & $\sqrt{k_{f}} A_{c-m}=\frac{1262 T}{\sqrt{\omega\left(\phi j c_{i}\right)_{f+m}}} \frac{1}{\tilde{m}_{1}}$ \\
\hline 2-Bilinear & $q_{D C}=\frac{\lambda_{A c}^{0.25}}{10.133 t_{D A c}^{025}}$ & $\left.\sqrt[*]{k_{f}} A_{c w}=\frac{4070 T}{\left[a k_{m}\left(\phi \mu c_{t}\right)_{f+m}\right.}\right]_{225} \frac{1}{\tilde{m}_{2}}$ \\
\hline 3 - Homogeneous & $q_{D L h}=\frac{1}{2 \pi \sqrt{\pi \pi_{\text {DAch }}}}$ & $\sqrt{k} A_{\sigma \sigma}=\frac{1262 T}{\sqrt{\left(\phi \mu c_{t}\right)}} \frac{1}{\tilde{m}_{3}}$ \\
\hline 4-Matrix transient linear & $\begin{array}{l}q_{D C}=\frac{1}{2 \pi \sqrt{\pi_{D A C}}} \sqrt{\frac{\lambda_{A c}}{3}} y_{D e} \\
\text { or } \\
q_{D C m}=\frac{1}{2 \pi \sqrt{\pi_{D A m}}}\end{array}$ & $\sqrt{k_{m}} A_{c m}=\frac{1262 T}{\sqrt{\left(\phi \mu c_{t}\right)_{f+m}}} \frac{1}{\tilde{m}_{4}}$ \\
\hline 5 - Boundary-dominated & 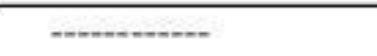 & 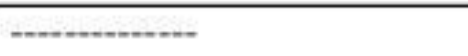 \\
\hline
\end{tabular}




\subsection{Flow Behavior in Horizontal Wells}

The flow behavior in horizontal wells when there are no hydraulic fractures is different compared to the behavior with existence of hydraulic fractures. Flow regimes including early radial flow, intermediate linear flow, and late pseudo-radial can be seen during pressure transient responses that are shown in figure 2 .

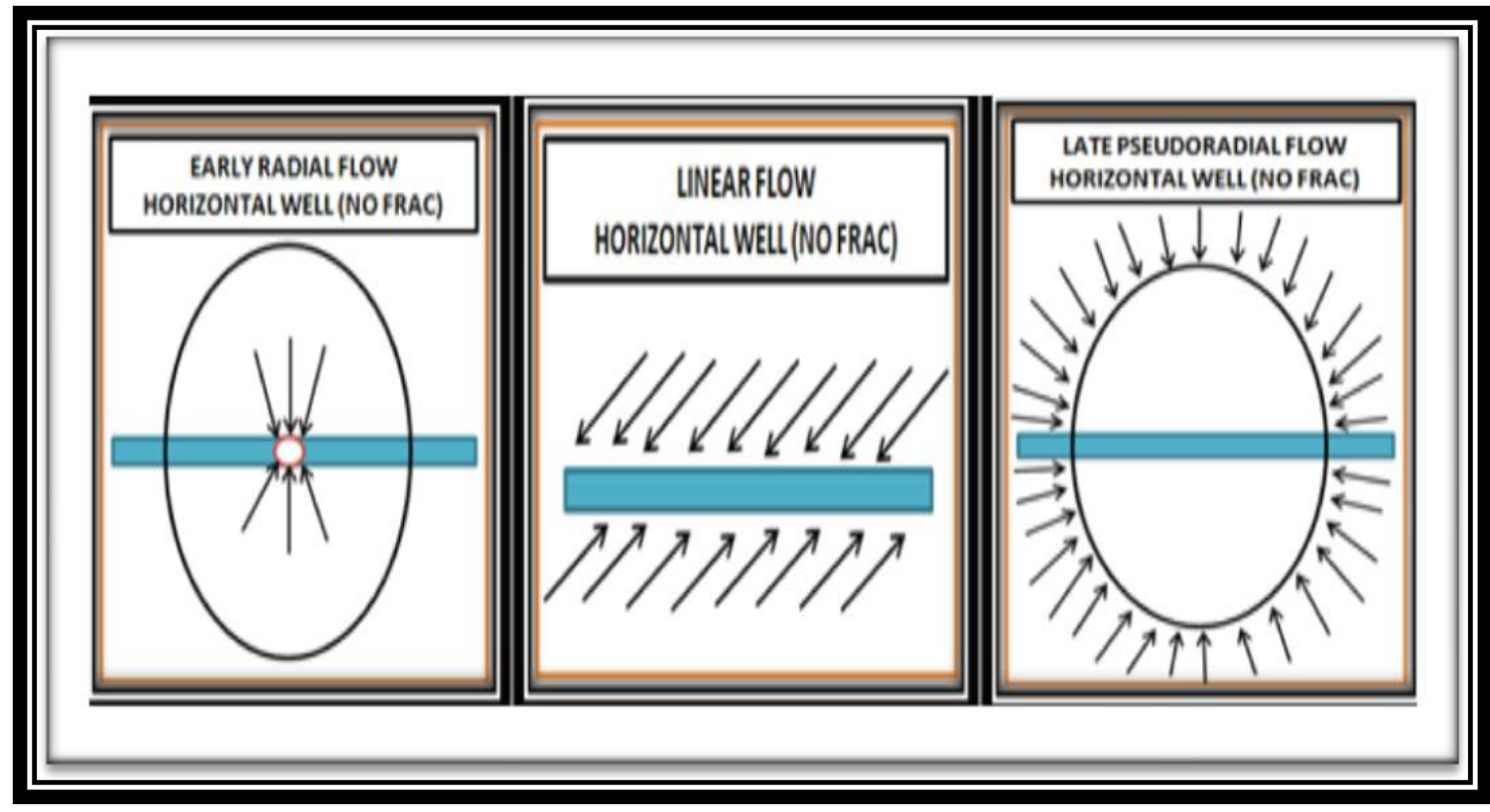

Figure 2 - Flow Behavior in Horizontal well (No Hydraulic Fractures)

When there is no storage effect the early radial flow will occur and upper and lower boundaries have not yet touched any boundaries during this stage. Meanwhile the flow regimes in horizontal wells with existence of hydraulic fractures break down into two different fracture behaviors known as finite conductivity and infinite conductivity fractures based on low conductivity and high conductivity High conductivity has no considerable pressure loss in the fracture compare to low conductivity fracture. Linear flow and Pseudo-steady state flow are different flow regimes that can occur during transientpressure effects. Below in figure 3, shows the early radial flow, which has short duration and can be classified using unit slope line on log-log plot. (Belyadi, 2011) 


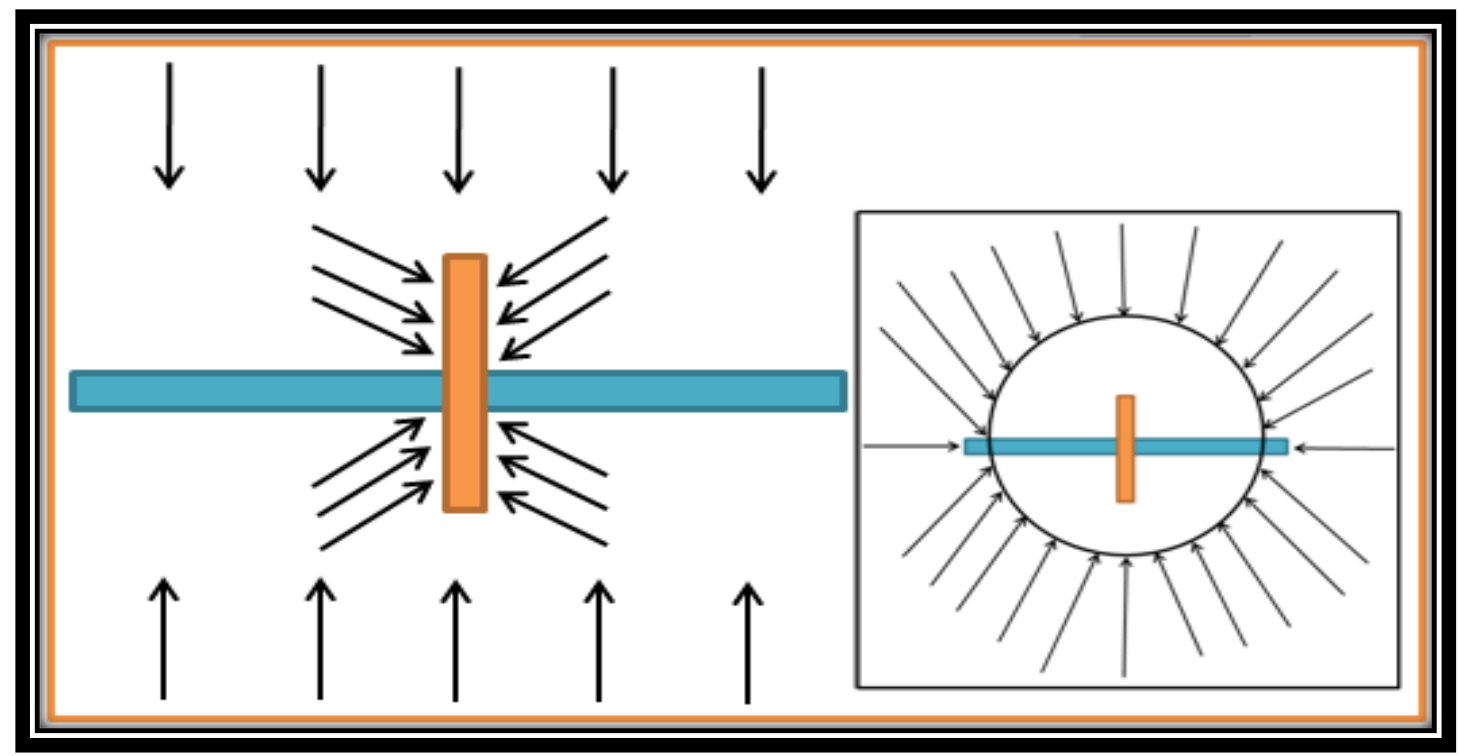

Figure 3 - Early Radial Flow with single hydraulic fracture

As it has been mentioned before, the number of hydraulic fractures effects on the flow regime. Figure 4 shows the behavior of the flow regime with two hydraulic fractures along the length of the horizontal well. Also the linear flow can be identified using $1 / 2$ slope line on log-log plot.

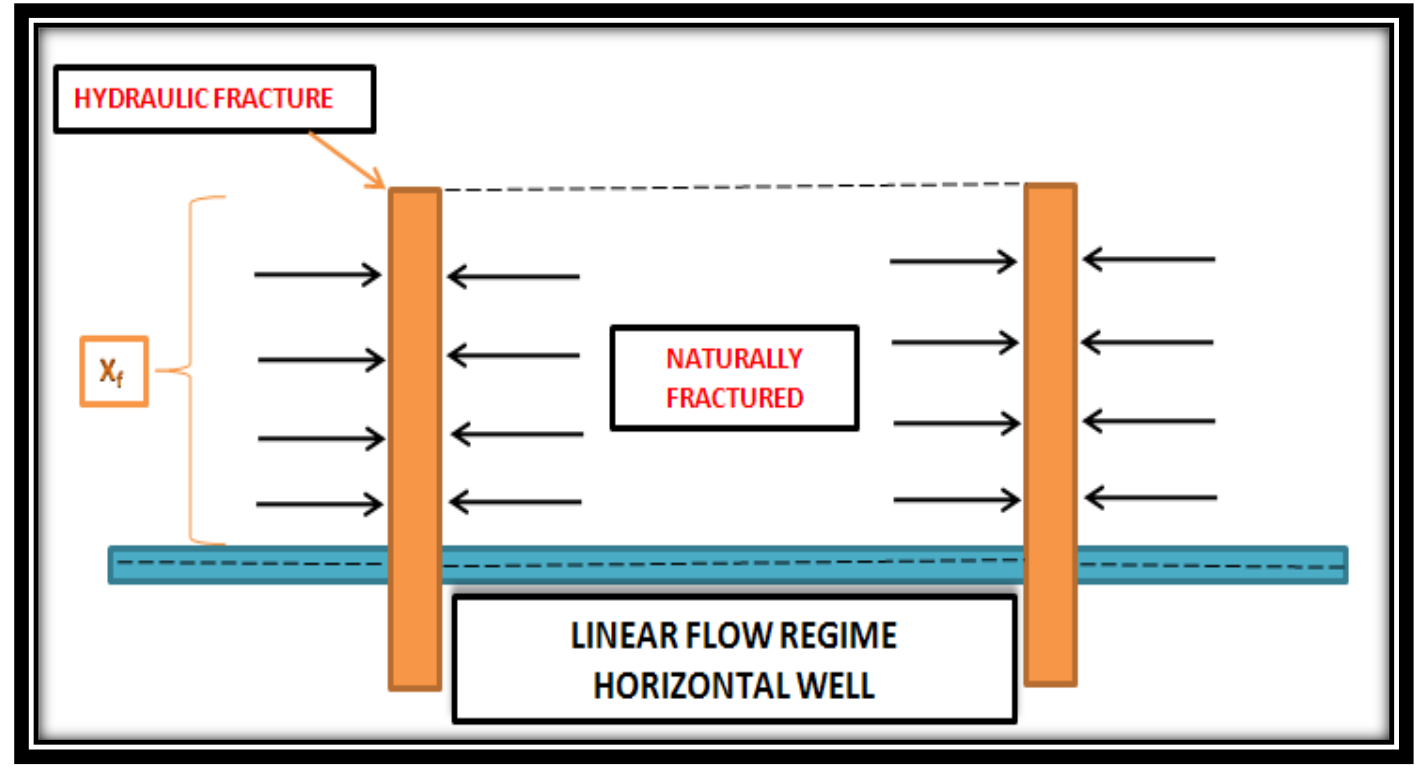

Figure 4 - Linear flow regimes with two hydraulic fractures 
When the fluid in the reservoir hits the boundaries then boundary dominated flow or pseudo steady state occurs in entire reservoir. Below figure 5 shows the pseudo steady state flow regime.

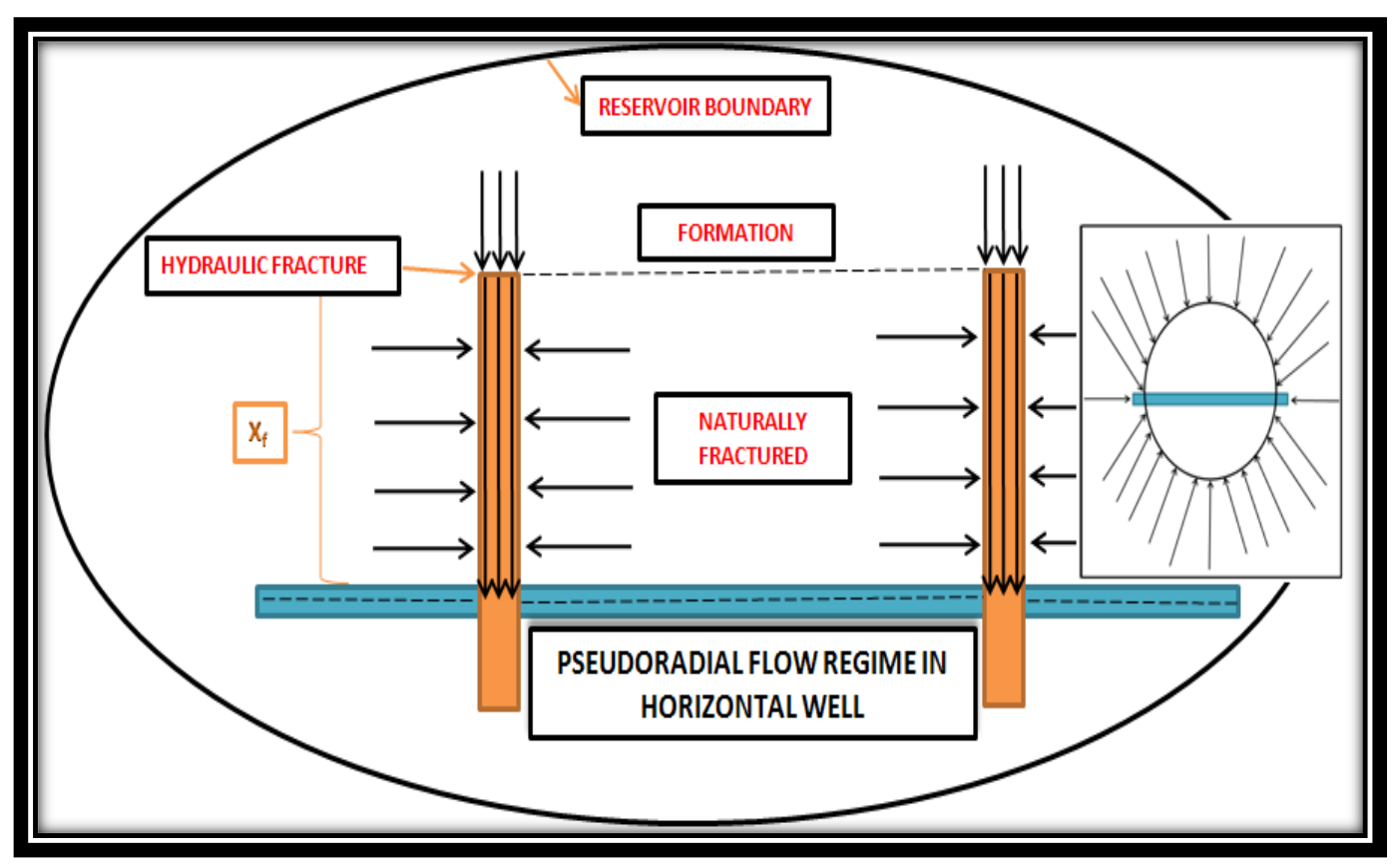

Figure 5 - Pseudo steady state flow regime

\subsection{Diagnostic Plots}

The derivative type curves were introduced by Bourdet et al. to improve the type curve analysis of pressure transient tests since the derivative curve was an indispensable aid to diagnostic pressure transient behavior for infinite-acting radial flow, for dual porosity behavior, and for bounded reservoir behavior (Bourdet, 1983). In order to develop diagnostic plot, calculate the derivative with respect to the superposition time function, and graphing the result vs. the shutin time and the use of this technique involves the pressure change and pressure derivative calculated with respect to, and graph vs. shutin time (Spivey, 1999). The advantages of using diagnostic plot are such as:

1. It does not assume a certain flow regime, as the use of the superposition time function accepts infinite-acting radial flow.

2. It encourages the analyst to think in terms of both reservoir boundaries and production history prior to the test as possible causes for unusual behavior occurring during the test.

3. It is compatible with the superposition type curve. 
The five-point derivative method, as described below in figure 6 , is commonly used to estimate the derivative values:

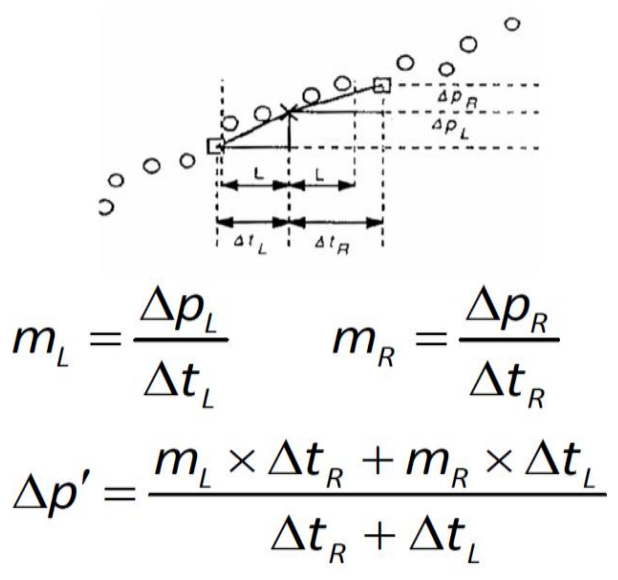

Figure 6 - Five-Point Derivative method (Belyadi, 2011) 


\section{Objective and Methodology}

\subsection{Objective}

The objective of this study is to understand the impacts of hydraulic fractures on flow behavior of the horizontal wells completed in ultra-low permeability shale formations such as Marcellus Shale. A commercial reservoir simulator has been employed to build a model with a horizontal well completed in ultra-low permeability shale with several hydraulic fracture stages.

\section{2. Methodology}

The methodology that was employed in this study consisted of the following steps:

1. Creating a base model to simulate production history for a horizontal well completed in ultra-low permeability formation.

2. Identifying the various flow periods (regimes) associated with hydraulically fractured horizontal wells using the diagnostic plots.

3. Investigating the impact of various shale characteristics on the duration of the flow periods.

\subsubsection{Step 1.Simulation Base Model}

A commercial reservoir simulator (ECLIPSE) was used to simulate 30-year production profile for a horizontal well in ultra-low permeability shale. The simulated production rates were then used to generate a diagnostic plot to determine the flow regimes. The base model consisted of a rectangular drainage area 4000 feet by 2000 feet containing a 3000-feet horizontal well.

The other important parameters for the model were established based on the available field information as well as the results of the previous production history matching for Marcellus Shale wells (Belyadi, H. 2011) and are listed below in Table 2. A multi-layer, dual porosity model, which included adsorbed gas, was employed to generate the production profiles. In addition, production profiles without adsorbed gas were generated by setting the Langmuir Concentration to $0 \mathrm{MSCF} /$ ton.

Tables 2 through 4 summarize other constant inputs and different properties for various numbers of hydraulic fracture stages.

Table 3 illustrates the layers and rock properties that were used for the base model. There were total of five layers in the model and top of the first layer is at 7000 feet. Each layer has a thickness of 15 feet. Table 4 includes the hydraulic fractures' properties. Four different cases were investigated, they are the 
model with No hydraulic fractures, 1, 2, 4 hydraulic fracture stages. The hydraulic fracture stages were placed as summarized in table 4 to have uniform spacing.

The grid-size in the model was chosen as 10 feet in all directions. The early production rates were found to be significantly higher than the rest of the production profile. This problem is due to the fact that the model treats the first grid block next to the wellbore as the hydraulic fracture. Consequently, the fracture dimensions, in a model with large grid blocks, are significantly larger than the actual fracture dimensions. This leads to over-prediction of the production rate at early times. To resolve this issue, the simulation runs were performed using minimum grid sizes of $1 \mathrm{ft}$. in all directions. It should also mention that the run-time for the model with small gird blocks was excessive. After comparing the new results to previous results, it became clear that after 3 to 4 years of production, the simulated production rates were almost identical for both runs. In order to have consistent results while reducing the run-time, the first 5 years of the production was simulated using the model with smaller minimum grid size and the remainder of production profile was obtained from the model with the larger minimum grid block size.

\subsubsection{Step 2.Flow Regime Determination}

In this step, a diagnostic plot of $1 / q$ and derivative of $1 / q$ as function of time was prepared based on the production profile generated by reservoir simulator to identify the flow regimes. Figures 7 and 8 shows the diagnostic plot for case 4 , which is the base model with 4 hydraulic fractures. As it can be seen from the plot, several flow periods (regimes) are present. The early flow period is associated with the radial flow in the vertical plane and is characterized by a valley in the derivative data representing the dual porosity system. The linear flow period is identified by $1 / 2$-slope line on the derivative data which is followed by boundary effects. Figure 7 shows the diagnostic plot illustrating various flow regimes based on the production history for the model with 4 hydraulic fractures with adsorbed gas and figure 8 shows the diagnostic plot illustrating various flow regimes based on the production history for the model with 4 hydraulic fractures without adsorbed gas. 


\begin{tabular}{|c|c|}
\hline \multicolumn{2}{|c|}{ Table 2 - Basic Model Parameters } \\
\hline \multicolumn{2}{|c|}{ Reservoir parameters } \\
\hline Depth, ft. & $7,7,000$ \\
\hline Thickness, ft. & 75 \\
\hline \multicolumn{2}{|l|}{ Rock Properties } \\
\hline Fracture spacing, dimensionless & 0.0073 \\
\hline Coal Compress, 1/psia & 0.000001 \\
\hline Rock Density, Units & 150 \\
\hline Fracture Porosity & 0.002 \\
\hline Matrix Porosity, $\mathrm{mD}$ & 0.05 \\
\hline Fissure Permeability $\mathrm{x}, \mathrm{y}, \mathrm{z} \quad \mathrm{mD}$ & $0.002,0.002,0.0002$ \\
\hline Matrix Permeability $\mathrm{x}, \mathrm{y}, \mathrm{z} \quad \mathrm{mD}$ & $0.0004,0.0004,0.00004$ \\
\hline \multicolumn{2}{|l|}{ Initial Conditions } \\
\hline Pressure, psia & $3,3,000$ \\
\hline Water Saturation, fraction & 0.15 \\
\hline \multicolumn{2}{|c|}{ Hydraulic Fractures Properties } \\
\hline Half Length, ft. & $\overline{500}$ \\
\hline Width, in & 0.01 \\
\hline Top of Fracture, $\mathrm{ft}$. & 7,000 \\
\hline Bottom of Fracture, ft. & 7,075 \\
\hline Permeability, $\mathrm{mD}$ & 20,000 \\
\hline Porosity, fraction & 0.1 \\
\hline \multicolumn{2}{|l|}{ Well Production Control } \\
\hline Bottom Hole Pressure, psia & 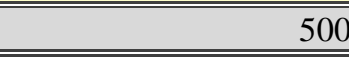 \\
\hline \multicolumn{2}{|l|}{ Fluid Properties } \\
\hline Standard Pressure, psia & 14.7 \\
\hline Standard Temperature, $\mathrm{F}$ & 60 \\
\hline Reference Temperature, $\mathrm{F}$ & 120 \\
\hline \multicolumn{2}{|l|}{ Desorption } \\
\hline Gas Diffusion Coefficient, Units & 1 \\
\hline Sorption Time, day & 62 \\
\hline Langmuir Pressure, psia & 635 \\
\hline Langmuir Concentration, MSCF/ton & 0.08899 \\
\hline
\end{tabular}




\begin{tabular}{|c|c|c|c|c|c|c|}
\hline \multicolumn{7}{|c|}{ Table 3 - Constant Inputs for layers and Rock properties } \\
\hline \multicolumn{4}{|c|}{ Total of 5 Layers } & \multicolumn{3}{|c|}{ Rock Properties } \\
\hline Top Depth, ft. & $\begin{array}{c}\text { Thickness, } \\
\text { ft. }\end{array}$ & $\begin{array}{c}\text { Length of } \\
\text { Reservoir, } \mathrm{ft} .\end{array}$ & $\begin{array}{c}\text { Width of Reservoir, } \\
\mathrm{ft} .\end{array}$ & $\begin{array}{l}\text { Fracture } \\
\text { Porosity }\end{array}$ & $\begin{array}{c}\text { Fissure Perm, } \\
\mathrm{mD}\end{array}$ & $\begin{array}{c}\text { Matrix Perm, } \\
\mathrm{mD}\end{array}$ \\
\hline \begin{tabular}{|l|l|}
7000 & 7060
\end{tabular} & 15 & 4000 & 2000 & 0.002 & 0.002 & 0.0004 \\
\hline
\end{tabular}

\begin{tabular}{||l||c|c|c|c||}
\hline \multicolumn{4}{||c|}{ Table 4 - Properties for 4 Hydraulic Fractures } \\
\hline \hline Fracture Name & F1 & F2 & F3 & F4 \\
\hline \hline Half Length & $500 \mathrm{ft}$. & $500 \mathrm{ft}$. & $500 \mathrm{ft}$. & $500 \mathrm{ft}$. \\
\hline \hline Width & $0.01 \mathrm{in}$ & $0.01 \mathrm{in}$ & $0.01 \mathrm{in}$ & $0.01 \mathrm{in}$ \\
\hline \hline Top of Fracture & $7000 \mathrm{ft}$. & $7000 \mathrm{ft}$. & $7000 \mathrm{ft}$. & $7000 \mathrm{ft}$. \\
\hline \hline Bottom of Fracture & $7075 \mathrm{ft}$. & $7075 \mathrm{ft}$. & $7075 \mathrm{ft}$. & $7075 \mathrm{ft}$. \\
\hline \hline X Center & $500 \mathrm{ft}$. & $1500 \mathrm{ft}$. & $2500 \mathrm{ft}$. & $3500 \mathrm{ft}$. \\
\hline \hline Y Center & $1000 \mathrm{ft}$. & $1000 \mathrm{ft}$. & $1000 \mathrm{ft}$. & $1000 \mathrm{ft}$. \\
\hline \hline Permeability & $20000 \mathrm{mD}$ & $20000 \mathrm{mD}$ & $20000 \mathrm{mD}$ & $20000 \mathrm{mD}$ \\
\hline \hline Porosity & 0.1 & 0.1 & 0.1 & 0.1 \\
\hline
\end{tabular}

Figure 8 shows the diagnostic plot illustrating various flow regimes based on the production history for the model with 4 hydraulic fractures without adsorbed gas.

\subsubsection{Step 3.Sensitivity Analysis}

To investigate the impact of various shale characteristics on the duration of the flow period, calculated derivatives and diagnostic plots were used. After plotting each case and found the start and end point for each flow rate, it was easy to see the behavior of each flow regime based on variable parameters. There are 4 scenarios that are shown in Table 5. Also Table 6 to Table 9 listed below show the detail inputs for each scenarios and variable parameters are shown in bold.

\subsubsection{First Scenario}

As it shows in table 5, the base model with no desorption for cases 2, 3, and 4 were run with 250 feet half-length size for hydraulic fractures with actual fissure permeability (0.002). Table 6 is an example for case 4 inputs.

\subsubsection{Second Scenario}

The base model with original half-length size (500 feet) was run with 0.001 fissure permeability for case 3 (base model with 2 hydraulic fractures) and case 4 (base model with 4 hydraulic fractures). Table 7 is an example for case 4 inputs. 


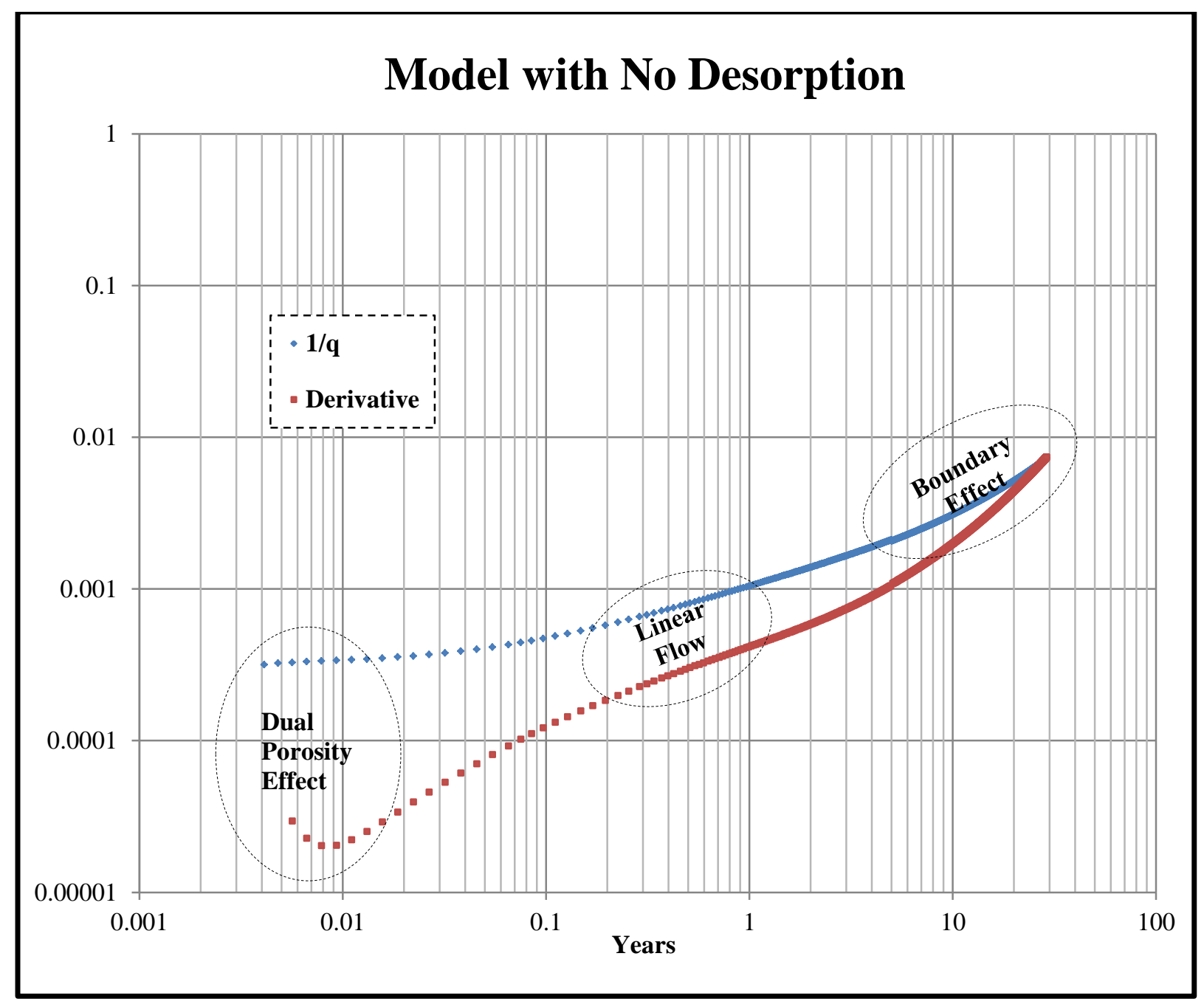

Figure 7 - Diagnostic Plot Illustrating Various Flow Regimes

\subsubsection{Third Scenario}

The base model with original half-length size (500 feet) was run with 0.001 fissure permeability for case 3 (base model with 2 hydraulic fractures) and case 4 (base model with 4 hydraulic fractures). Table 8 is an example for case 4 inputs.

\subsubsection{Fourth Scenario}

The base model with original half-length size (500 feet) was run with 0.001 fissure permeability for case 3 (base model with 2 hydraulic fractures) and case 4 (base model with 4 hydraulic fractures). Table 9 is an example for case 4 inputs. 


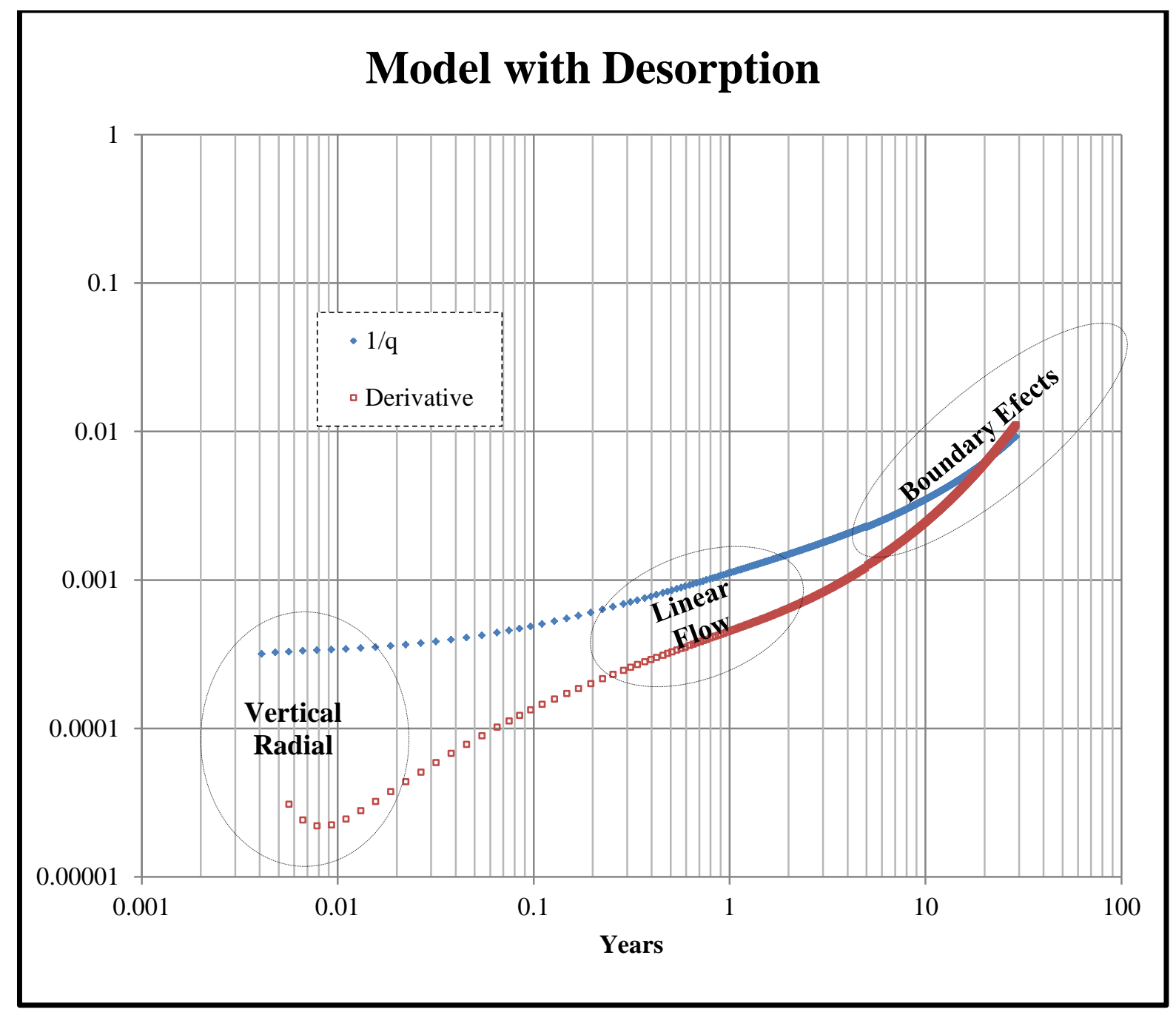

Figure 8 - Diagnostic Plot Illustrating Various Flow Regimes 


\begin{tabular}{||c|c|c||}
\hline \multicolumn{3}{|c|}{ Table 5 - Variable Parameters for Each Case } \\
\hline \hline Case studies & Half Length & Fissure Permeability \\
\hline \hline For cases 2,3, and 4 & $250 \mathrm{ft}$. & 0.002 \\
\hline \hline For case 3 and 4 & $500 \mathrm{ft}$. & 0.001 \\
\hline \hline For case 3 and 4 & $500 \mathrm{ft}$. & 0.005 \\
\hline \hline For case 3 and 4 & $500 \mathrm{ft}$. & 0.01 \\
\hline
\end{tabular}

\begin{tabular}{||l||c||c||c||c||}
\hline \multicolumn{4}{||c|}{ Table 6 - Hydraulic Fractures' Properties for 4 Fractures } \\
\hline \hline Fracture Name & F1 & F2 & F3 & F4 \\
\hline \hline Half Length & $250 \mathrm{ft}$ & $\mathbf{2 5 0} \mathrm{ft}$ & $\mathbf{2 5 0} \mathrm{ft}$ & $\mathbf{2 5 0} \mathrm{ft}$ \\
\hline \hline Width & $0.01 \mathrm{in}$ & $0.01 \mathrm{in}$ & $0.01 \mathrm{in}$ & $0.01 \mathrm{in}$ \\
\hline \hline Top of Fracture & $7000 \mathrm{ft}$ & $7000 \mathrm{ft}$ & $7000 \mathrm{ft}$ & $7000 \mathrm{ft}$ \\
\hline \hline Bottom of Fracture & $7075 \mathrm{ft}$ & $7075 \mathrm{ft}$ & $7075 \mathrm{ft}$ & $7075 \mathrm{ft}$ \\
\hline \hline X Center & $500 \mathrm{ft}$ & $1500 \mathrm{ft}$ & $2500 \mathrm{ft}$ & $3500 \mathrm{ft}$ \\
\hline \hline Y Center & $1000 \mathrm{ft}$ & $1000 \mathrm{ft}$ & $1000 \mathrm{ft}$ & $1000 \mathrm{ft}$ \\
\hline \hline Permeability & $20000 \mathrm{md}$ & $20000 \mathrm{md}$ & $20000 \mathrm{md}$ & $20000 \mathrm{md}$ \\
\hline \hline Porosity & 0.1 & 0.1 & 0.1 & 0.1 \\
\hline \hline
\end{tabular}

\begin{tabular}{|c|c|c|c|c|c|c|c|}
\hline \multicolumn{8}{|c|}{ Table 7 - Inputs for layers and Rock properties } \\
\hline \multicolumn{5}{|c|}{ Total of 5 Layers } & \multicolumn{3}{|c|}{ Rock Properties } \\
\hline \multicolumn{2}{|c|}{$\begin{array}{l}\text { Top Depth, } \\
\mathrm{ft}\end{array}$} & $\begin{array}{c}\text { Thickness, } \\
\mathrm{ft}\end{array}$ & $\begin{array}{l}\text { Length of } \\
\text { Reservoir, } \mathrm{ft}\end{array}$ & $\begin{array}{l}\text { Width of } \\
\text { Reservoir, } \mathrm{ft}\end{array}$ & $\begin{array}{l}\text { Fracture } \\
\text { Porosity }\end{array}$ & $\begin{array}{c}\text { Fissure Perm, } \\
\mathrm{mD}\end{array}$ & $\begin{array}{c}\text { Matrix Perm, } \\
\mathrm{mD}\end{array}$ \\
\hline 7000 & 7060 & 15 & 4000 & 2000 & 0.002 & 0.001 & 0.0001 \\
\hline
\end{tabular}

\begin{tabular}{|c|c|c|c|c|c|c|}
\hline \multicolumn{7}{|c|}{ Table 8 - Inputs for layers and Rock properties } \\
\hline \multicolumn{4}{|c|}{ Total of 5 Layers } & \multicolumn{3}{|c|}{ Rock Properties } \\
\hline Top Depth, ft & $\begin{array}{c}\text { Thickness, } \\
\mathrm{ft}\end{array}$ & $\begin{array}{l}\text { Length of } \\
\text { Reservoir, } \mathrm{ft}\end{array}$ & $\begin{array}{c}\text { Width of } \\
\text { Reservoir, } \mathrm{ft}\end{array}$ & $\begin{array}{l}\text { Fracture } \\
\text { Porosity }\end{array}$ & $\begin{array}{c}\text { Fissure Perm, } \\
\mathrm{mD}\end{array}$ & $\begin{array}{c}\text { Matrix Perm, } \\
\mathrm{mD}\end{array}$ \\
\hline \begin{tabular}{|l|l|}
7000 & 7060
\end{tabular} & 15 & 4000 & 2000 & 0.002 & 0.005 & 0.0005 \\
\hline
\end{tabular}

\begin{tabular}{|c|c|c|c|c|c|c|c|}
\hline \multicolumn{8}{|c|}{ Table 9 - Inputs for layers and Rock properties } \\
\hline \multicolumn{5}{|c|}{ Total of 5 Layers } & \multicolumn{3}{|c|}{ Rock Properties } \\
\hline \multicolumn{2}{|c|}{ Top Depth, ft } & $\begin{array}{c}\text { Thickness, } \\
\mathrm{ft}\end{array}$ & $\begin{array}{c}\text { Length of } \\
\text { Reservoir, } \mathrm{ft}\end{array}$ & $\begin{array}{c}\text { Width of } \\
\text { Reservoir, } \mathrm{ft}\end{array}$ & $\begin{array}{l}\text { Fracture } \\
\text { Porosity }\end{array}$ & $\begin{array}{c}\text { Fissure Perm, } \\
\mathrm{mD}\end{array}$ & $\begin{array}{c}\text { Matrix Perm, } \\
\text { mD }\end{array}$ \\
\hline 7000 & 7060 & 15 & 4000 & 2000 & 0.002 & 0.01 & 0.001 \\
\hline
\end{tabular}




\section{Results and Discussions}

The following sections summarize the results of modeling and simulation studies as well as the interpretation of the results for each scenario.

\subsection{Step 1. Simulation Base Model}

The base model for all four cases (No hydraulic fracture, 1, 2, and 4 hydraulic fractures) was generated using given data and commercial software (ECLIPSE). This model was created based on 4000 feet by 2000 feet drainage area with 3000 feet horizontal well. A multi-layer, dual porosity model, which included adsorbed gas, was employed to generate the production profiles. In addition, production profiles without adsorbed gas were generated by setting the Langmuir Concentration to $0 \mathrm{MSCF} /$ ton. Figure 9, 10 are the production profiles and figure 11 and 12 are the cumulative production profiles of base models with and without desorption for all cases.

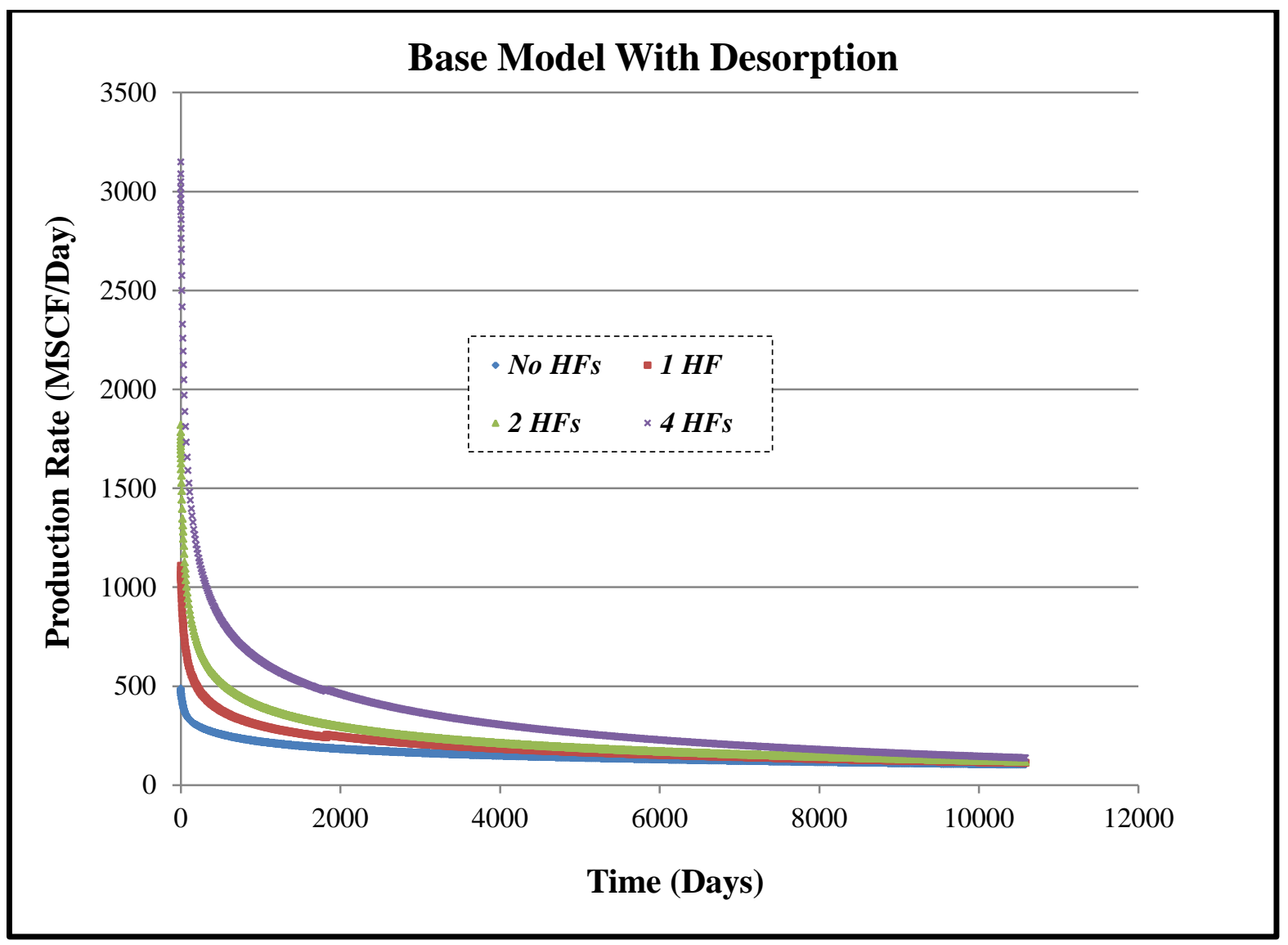

Figure 9 - Production profile of $\mathbf{3 0 0 0}$ feet horizontal well with Desorption 


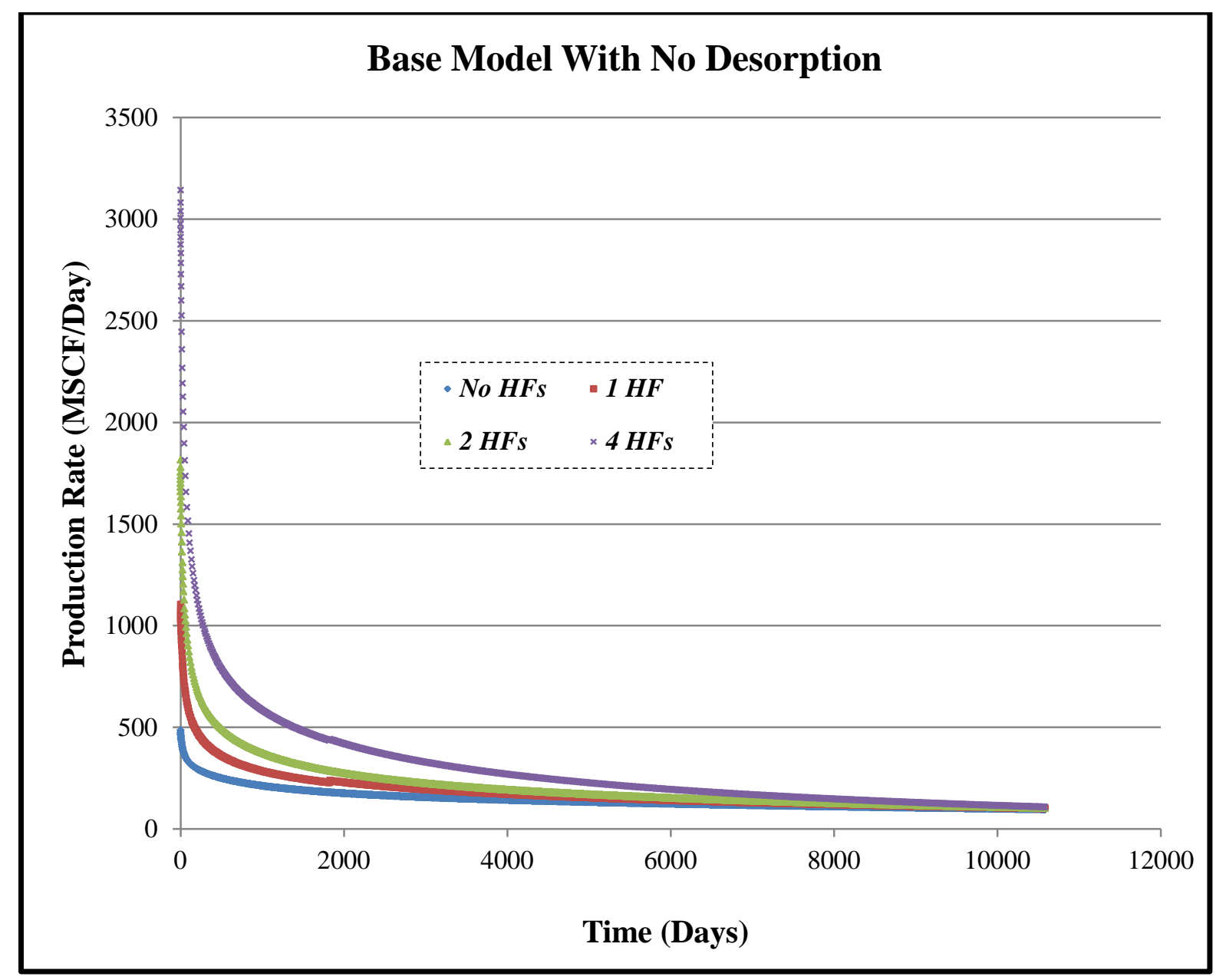

Figure 10 - Production profile of 3000 feet horizontal well with No Desorption 


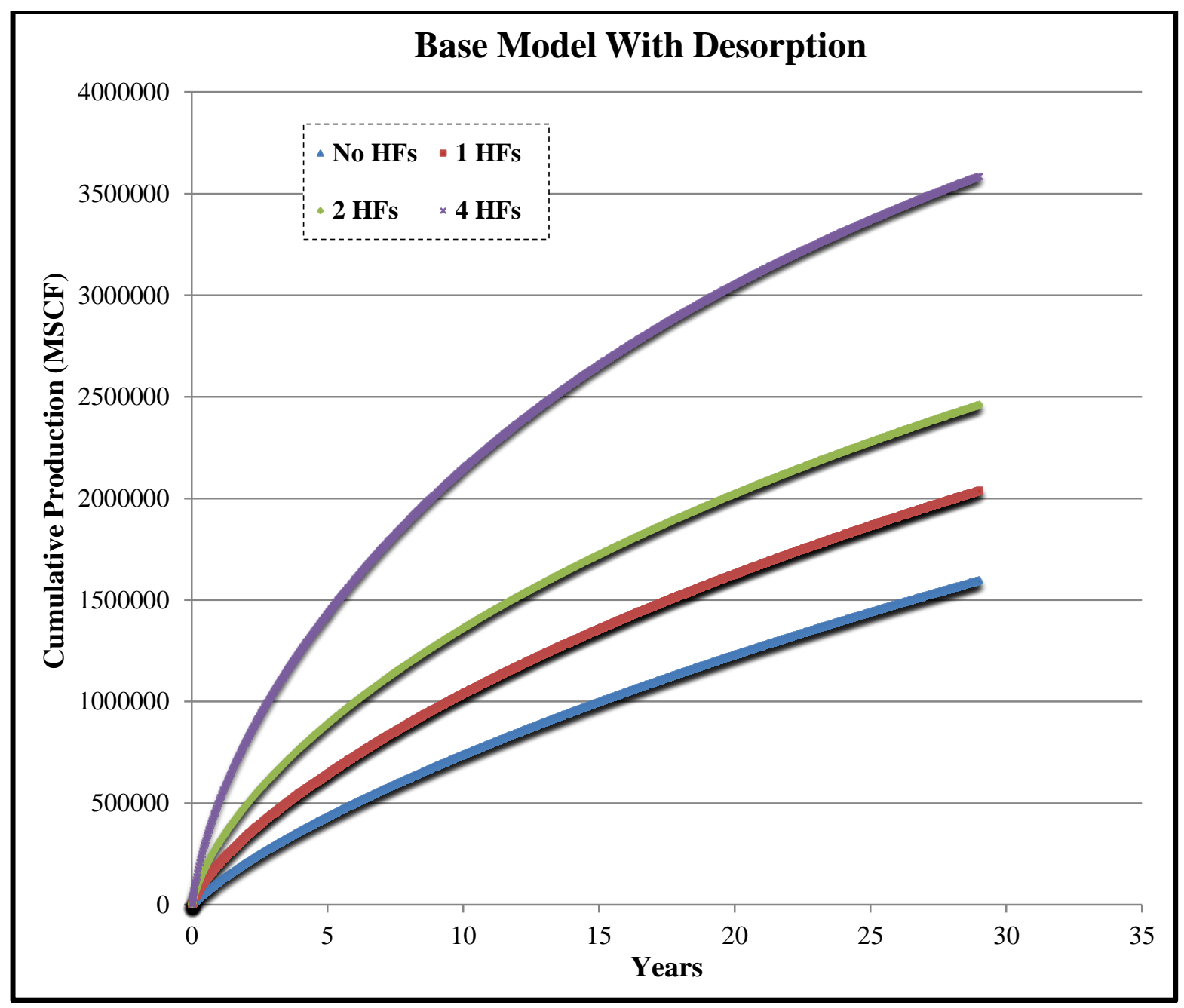

Figure 11 - The impact of different number of hydraulic fractures on cumulative production 


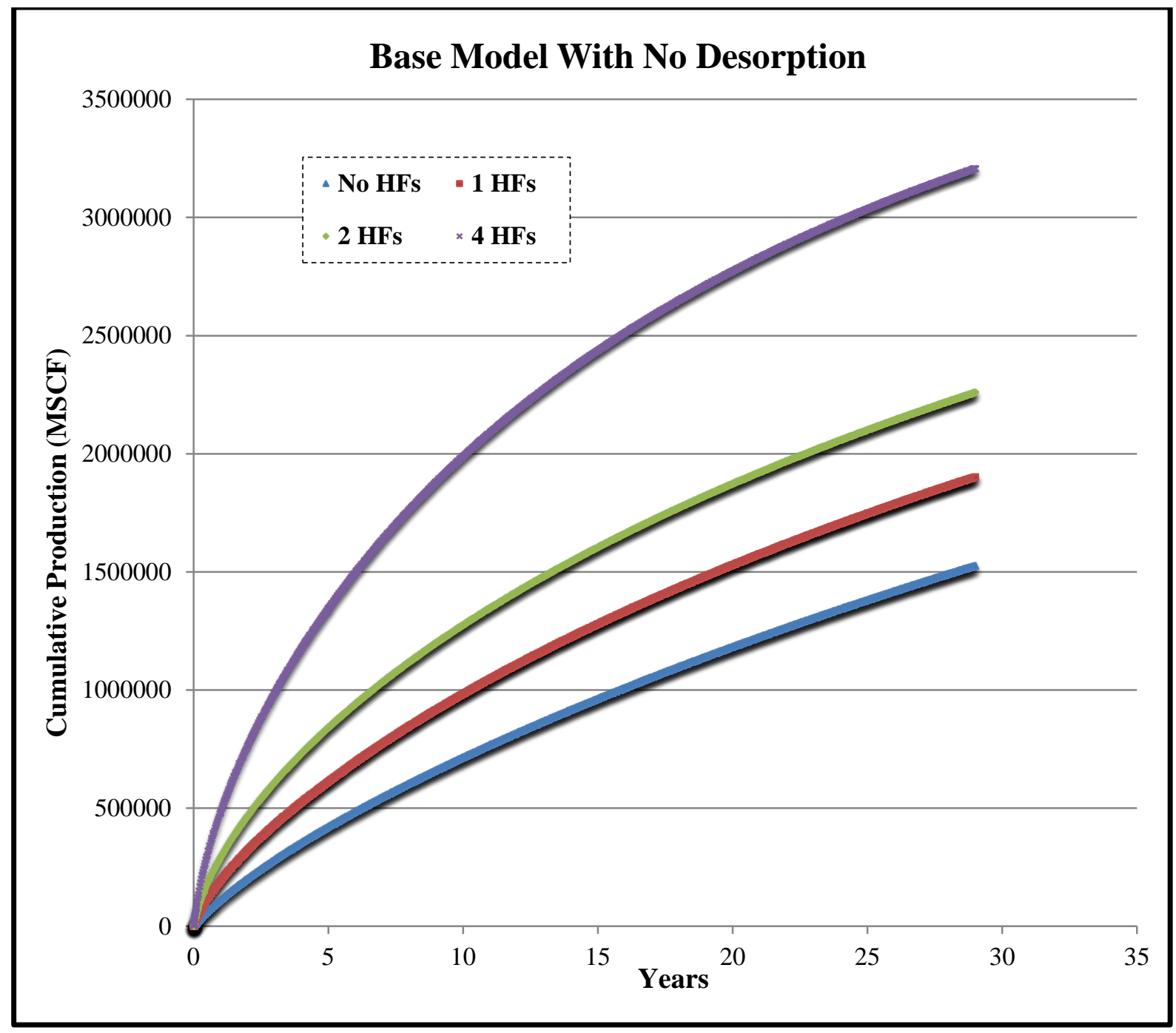

Figure 12 - The impact of different number of hydraulic fractures on cumulative production 


\section{2. $\quad$ Step 2. Flow Regime Determination}

To determine the flow regimes, the derivative of production rate has been calculated and the diagnostic plots were used to show the flow regime for each individual case with 3000 feet of horizontal lateral and 4000 by $2000 \mathrm{ft}^{2}$ drainage area. Figures 13and 14 are diagnostic plots that shows all case studies together and illustrates flow regimes for the case study with 1,2, and 4 hydraulic fractures with base model using diagnostic plots. The results include dual porosity effect and the flow is followed by linear flow and compounded linear flow. Duration period is based on the drainage geometry as it shows in listed figures.

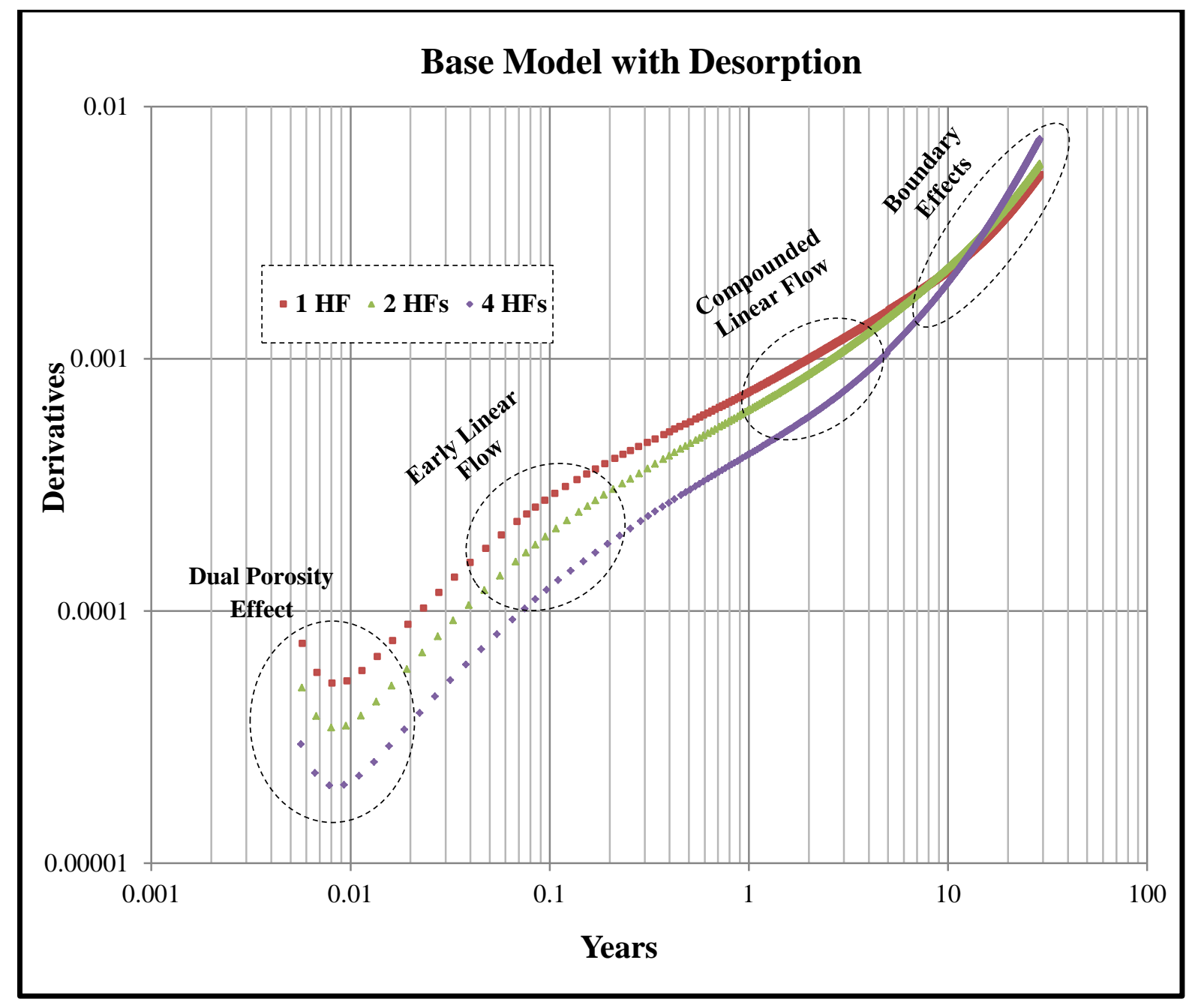

Figure 13 - Diagnostic plot showing flow periods for all 4 cases 


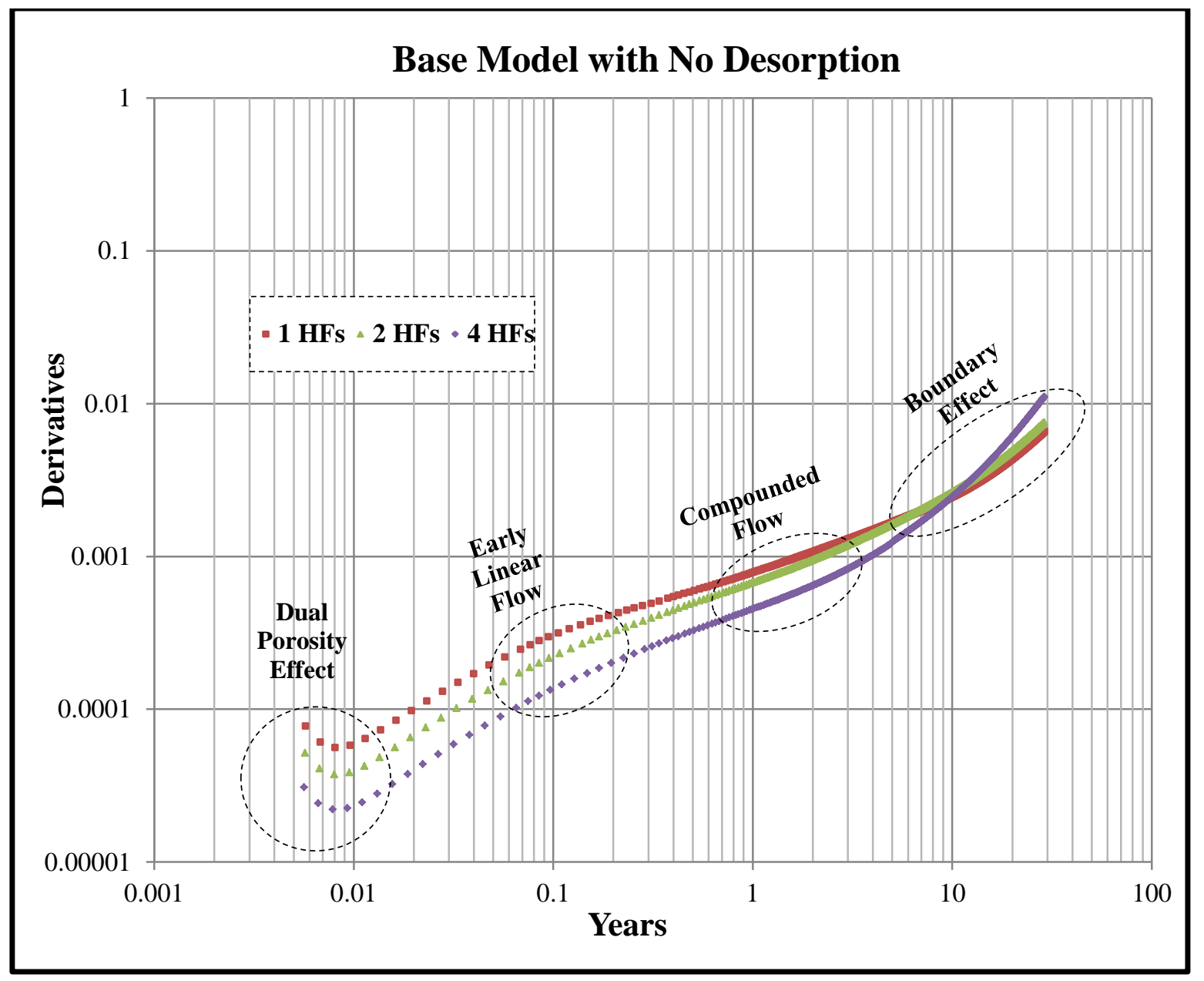

Figure 14 - Diagnostic plot showing flow periods for all 4 cases

Figures 15 and 16 are representing the base model with 4 hydraulic fractures with and with no desorption conditions. The properties for the base model are such as: permeability of $0.002 \mathrm{mD}$ with 500 feet halflength for hydraulic fractures and tables10 and 11 indicating the results for all cases. Below figures are diagnostic plots presenting the flow durations for each condition. The duration period for early linear flow for the model with 4 hydraulic fractures with desorption is 166 days and for the case when there is no desorption goes up to 322 days of early linear flow. Also the flow duration for compounded linear flow for desorption case travels up to 406 days and when there is no desorption, the duration flow is up to 174 days. The diagnostic plots for flow durations for models with 1 and 2 hydraulic fractures are included in appendices. 


\begin{tabular}{|c|c|c|c|c|c|c|}
\hline & \multicolumn{6}{|c|}{ Table 10 -Desorption w/ 500 feet Half Length \& 0.002 Permeability } \\
\hline & \multicolumn{3}{|c|}{ Early Linear Flow (Days) } & \multicolumn{3}{|c|}{ Compounded Linear Flow (Days) } \\
\hline & Start Points & End Points & Duration & Start Points & End Points & Duration \\
\hline No Hydraulic Fracture & 15 & 36 & 21 & 205 & 3986 & 3782 \\
\hline 1 Hydraulic Fracture & 35 & $\overline{778}$ & 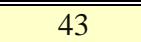 & $4 \overline{455}$ & 3150 & 2695 \\
\hline 2 Hydraulic Fractures & 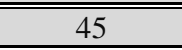 & 136 & 91 & 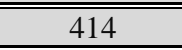 & 908 & 4995 \\
\hline 4 Hydraulic Fractures & 62 & 228 & 166 & 337 & 743 & 406 \\
\hline
\end{tabular}

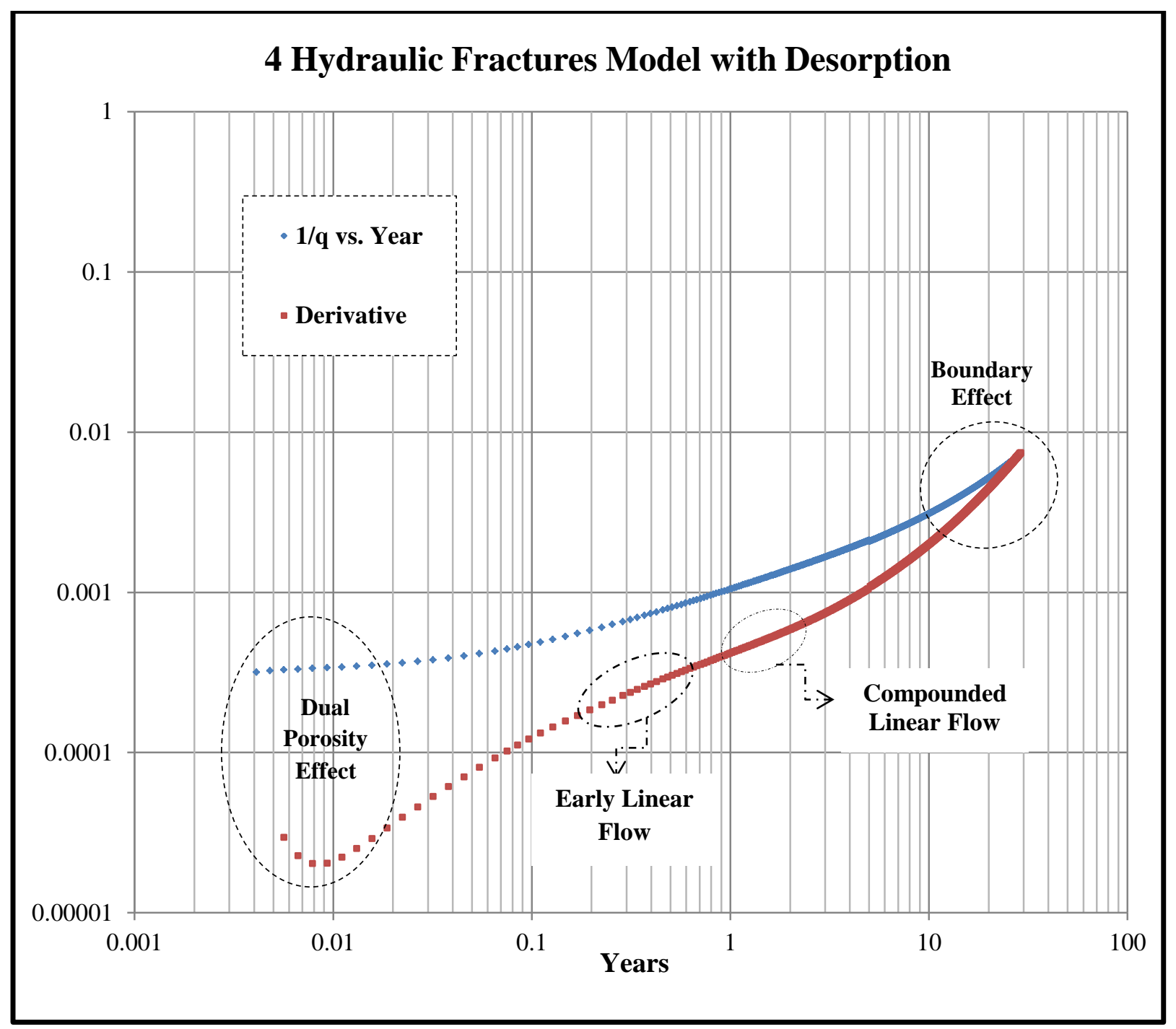

Figure 15 - Diagnostic plot illustrating various flow periods (4 Fracs) 


\begin{tabular}{|c|c|c|c|c|c|c|}
\hline & \multicolumn{6}{|c|}{ 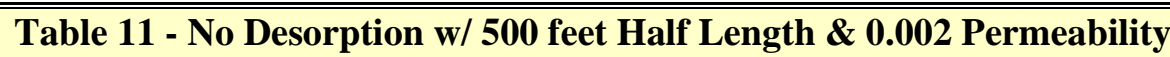 } \\
\hline & \multicolumn{3}{|c|}{ Early Linear Flow (Days) } & \multicolumn{3}{|c|}{ Compounded Linear Flow (Days) } \\
\hline & Start Points & End Points & Duration & Start Points & End Points & Duration \\
\hline No Hydraulic Fracture & 15 & 36 & 21 & 195 & 1642 & 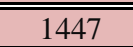 \\
\hline 1 Hydraulic Fracture & 25 & 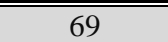 & $\overline{444}$ & 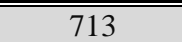 & 3110 & 22397 \\
\hline 2 Hydraulic Fractures & $\overline{445}$ & 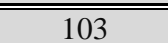 & $\overline{58}$ & 361 & 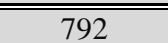 & $\overline{4431}$ \\
\hline 4 Hydraulic Fractures & $\overline{54}$ & 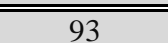 & $\overline{39}$ & 82 & $\overline{c 601}$ & $\overline{518}$ \\
\hline
\end{tabular}

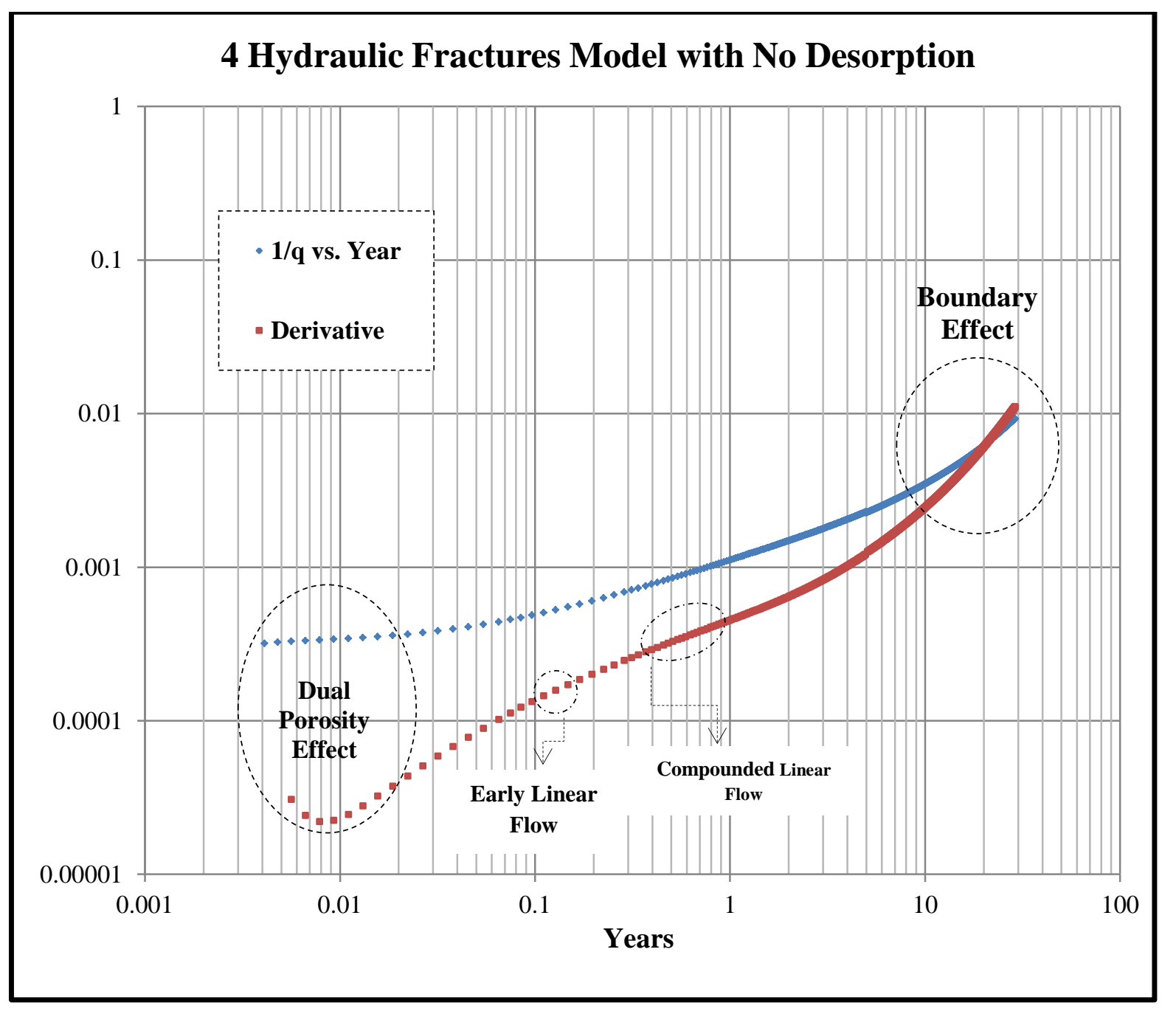

Figure 16 - Diagnostic plot illustrating various flow periods (4 Fracs) 


\subsection{Step 3. Sensitivity Analysis}

\subsubsection{Scenario1}

The base model with no desorption for the model with 1, 2, and 4 hydraulic fractures were run with 250 feet half-length size for hydraulic fractures with $0.002 \mathrm{mD}$ fissure permeability. Figure 17 illustrates this case study for the model with 4 hydraulic fractures vs. its original case study to show the differences in flow regimes. By decreasing the size of fracture half-length to 250 feet, the early linear flow becomes longer compare to the 500 feet case and same condition for compounded linear flow but for the case with one hydraulic fracture, the early linear flow ends sooner and compounded linear flow has longer duration compare to its original case and same condition for the model with 2 hydraulic fractures. Table 12 demonstrations the flow durations for current scenario. Other diagnostic plots for the models are included in appendices too.

\begin{tabular}{|c|c|c|c|c|c|c|}
\hline & \multicolumn{6}{|c|}{ Table 12 - No Desorption w/ 250 feet Half Length \& 0.002 Perm } \\
\hline & \multicolumn{3}{|c|}{ Early Linear Flow (Days) } & \multicolumn{3}{|c|}{ COmpounded Linear Flow (Days) } \\
\hline & Start Points & End Points & Duration & Start Points & End Points & Duration \\
\hline 1 Hydraulic Fracture & 25 & 44 & 18 & 372 & 3202 & 2830 \\
\hline 2 Hydraulic Fractures & 28 & 69 & 41 & 584 & 3030 & 2445 \\
\hline 4 Hydraulic Fractures & $\overline{35}$ & 1114 & $\overline{79}$ & $\overline{548}$ & 9886 & 4338 \\
\hline
\end{tabular}

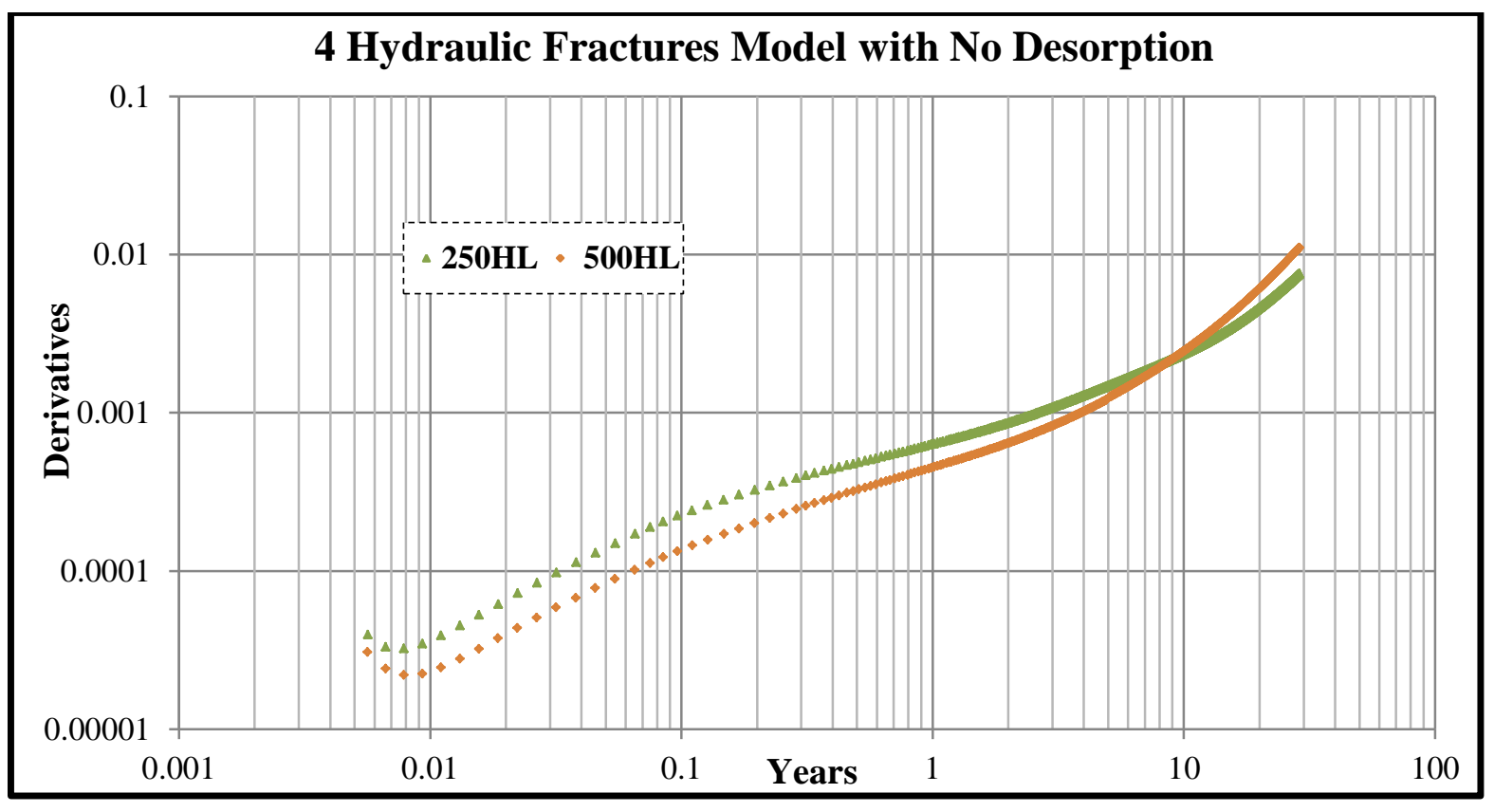

Figure 17 - Diagnostic plot illustrating model with 250 feet half-length vs. model with 500 feet half-length (4 Fracs) 


\subsubsection{Scenario2}

The base model with no desorption for cases with 2 and 4 hydraulic fractures were run with 500 feet halflength size of hydraulic fractures and $0.001 \mathrm{mD}$ fissure permeability. Figure 18 illustrates this case study for the model with 4 hydraulic fractures vs. its original case study to show the differences in flow regimes. By decreasing the fissure permeability to $0.001 \mathrm{mD}$, the early and compounded linear flows will have longer duration compare to the original case study. Table 13 shows the flow durations for both new scenarios. Also a diagnostic plot for the model with 2 hydraulic fractures is included in appendix as well.

\begin{tabular}{|c|c|c|c|c|c|c|}
\hline & \multicolumn{6}{|c|}{ Table 13 - No Desorption Model w/ 500 feet Half Length and 0.001 Perm } \\
\hline & \multicolumn{3}{|c|}{ Early Linear Flow (Days) } & \multicolumn{3}{|c|}{ Compounded Linear Flow (Days) } \\
\hline & Start Points & End Points & Duration & Start Points & End Points & Duration \\
\hline 2 Hydraulic Fractures & 44 & 118 & 74 & 723 & 1437 & 714 \\
\hline 4 Hydraulic Fractures & 57 & 155 & 98 & 681 & 1229 & 548 \\
\hline
\end{tabular}

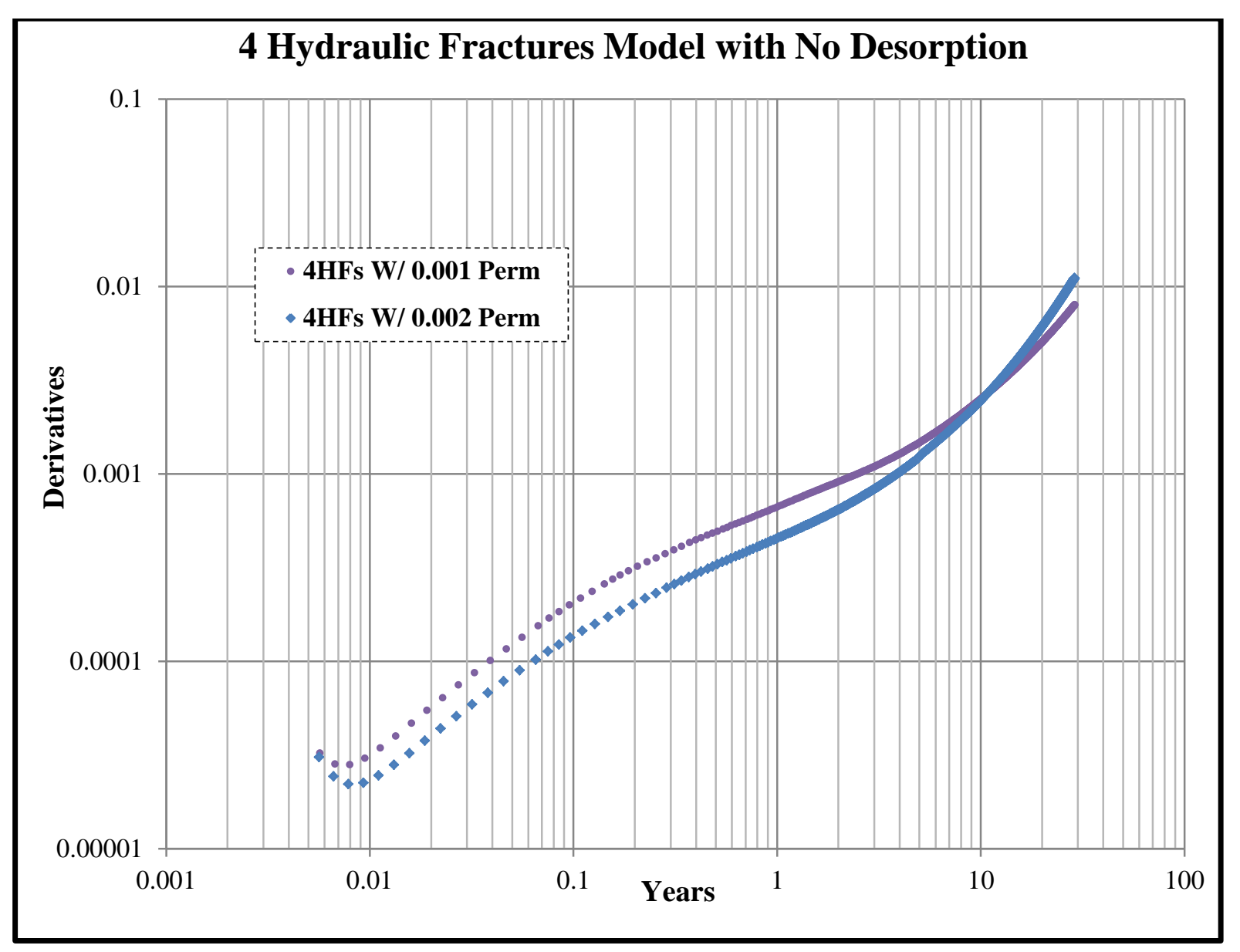

Figure 18 - Diagnostic plot to show model for 4 hydraulic fractures w/ 0.001 permeability 


\subsubsection{Scenario 3 and 4}

The base model with no desorption for cases 3 and 4 were run with 500 feet half-length size for hydraulic fractures with $0.005 \mathrm{mD}$ fissure permeability for scenario 3 , and $0.01 \mathrm{mD}$ fissure permeability for scenario 4. Figure 19 and 20 illustrates these two scenarios vs. their original case studies to show the differences in flow regimes. Table 14 shows the flow durations for both new scenarios. Also a diagnostic plot for case 3 is included in appendices section. By increasing the fissure permeability to $0.005 \mathrm{mD}$, the linear flow for both scenarios flows longer period but for the scenario with $0.01 \mathrm{mD}$ fissure permeability, the linear flow becomes shorter and smaller duration periods.

\begin{tabular}{|c|c|c|c|c|c|c|}
\hline & \multicolumn{6}{|c|}{ Table 14 -No Desorption Model w/ 500 feet Half Length } \\
\hline & \multicolumn{3}{|c|}{ With 0.005 Perm } & \multicolumn{3}{|c|}{ With 0.01 Perm } \\
\hline & Start Points & End Points & Duration & $\overline{~ S t a r t ~ P o i n t s ~}$ & End Points & Duration \\
\hline 2 Hydraulic Fractures & 39 & 290 & 251 & 44 & 124 & 80 \\
\hline 4 Hydraulic Fractures & 45 & 207 & 162 & 52 & 124 & 72 \\
\hline
\end{tabular}

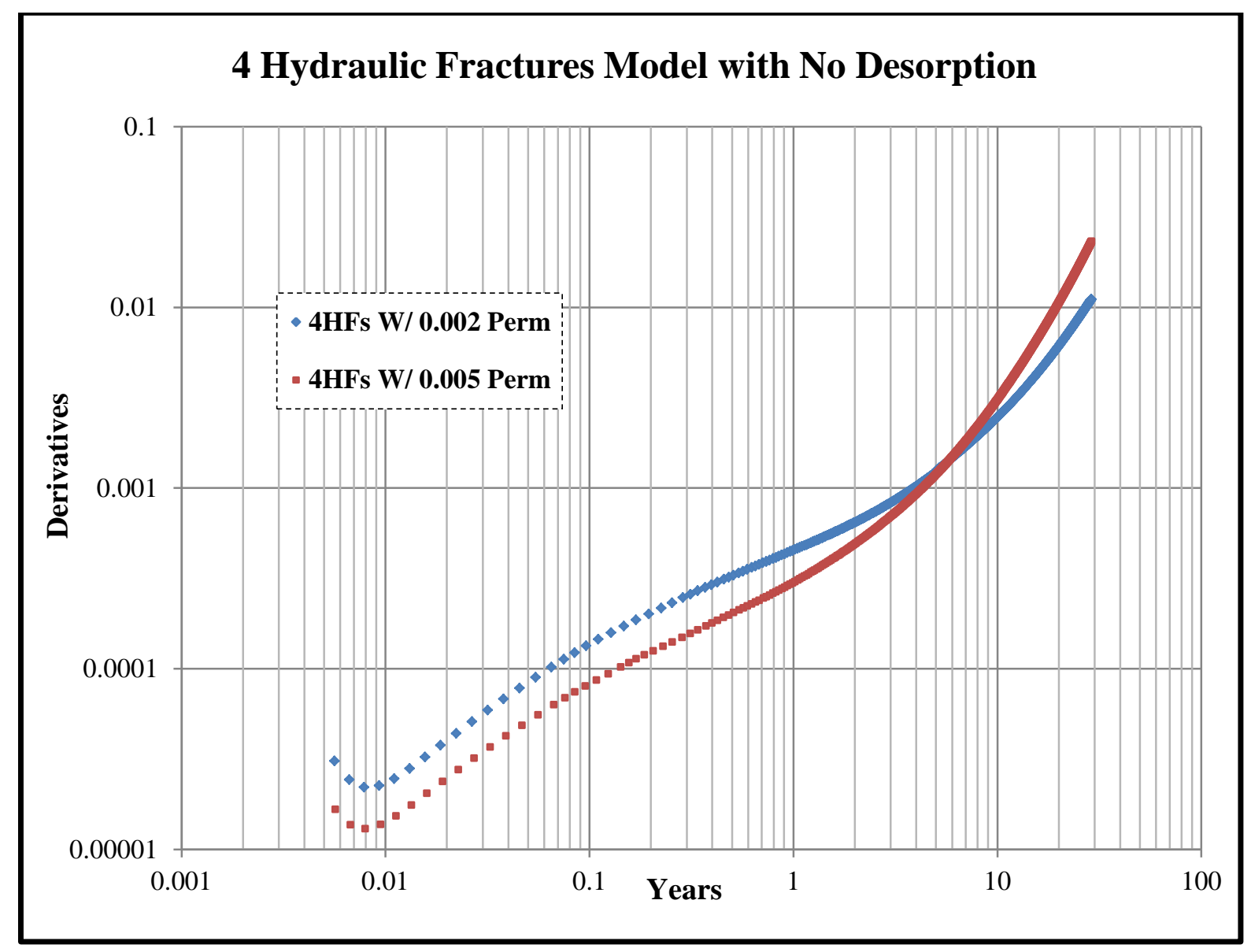

Figure 19 - Diagnostic plot to show model for 4 hydraulic fractures w/ 0.005 permeability 


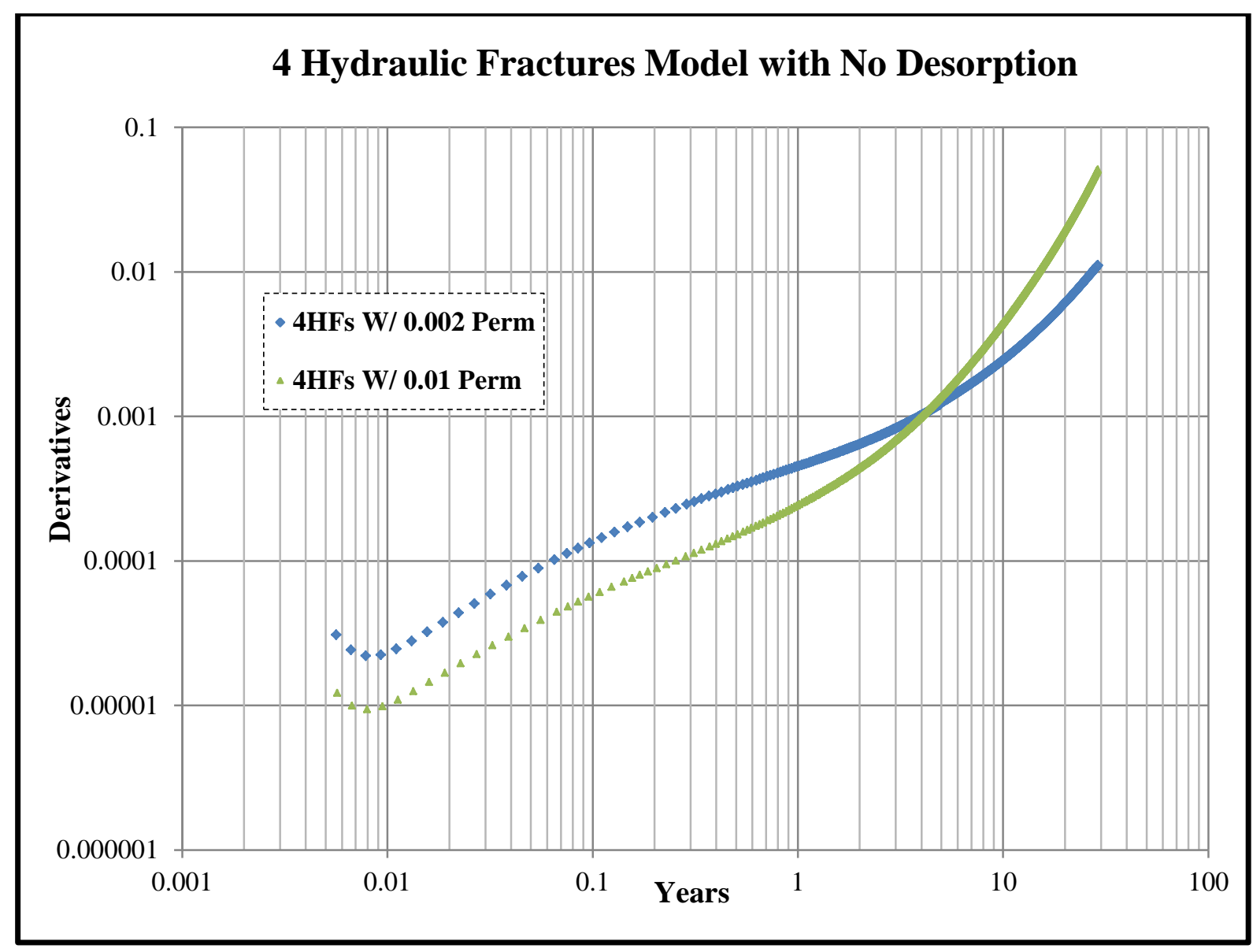

Figure 20 - Diagnostic plot to show model for 4 hydraulic fractures w/ 0.01 permeability 


\section{Conclusions}

The objective of this thesis was to understand the impacts of hydraulic fractures on flow behavior of the horizontal wells completed in ultra-low permeability shale formations such as Marcellus Shale. After creating the model and analyzed multiple cases, it was concluded that the number of hydraulic fractures significantly impacts the production. Meanwhile the impact of desorption was found to be negligible during the early stage of the production. This study identified a number of different flow regimes. The first flow period identified was vertical radial flow that was influenced by the dual porosity effects. The second flow period was "Early Linear Flow" which its duration depended on the number of hydraulic fractures. The next flow period identified was "Compounded Linear Flow" which its duration also depended on the number of hydraulic fractures. Finally, the flow becomes elliptical due to boundary effects.

The detail investigation of the flow regimes revealed that as the number of hydraulic fracture increases, the duration of the "Early Linear Flow" becomes longer. However, as the number of hydraulic fracture increases, the duration of the "Compounded Linear Flow" becomes shorter. This is because the boundary effects occur earlier with the increase in the number of hydraulic fracture. The fracture half-length also impacts the flow periods. The shore the fracture half-length, the shorter is the "Early Linear Flow" and the longer is the "Compounded Linear Flow. Also fissure permeability is another parameter that had major impact on the flow periods. The study showed that as the fissure permeability increases, the linear flow diminishes because the transient period becomes shorter. 


\section{Recommendations for future work}

A case with more horizontal wells with multiples clusters of hydraulic fractures can be investigated for the flow regimes identifications. Moreover, a real case can be used to apply the developed workflow for identifying different flow regimes. 


\section{References}

1. Anon., 2013. Shale gas in the United States. [Online]

Available at: http://en.wikipedia.org

[Accessed 19 May 2013].

2. Barenblatt, 1960. Basic concepts in the theory of homogeneous liquids in fissure rocks, s.l.: s.n.

3. Belyadi, A., 2010. Performance of the Hydraulically Fractured Horizontal Wells in Low Permeability Formation. s.l., Society of Petroleum Engineers Inc. SPE139082.

4. Belyadi, A., 2011. Modeling Studies To Evaluate Performance of the Horizontal Wells Completed in shale, Morgantown: West Virginia.

5. Belyadi, A., 2012. Production Performance of Mulityply Fractured Horizontal Wells. Morgantown, SPE.

6. Bourdet, D. e. a., 1983. A new set of type curves simplifies well test analysis. s.l.:s.n.

7. Gringarten, A. C., n.d. Type-Curve Analysis. s.l., Society of Petroleum Engineers Inc. .

8. Kalantari, A., 2010. Reservoir Modeling of New Albany Shale, Morgantown: s.n.

9. Olusehun, R., 2009. Rate Transient Analysis in Shale Gas Reservoirs with Transient Linear Behavior, College Station, TX: s.n.

10. Spivey, J. P., 1999. Application of the Diagnostic plot using a Derivative Based on Shut-In Time. s.1., Society of Petroleum Engineers Inc. SPE 56424..

11. Warren, 1963. The Behavior of Naturally Fractured Reservoirs. s.1., Society of Petroleum Engineers. 


\section{Appendices}

\section{Appendix A (ECLIPSE)}

Appendix A-1 shows simple procedure using Schlumberger ECLIPSE software to model horizontal well completed in shale. Step by step of this procedure is included. Figure A-1 shows an Eclipse software launcher screen that was used in this research.

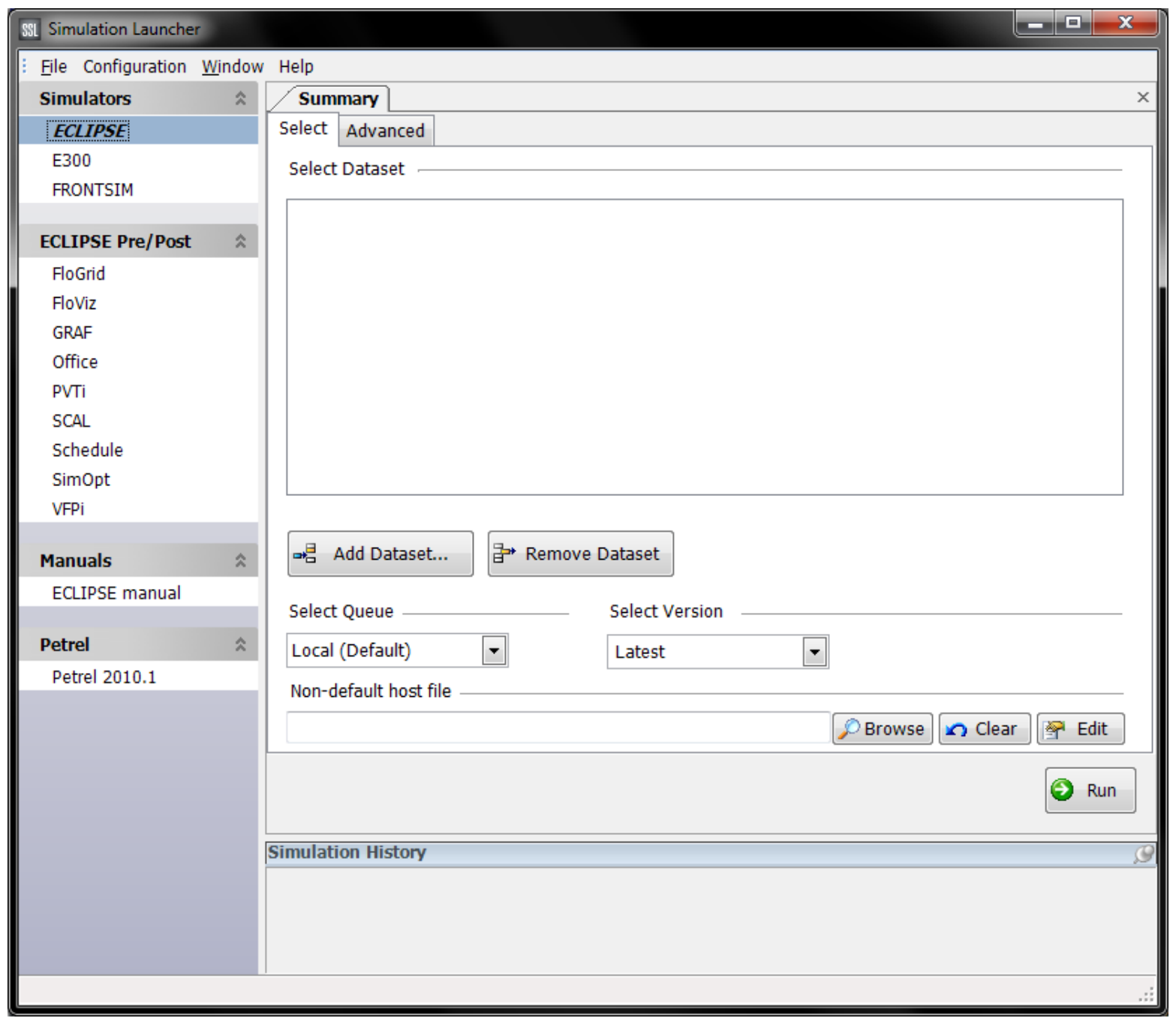

Figure 17 - Appendix A-1: ECLIPSE Launcher 
Before choosing of any options excited in the launcher, create a file for the model that needs to becreated, then click on the office tab from the software launcher window to select the file that has been created and run the launcher. Figure 18 is an example of what was explained.

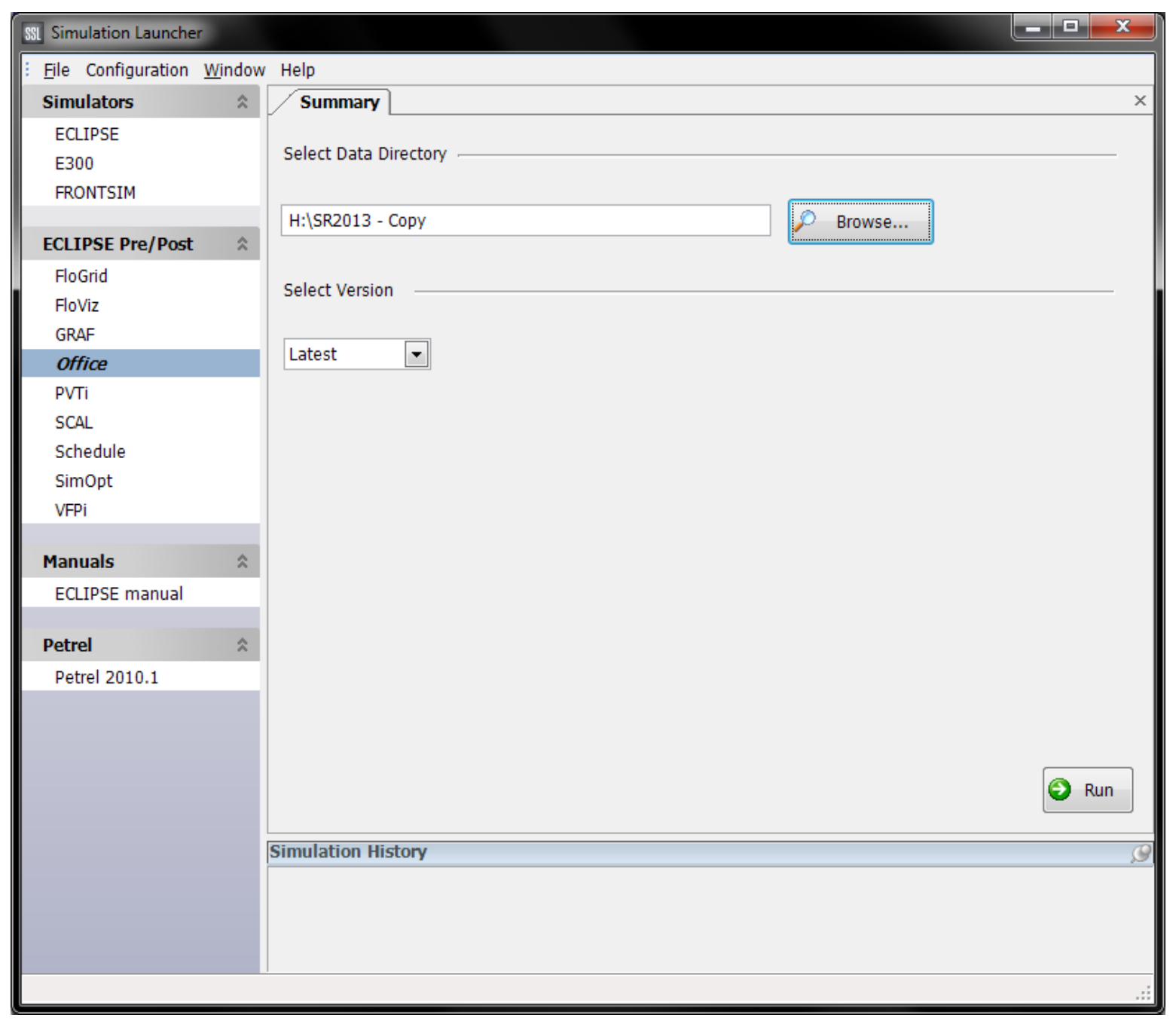

Figure 18 - Appendix A-2: ECLIPSE Office Launcher 
Figure 19 shows the next step, which is creating a project. Click on file and there click on the "New Project" option.

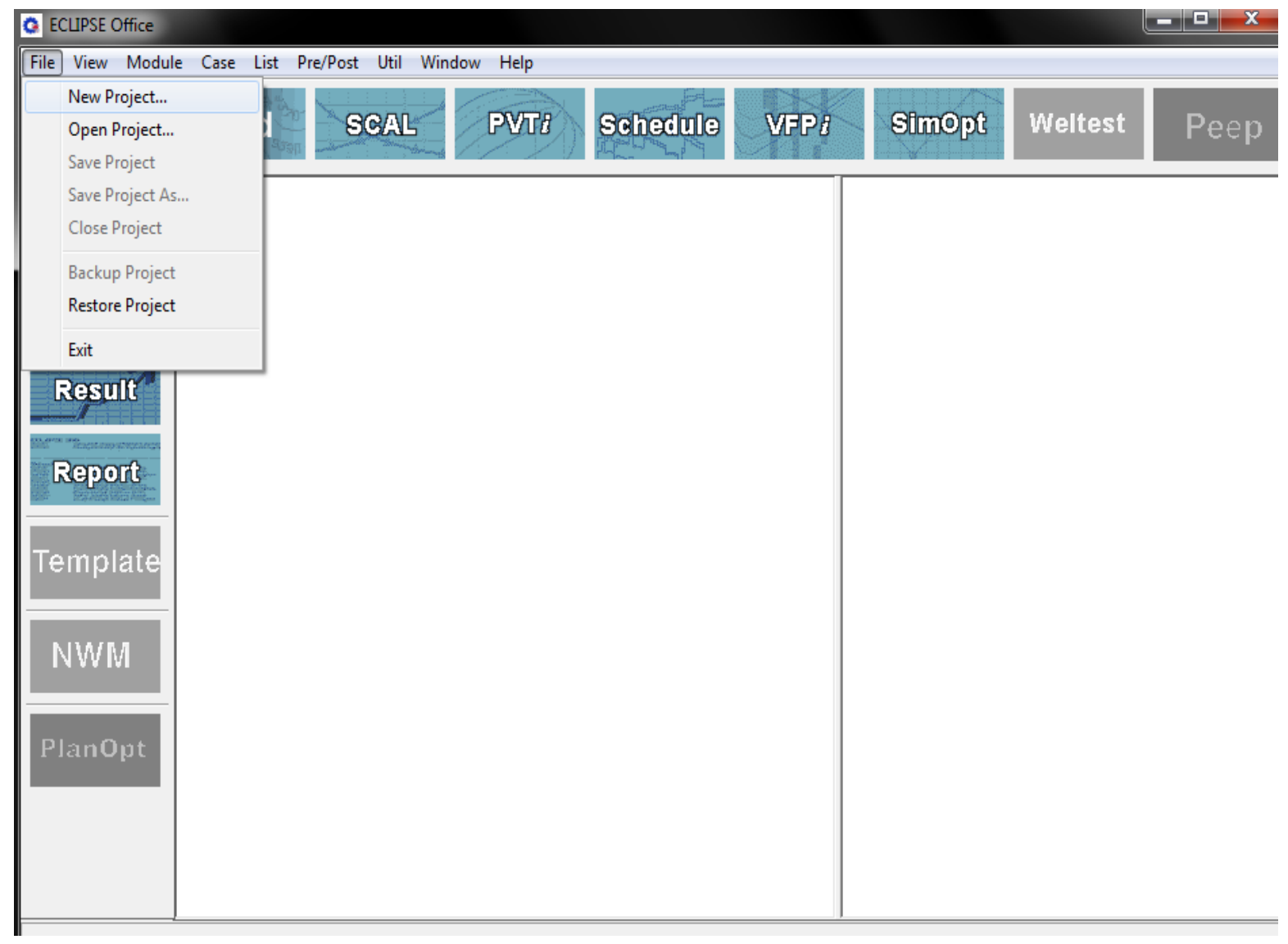

Figure 19 - Appendix A-3: ECLIPSE Office Screen 
After creating the project, click on the "Add Template Case" option as it shown in figure 20. Then the template selection panel will be displayed as it shows in figures 21 and 22 . The user will be able to select the detail of the model.

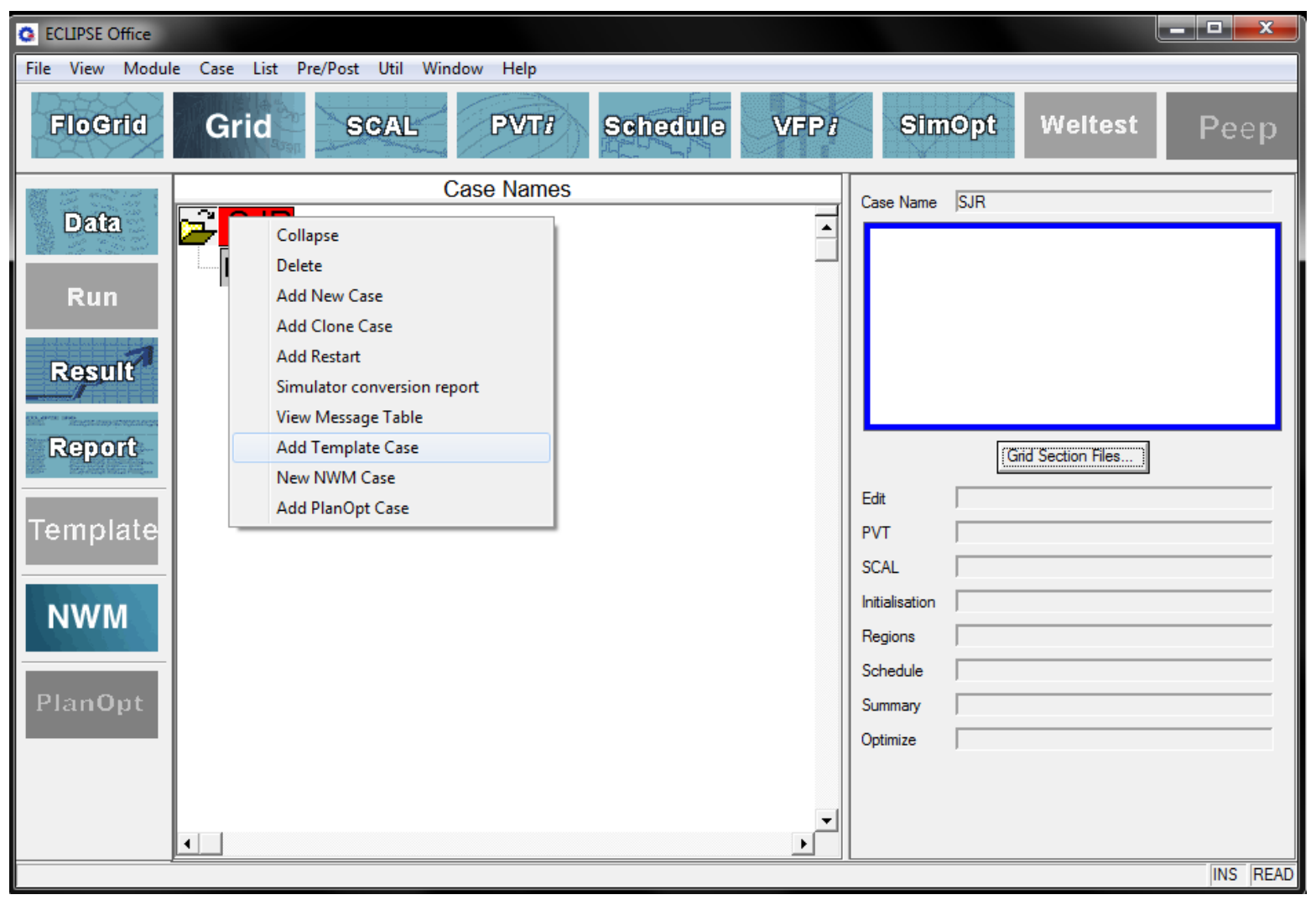

Figure 20 - Appendix A-4: ECLIPSE Template Screen 


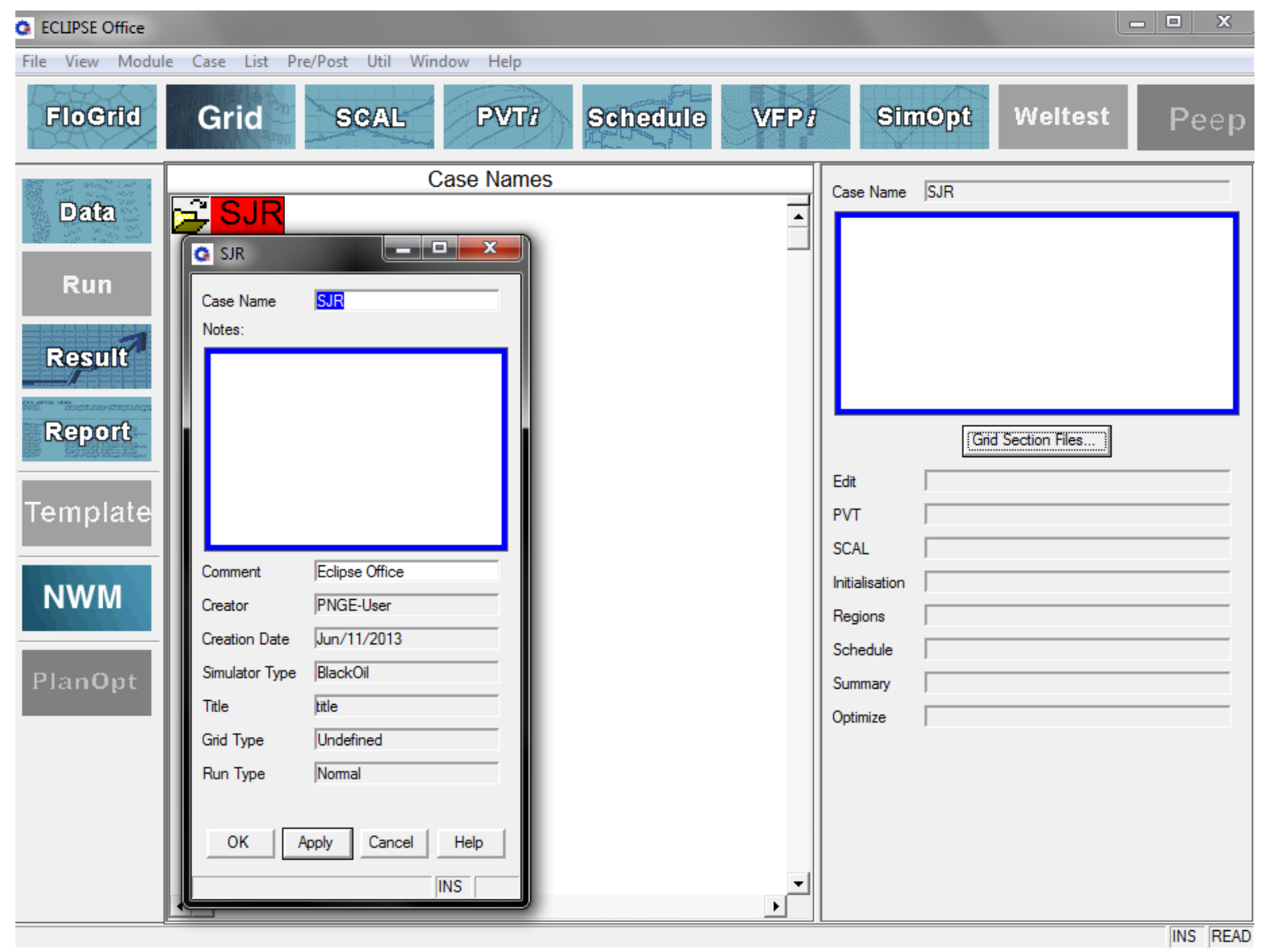

Figure 21 - Appendix A-5: ECLIPSE Template Selections 


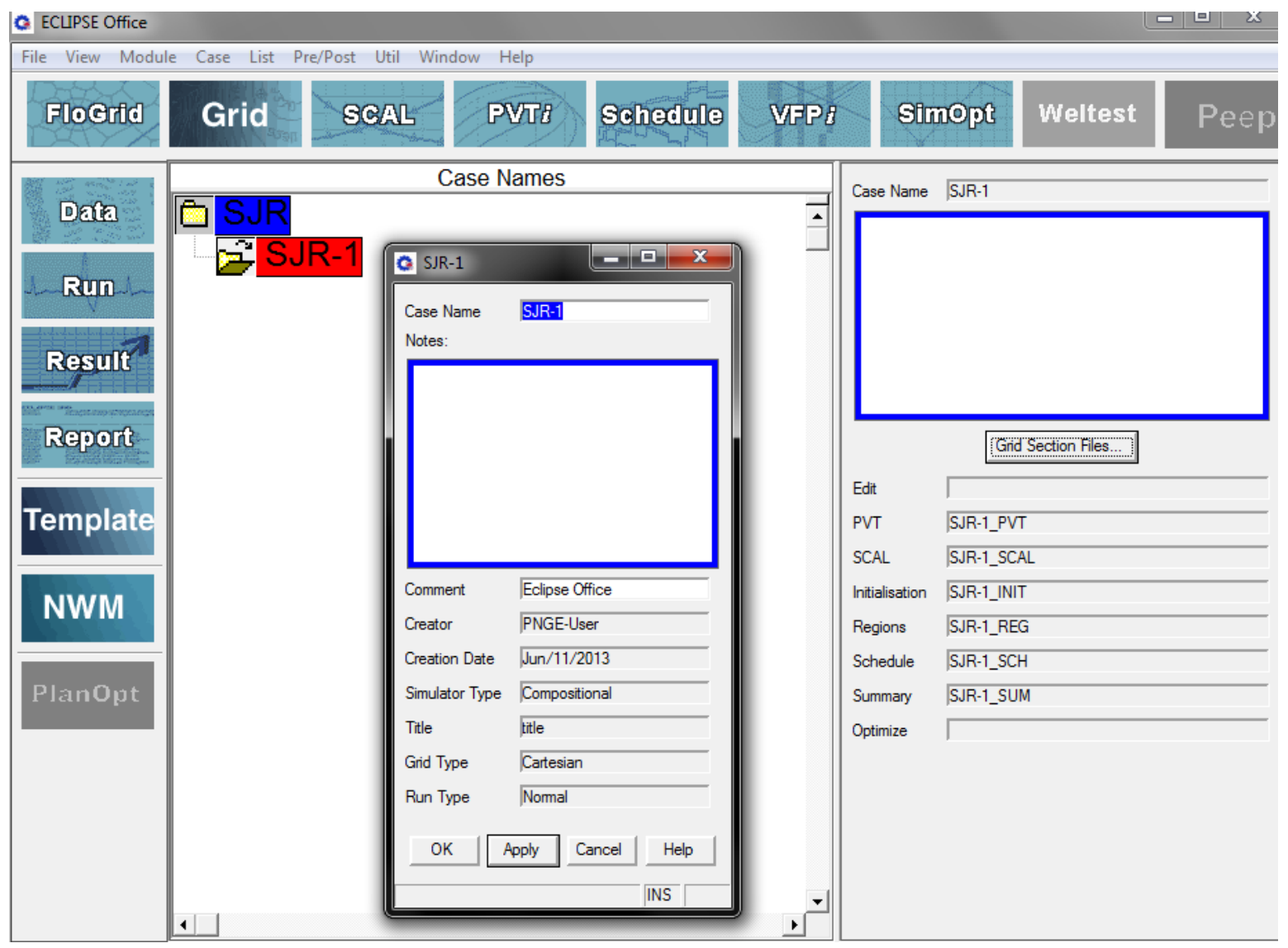

Figure 22 - Appendix A-6: ECLIPSE Template Screen 
After creating the template for the model, click on to move on to the next step of the creating the model. Figure 23 shows the Model Definition window, which has the start and end day, month, and year, also model properties. The user selects and enters the workflow is shown in this figure.

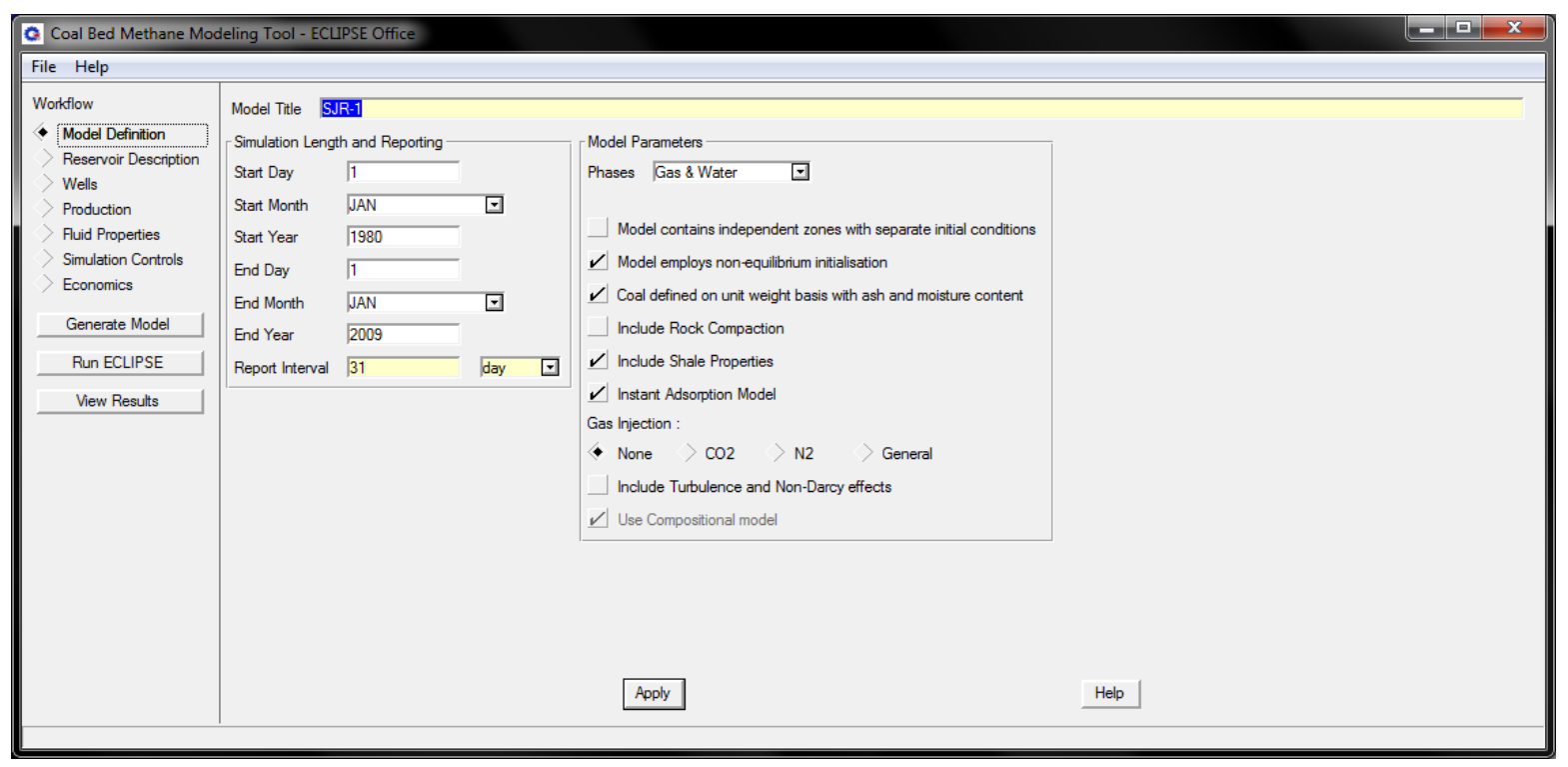

Figure 23 - Appendix A-7: Model Definition

The next step is the "Reservoir Description", which this section has its own work flow to follow. Figure 24 displays the window for layer information, which includes layer name, top depths, thickness, Length and width for each layer.

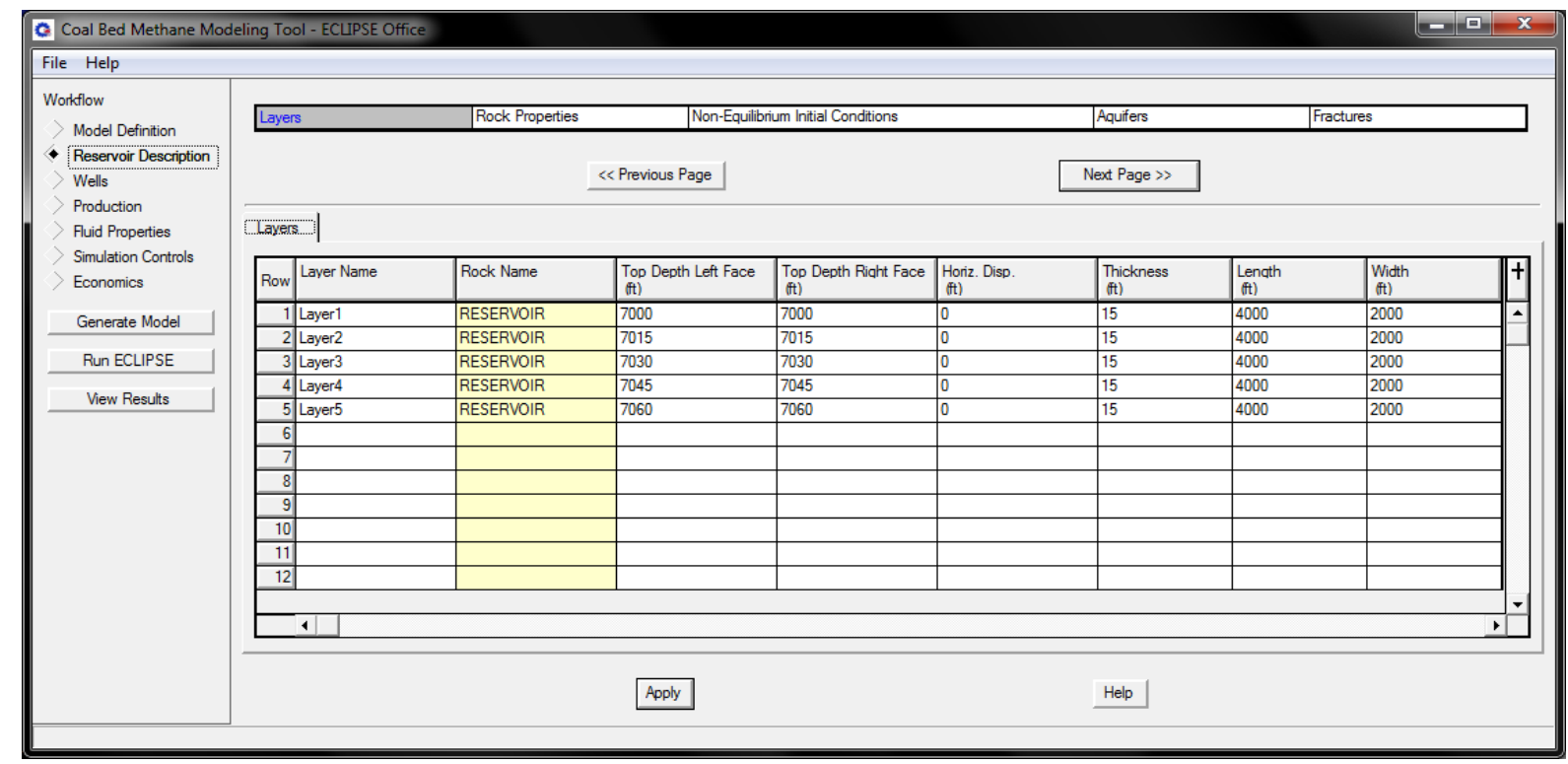

Figure 24 - Appendix A-8: Reservoir Layers Description 
Figure 25 displays the "Rock Properties" window, which is the next work flow in "Reservoir Description”. Rock properties contain rock name, fracture porosity, fissure permeability, matrix porosity and so on that shows in listed figure.

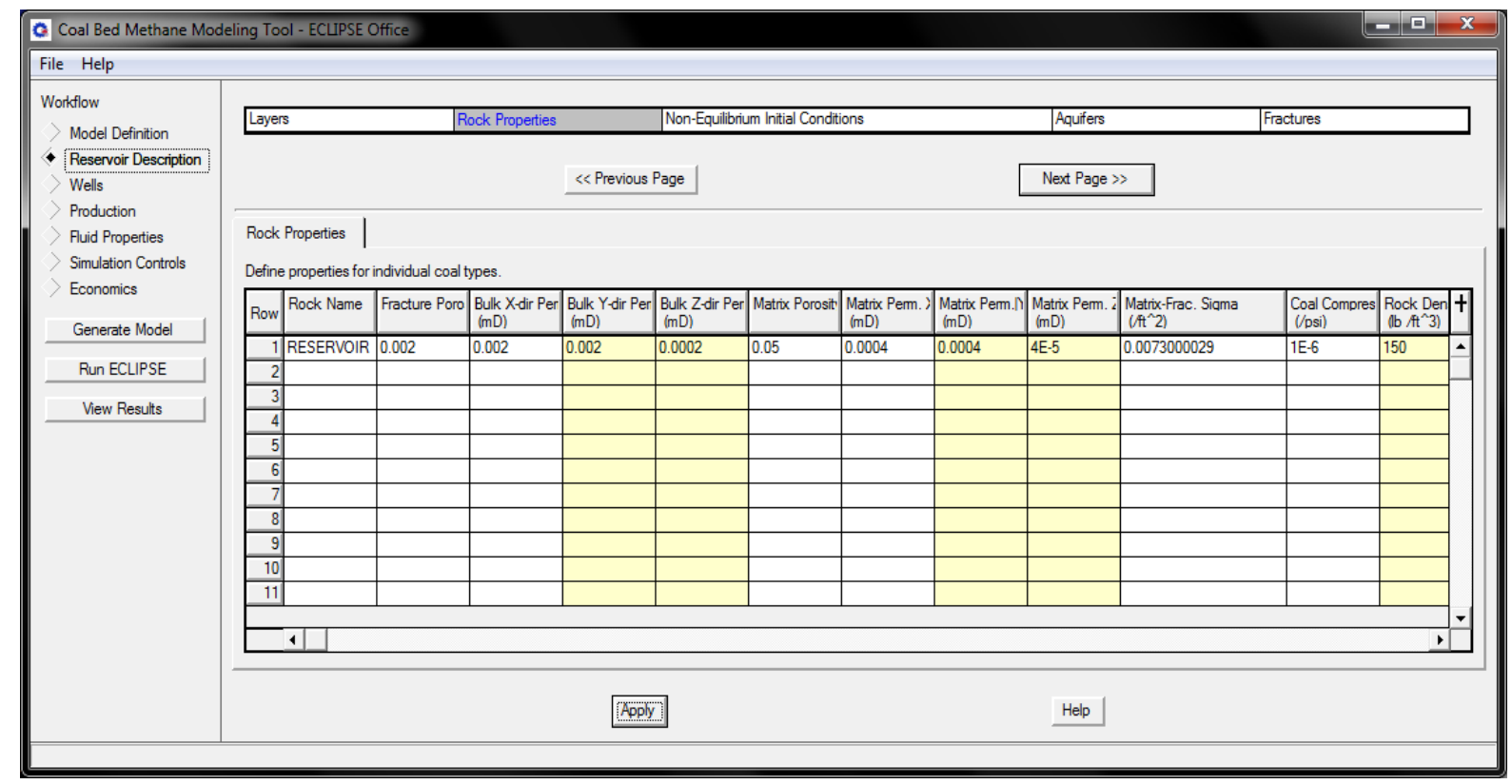

Figure 25 - Appendix A-9: Rock Properties

Next step in Reservoir Description is the "Non-Equilibrium Initial Conditions", which the user enters the reservoir pressure and water saturation for the model.

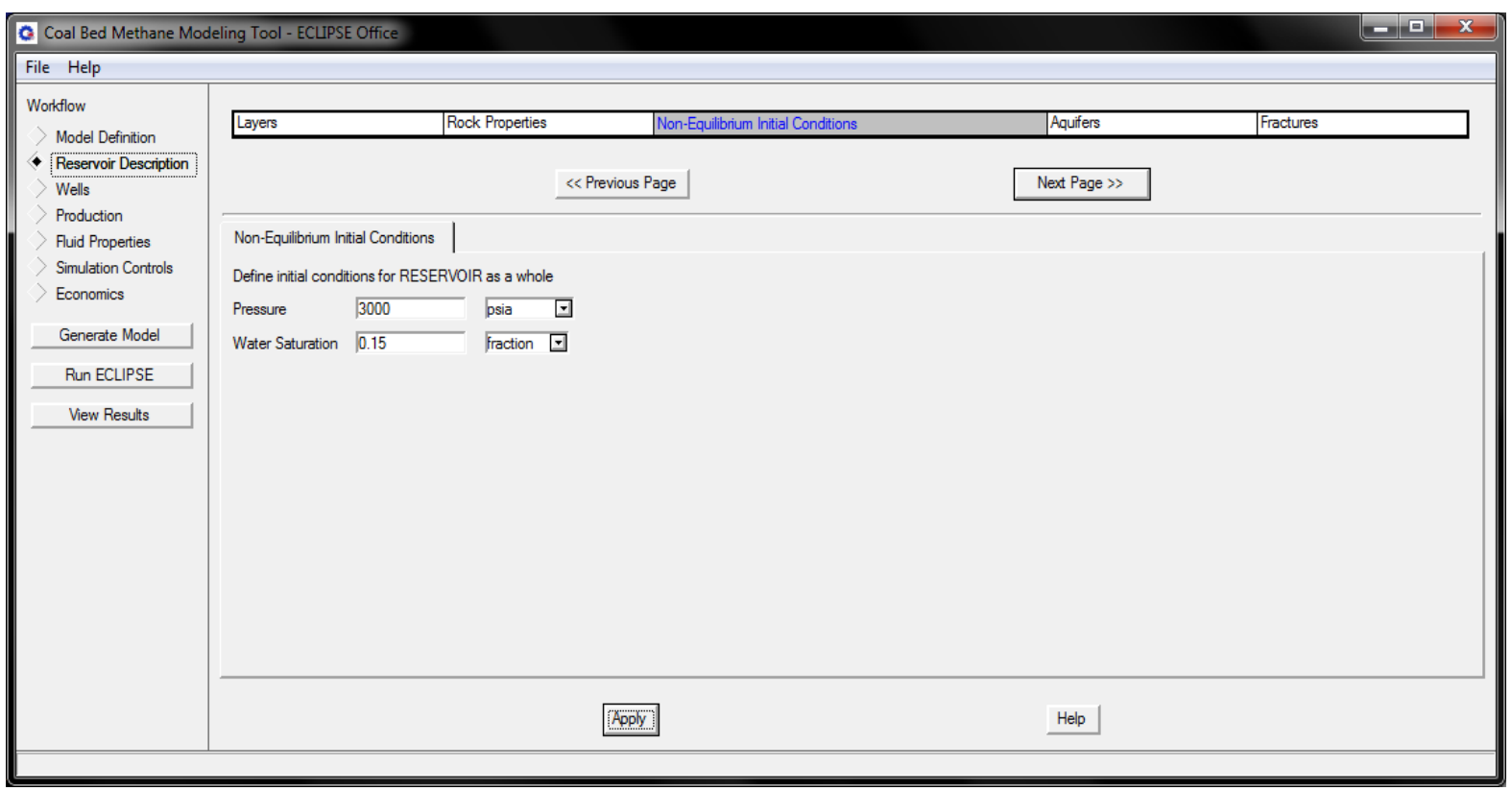

Figure 26 - Appendix A-10: Non-Equilibrium Initial Conditions 
For this study, the aquifers data wasn't used. The last step of the reservoir description is the "Fractures" data entry. Figure 27 shows the detail of this work.

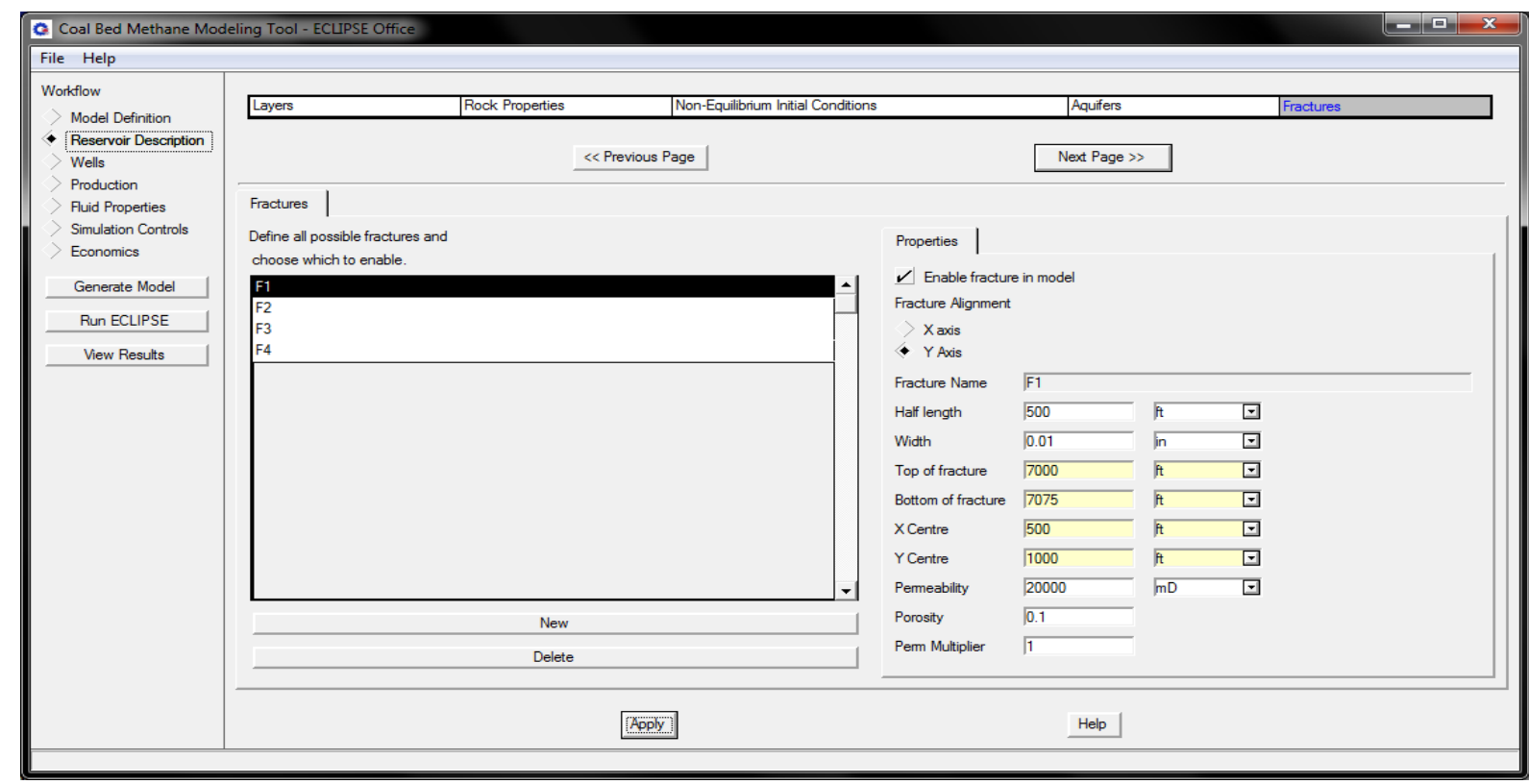

Figure 27 - Appendix A-11: Fractures

Continuing the next work flow is the access to well location in terms of its deviation survey data coordinates. Figure 28 shows the detail of this work flow to enter either horizontal or vertical wells for the model.

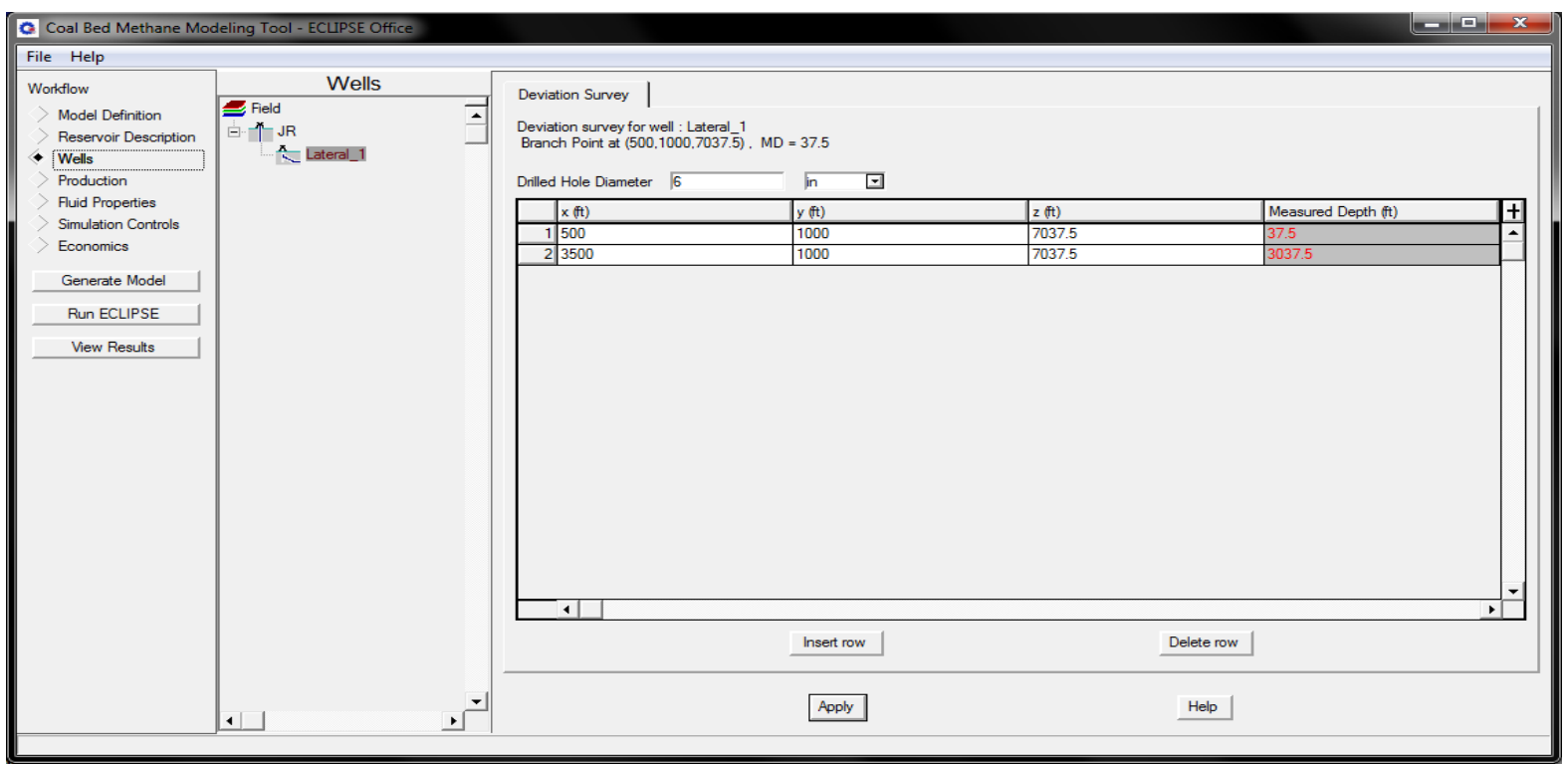

Figure 28 - Appendix A-12: Well Control

At this point, the user is fully done with 3 steps and following steps starts off with production tab. In this step, new even from available event types needs to be selected and the user can click on the "Production 
Well Schedule Data". Continue selecting well controls tab and enter the information related to start date, control mode, open/shut flag and target pressure. Figure 29 shows listed stages also figure 30 shows the user to define the perforation from the event type' drop-down box.

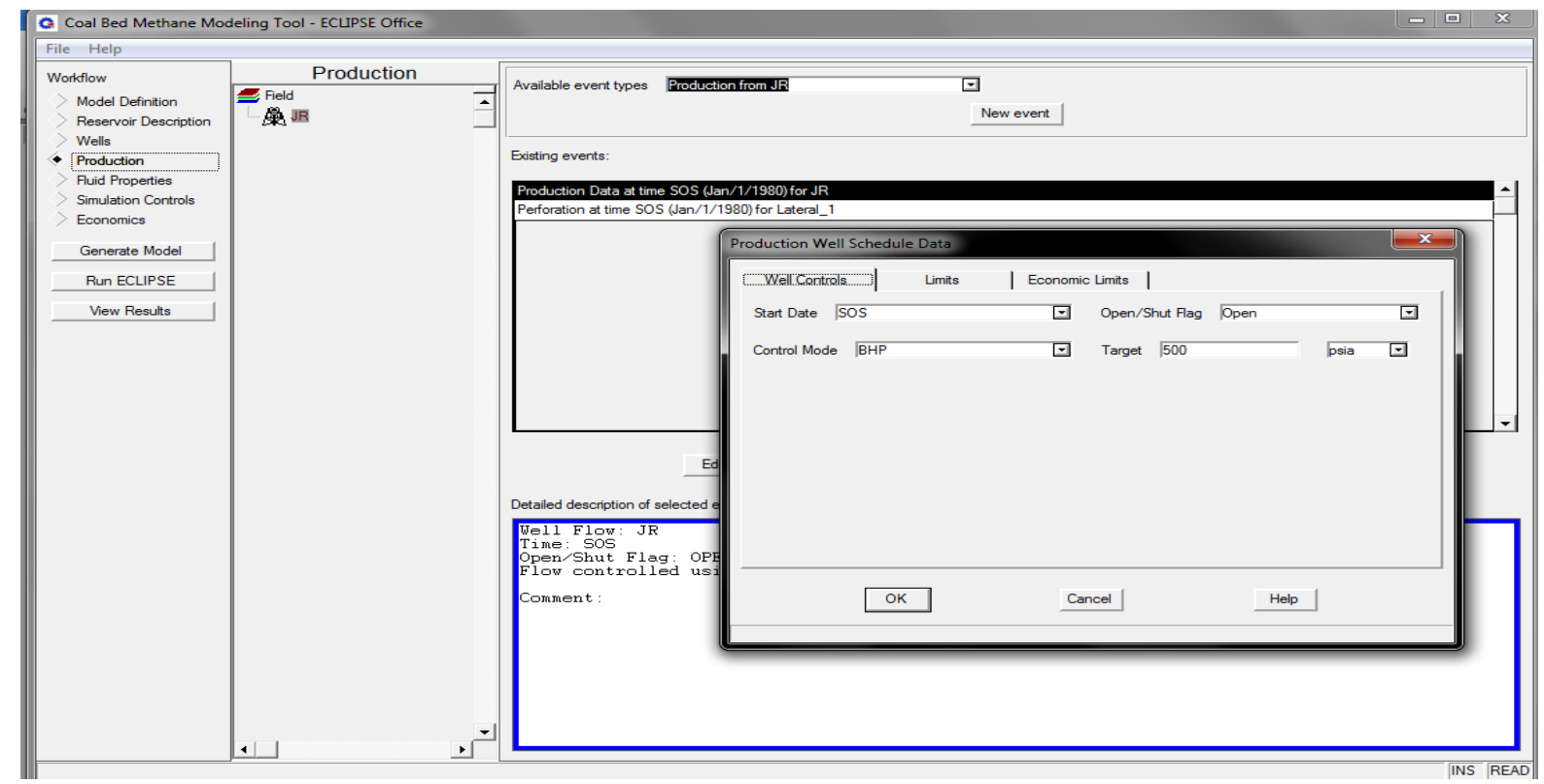

Figure 29 - Appendix A-13: Production Well Control

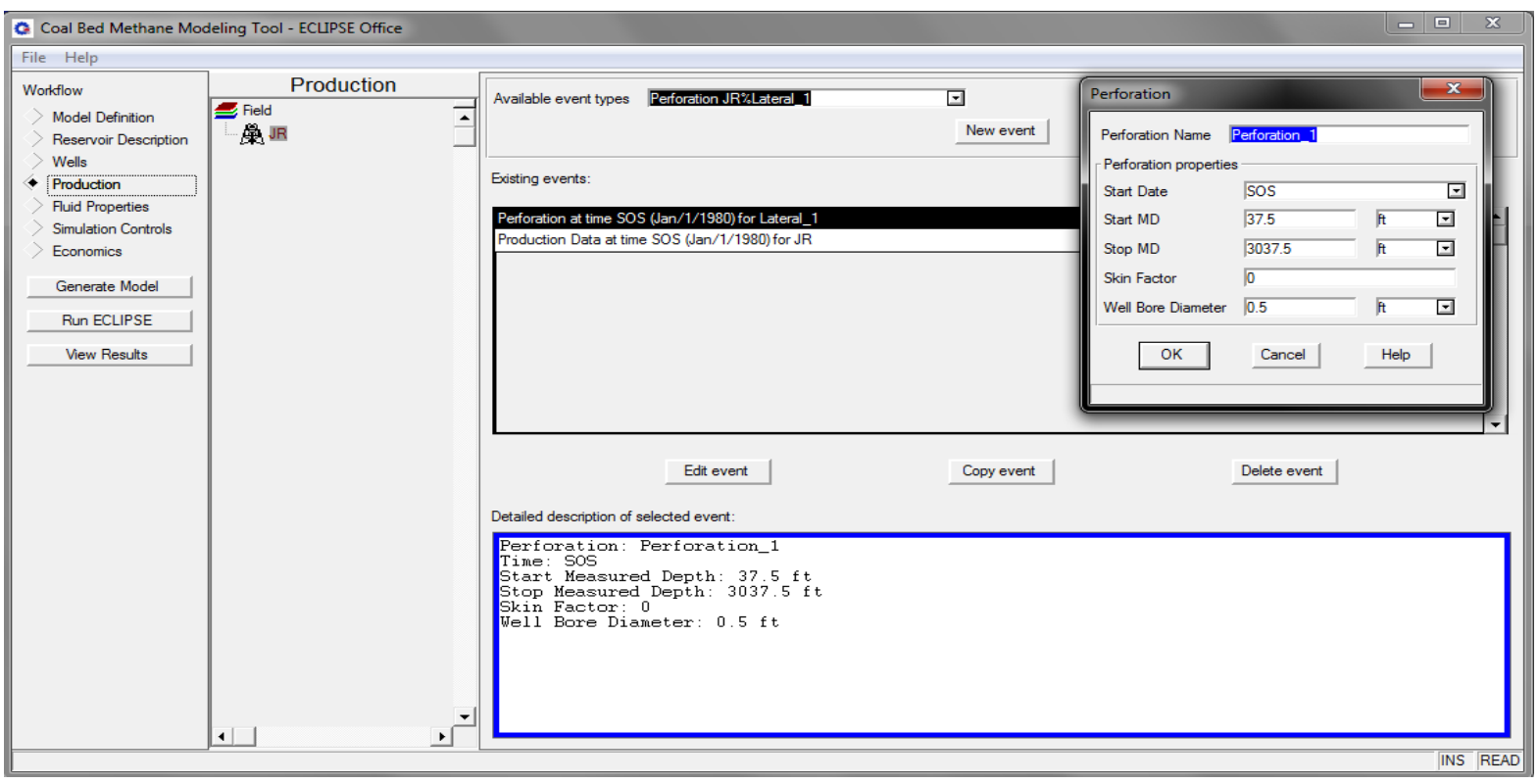

Figure 30 - Appendix A-14: Perforation Control

Figures 31to 34 illustrates the work flow for the "Fluid Properties" for the model. At this stage, the information for PVT Composition, Rel. Perm, and Coal Bed Methane are used. 


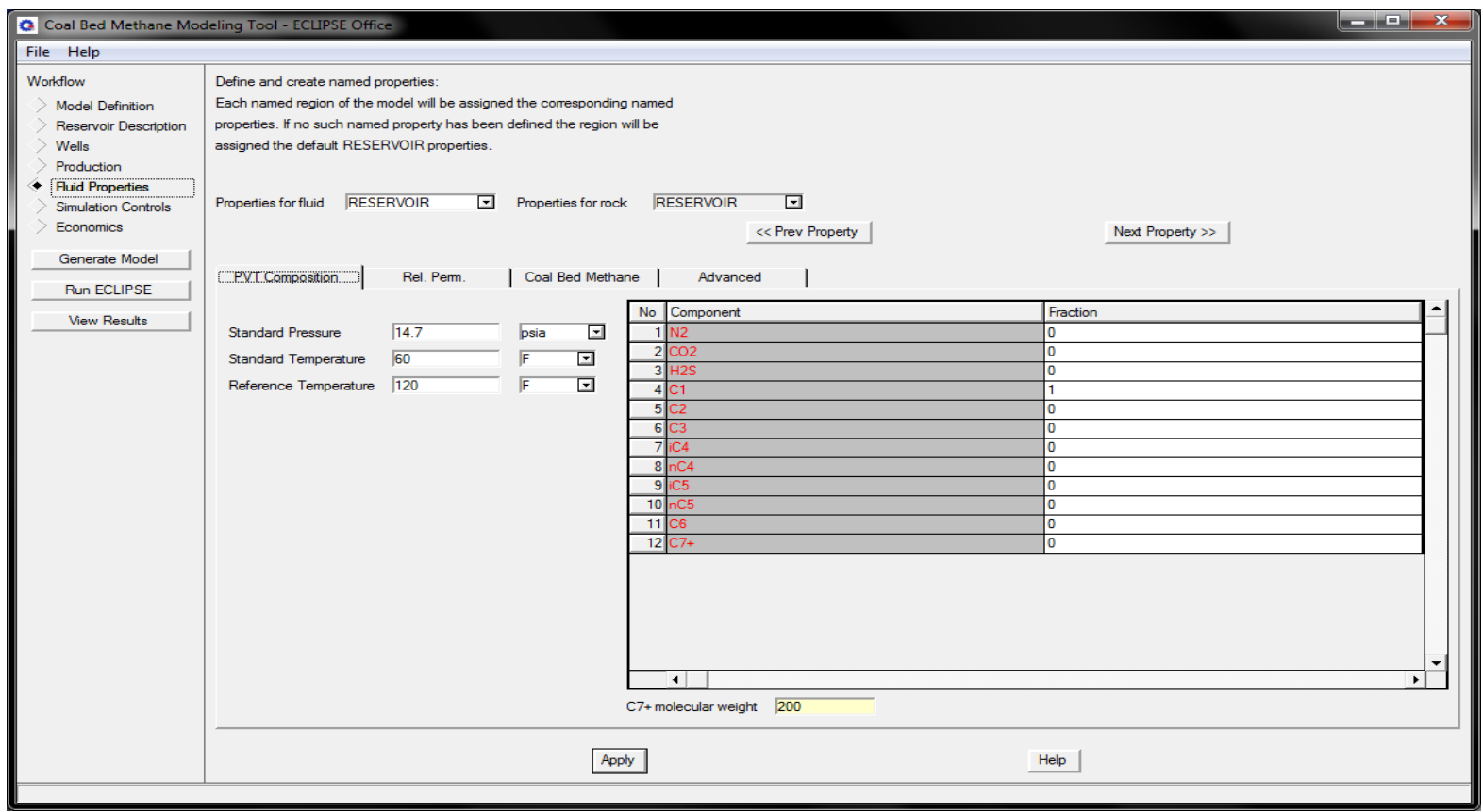

Figure 31 - Appendix A-15: PVT Composition

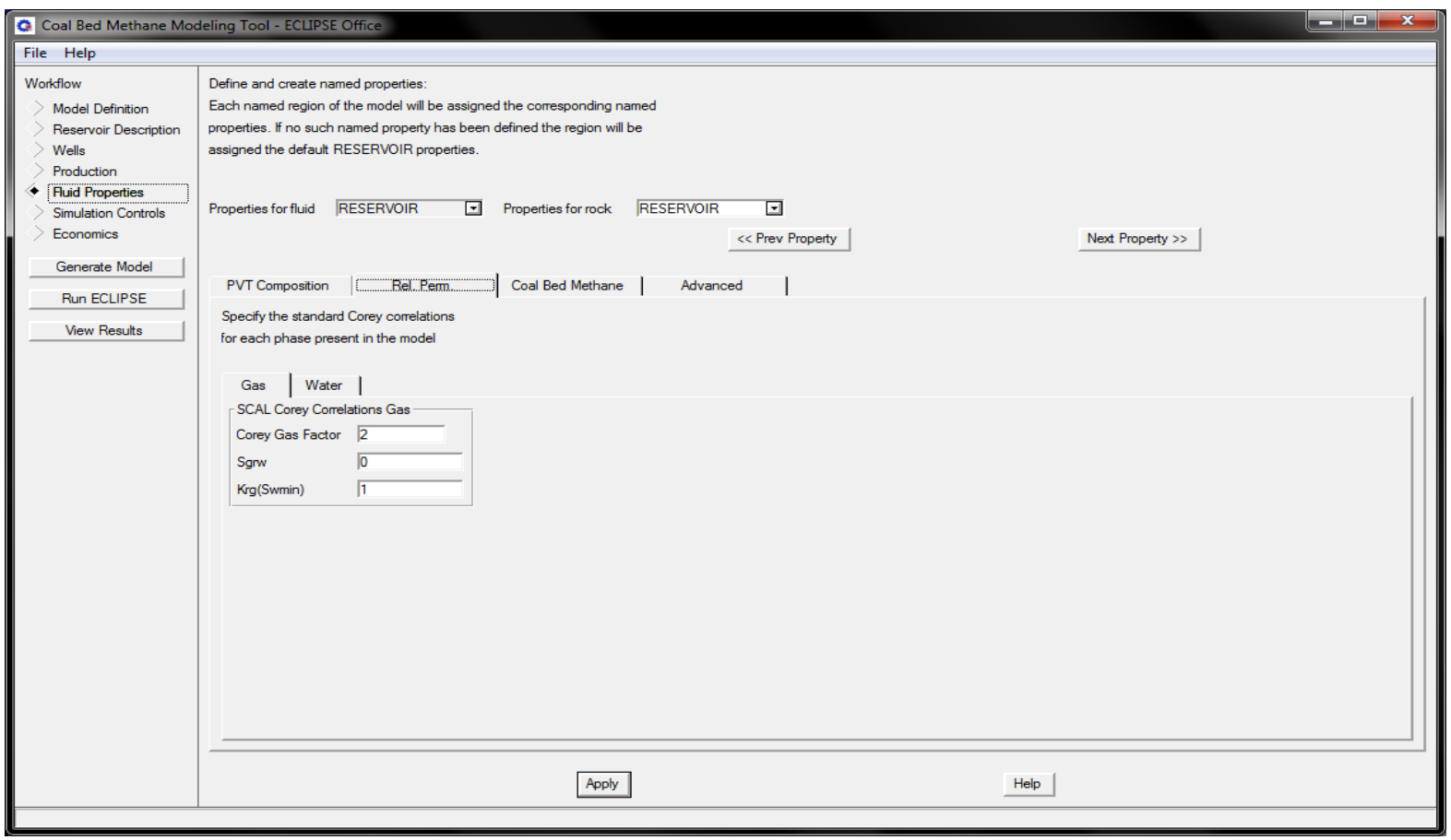

Figure 32 - Appendix A-16: Rel. Perm for Gas 


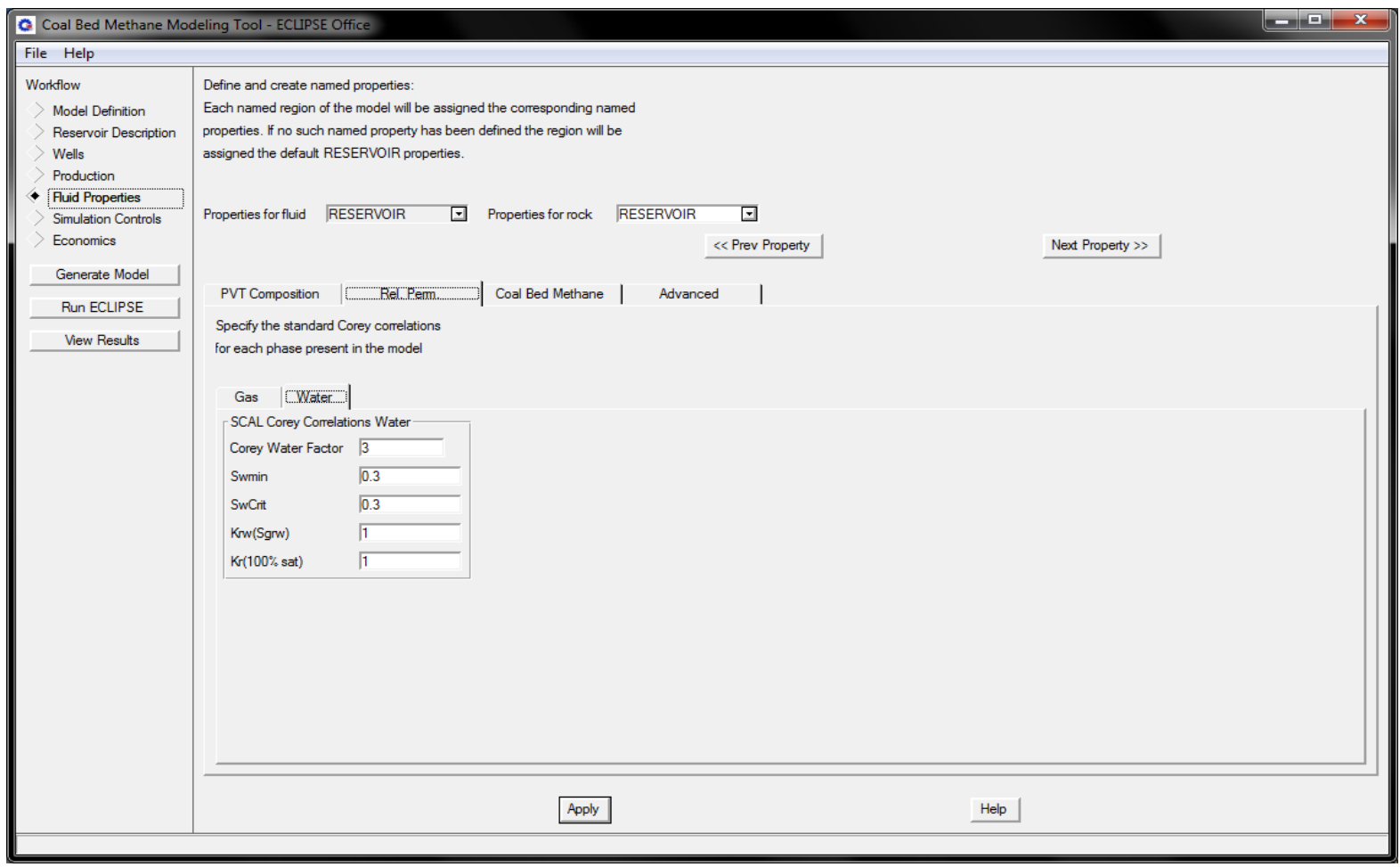

Figure 33 - Appendix A-17: Rel. Perm for Water

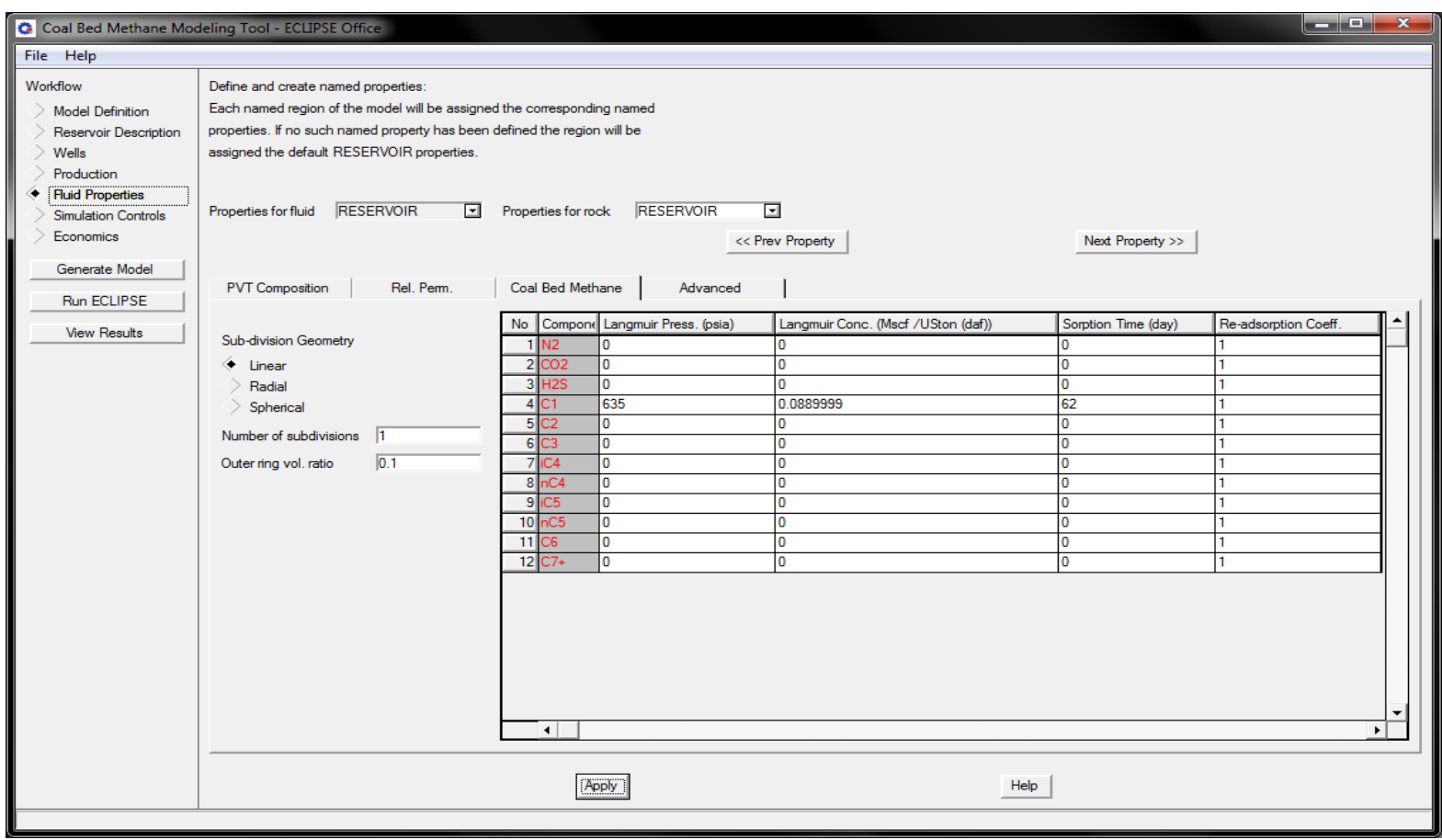

Figure 34 - Appendix A-17: Coal Bed Methane 
The last work flow that was used to complete this model is the "Simulation Control for Gridding Control". Figures 35 and 36 illustrate the details for gridding and turning controls. The minimum and maximum cell sizes needs to be determined by the user, also cell per layers in the gridding control data. Meanwhile, turning controls was used for time-step, minimum time-step, maximum time-step, maximum pressure change per time-step, maximum non-linear iteration, and maximum linear iteration data entry.

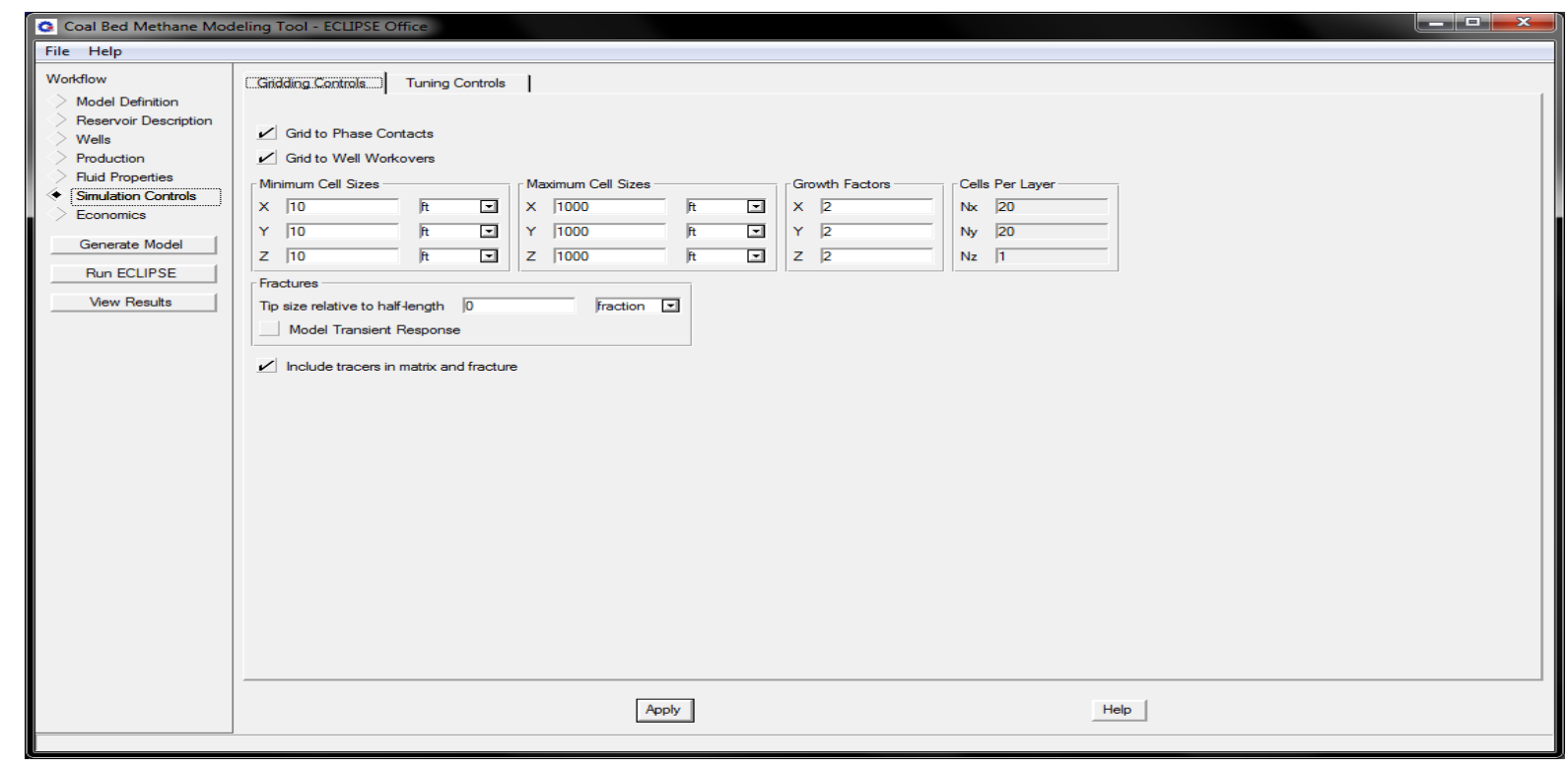

Figure 35 - Appendix A-18: Simulation Controls for Gridding Controls

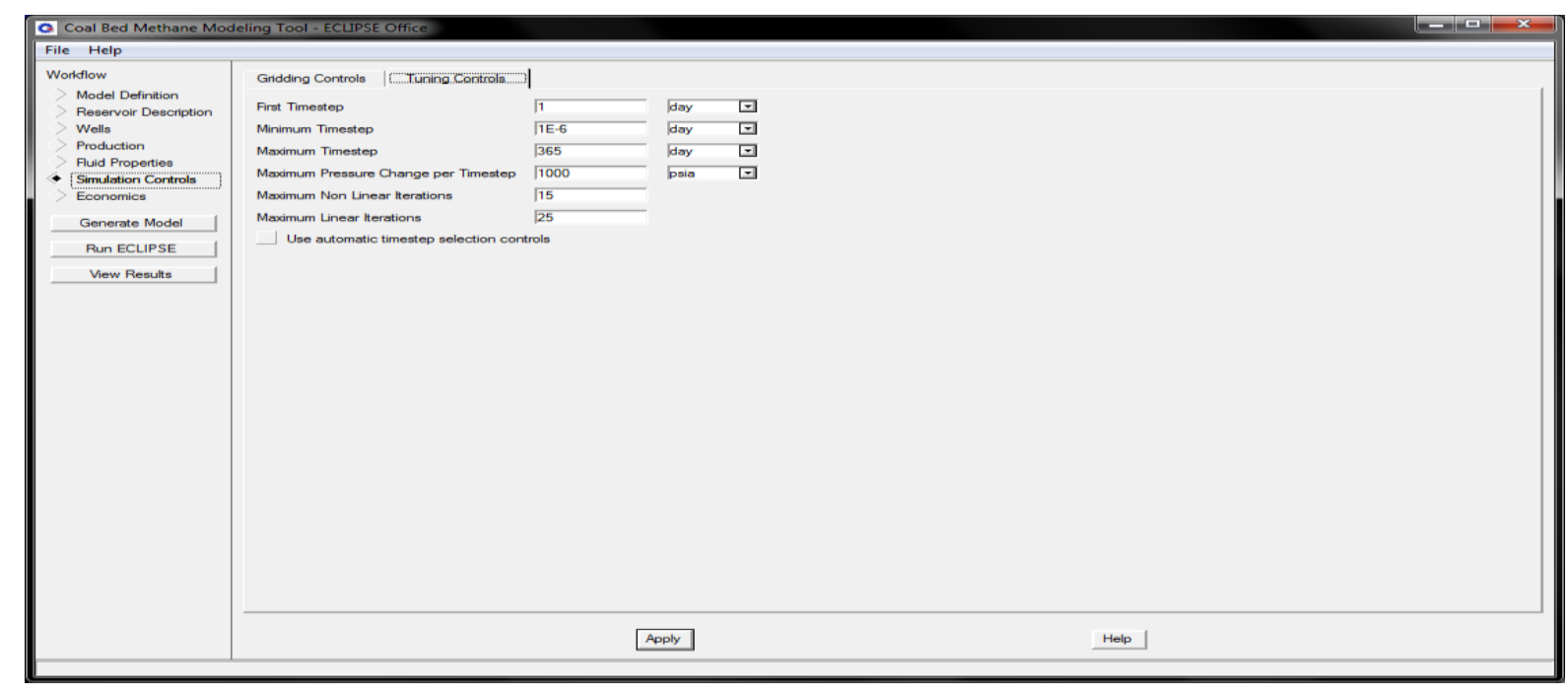

Figure 36 - Appendix A-19: Simulation Controls for Turning Controls

At this point, the user has completed data entry to build the model and by clicking on generating model, then run ECLIPSE, and at the end view results will be able to achieve the results. 


\section{Appendix B (ECLIPSE Models Layouts)}

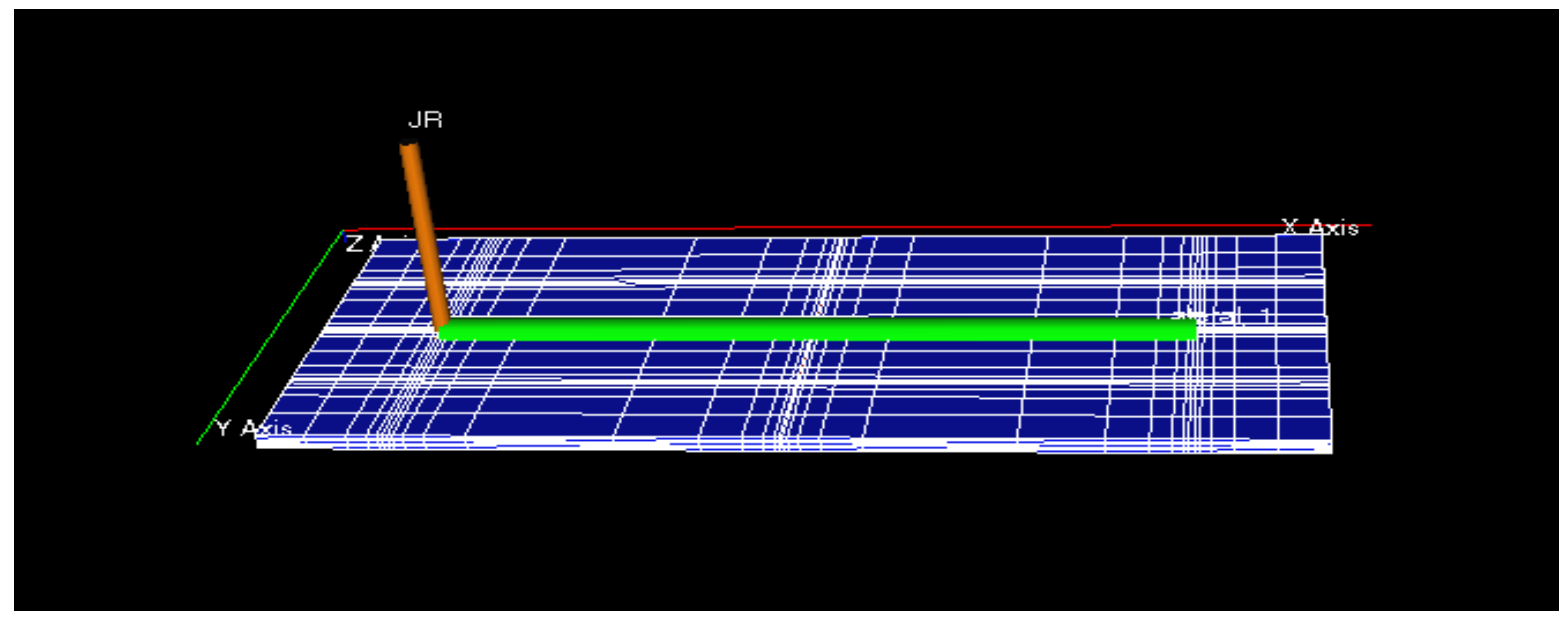

Figure 37 - Appendix B-1: Model with 1 Hydraulic Fracture

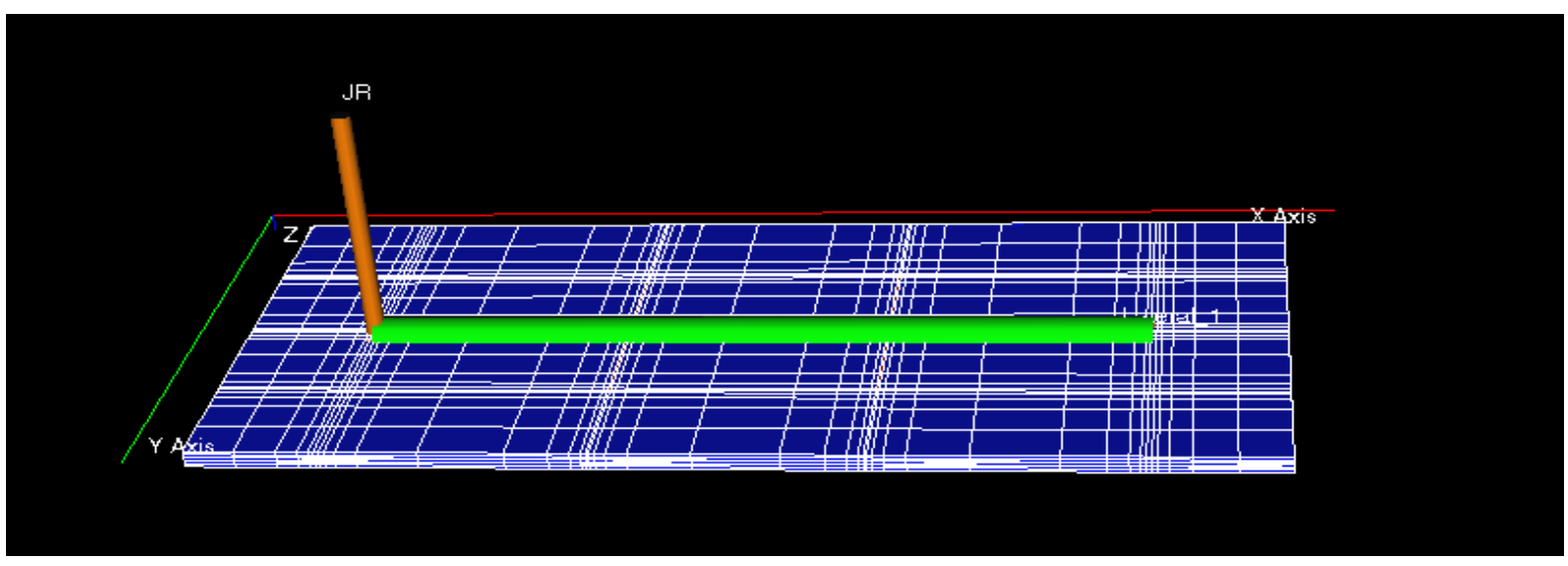

Figure 38 - Appendix B-2: Model with 2 Hydraulic Fractures

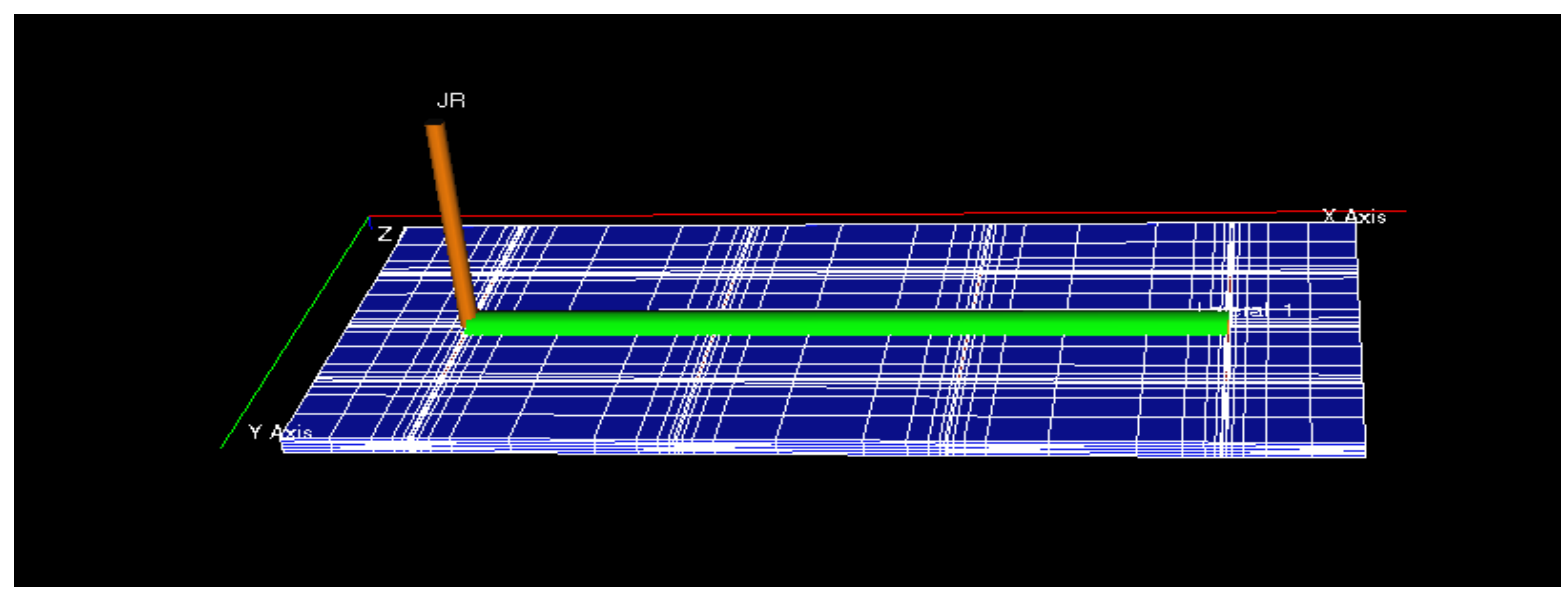

Figure 39 - Appendix B-3: Model with 4 Hydraulic Fractures 


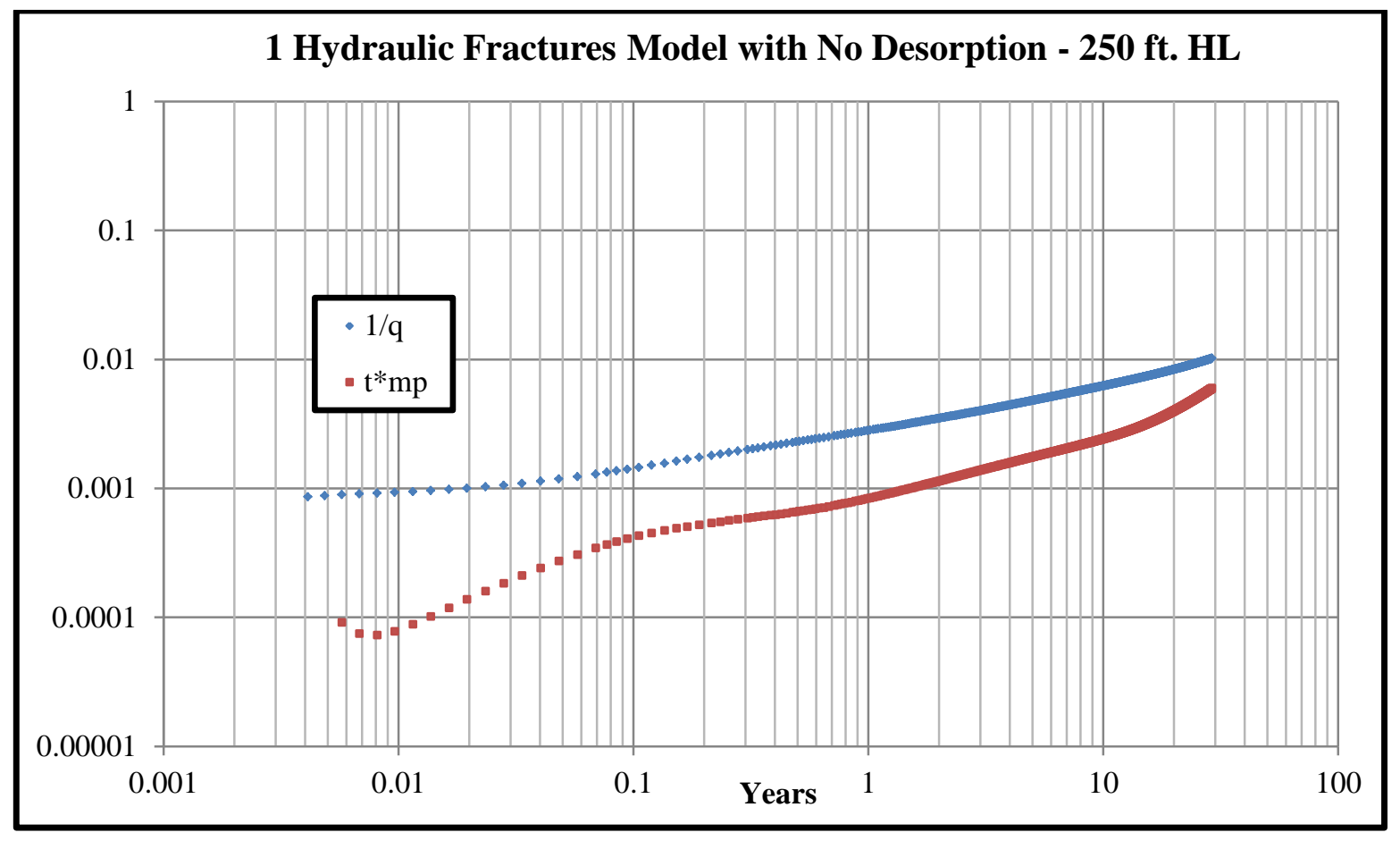

Figure 40 - Appendix C-1: Diagnostic Plot for the model w/ no desorption-250 ft Half-length (1HF)

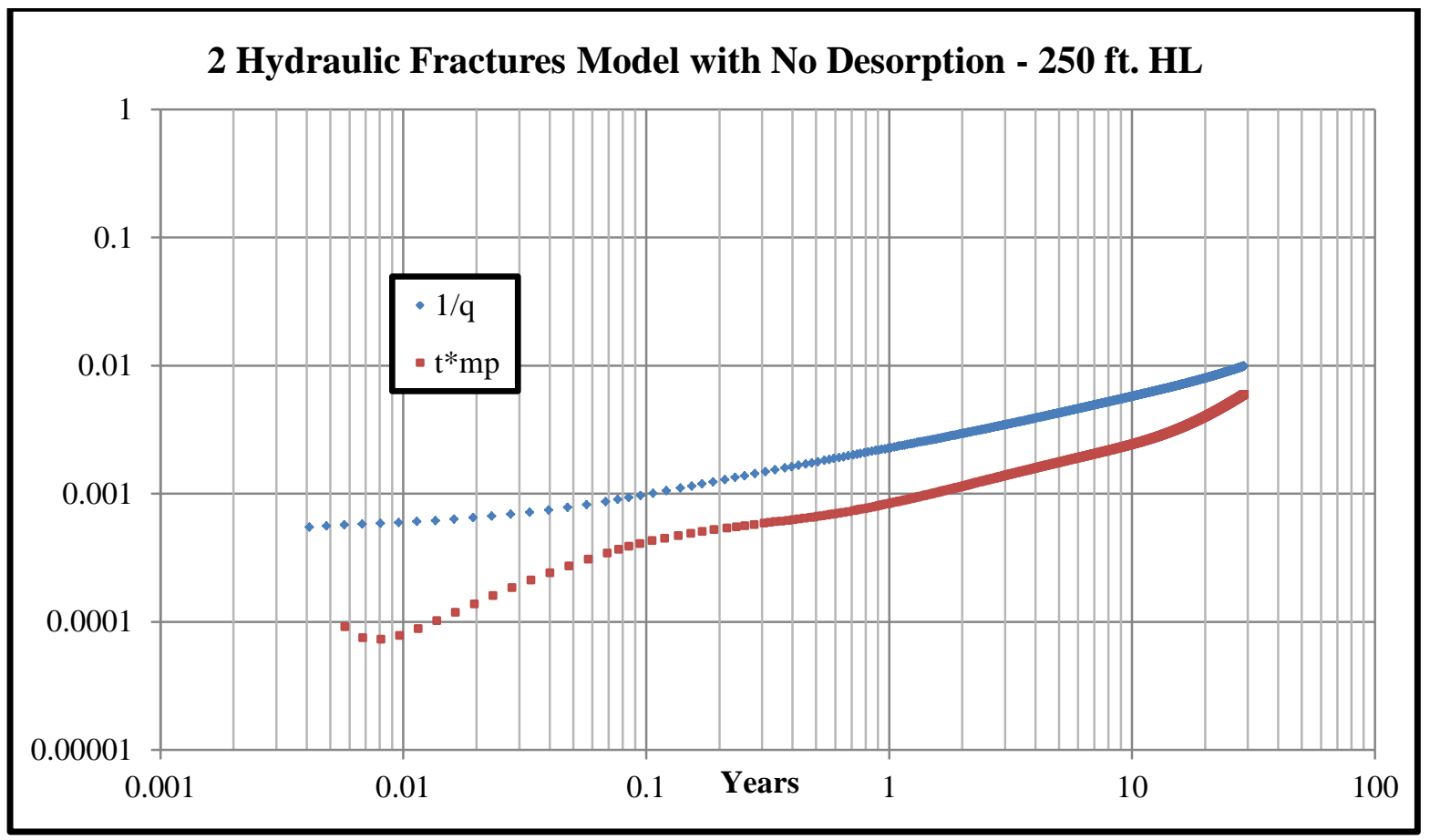

Figure 41 - Appendix C-2: Diagnostic Plot for the model w/ no desorption-250 ft Half-length (2HFs) 


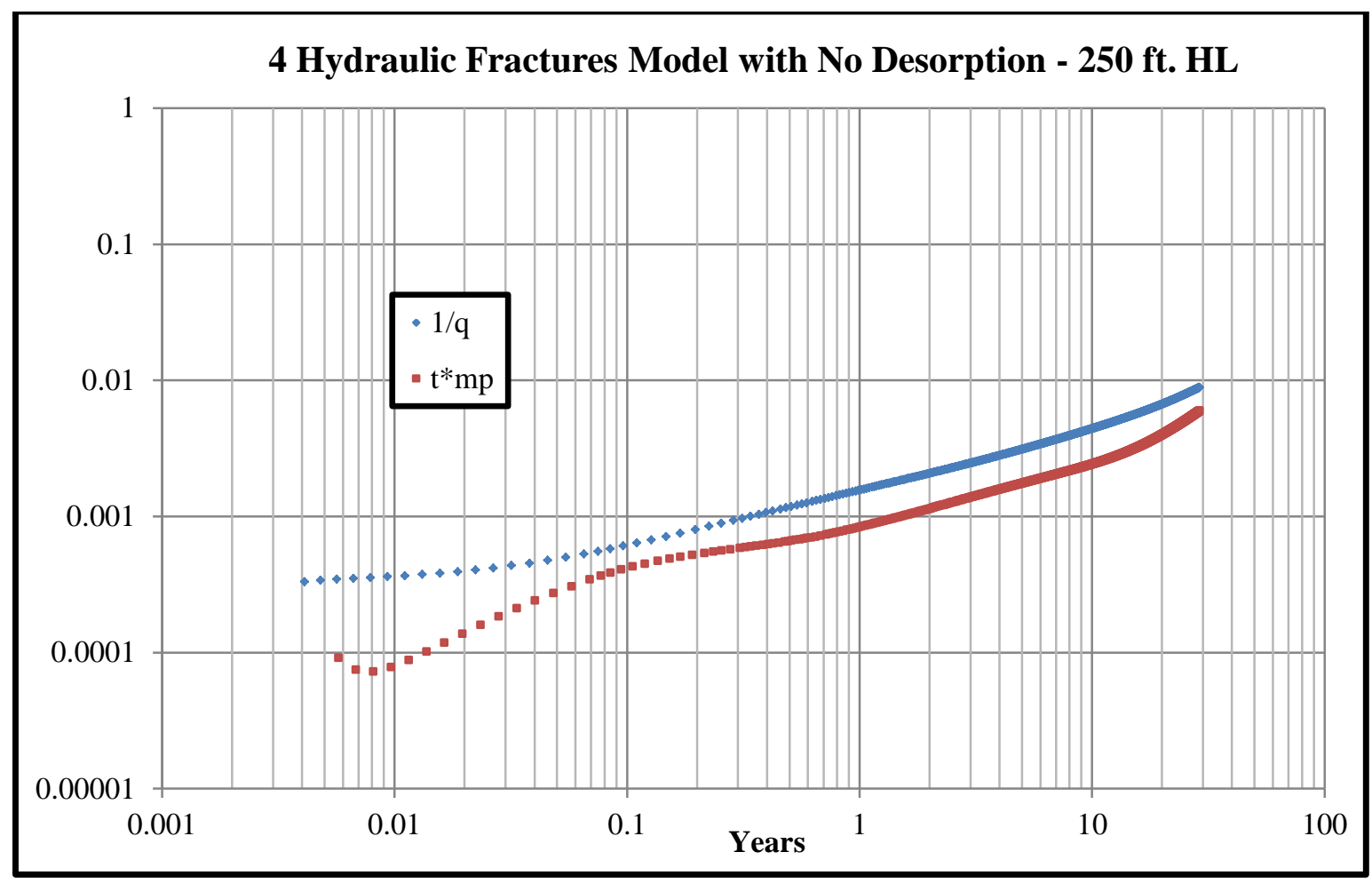

Figure 42 - Appendix C-3: Diagnostic Plot for the model w/ no desorption-250 ft Half-length (4HFs)

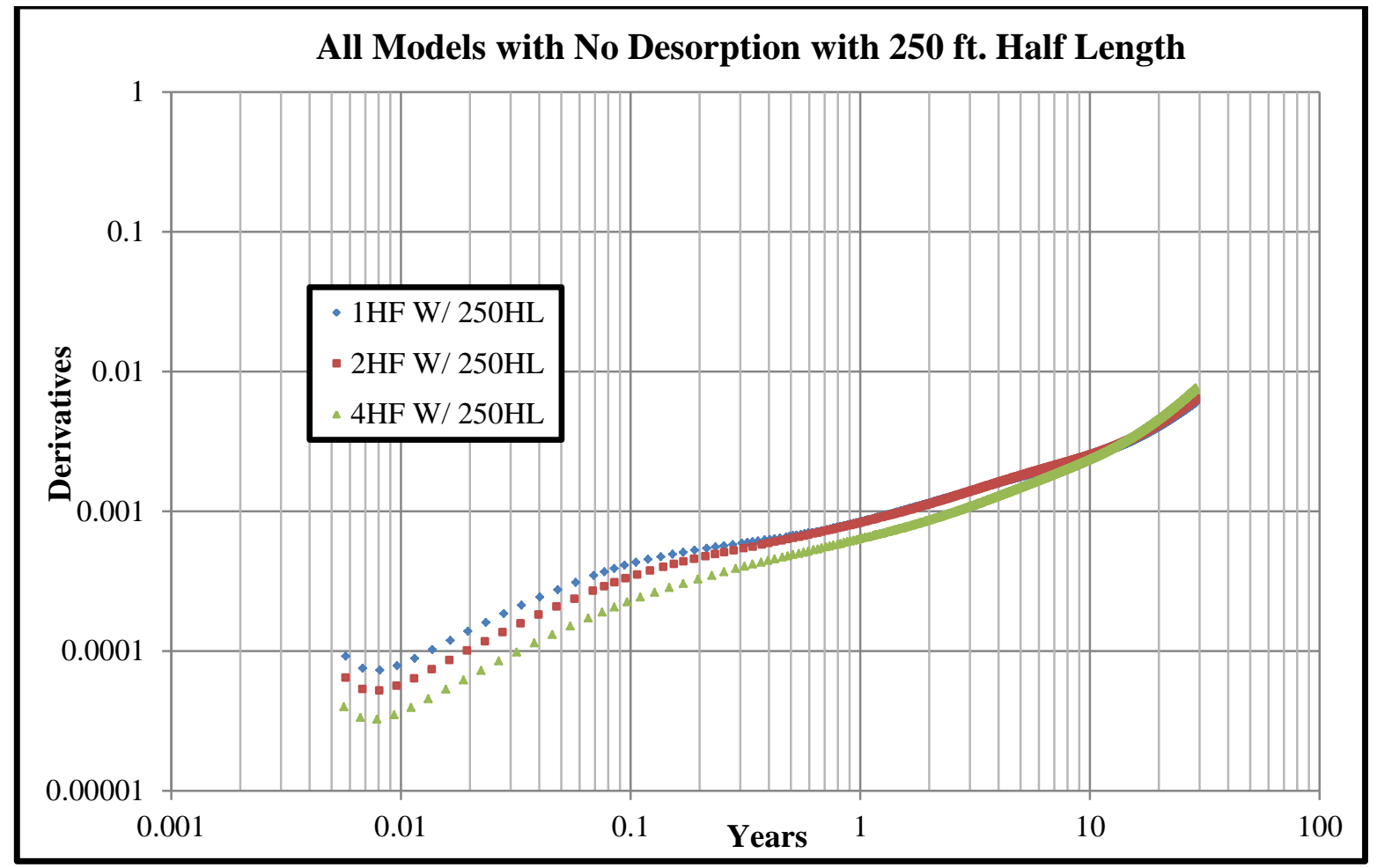

Figure 43 - Appendix C-4: Diagnostic Plot for the model w/ no desorption-250 ft Half-length 


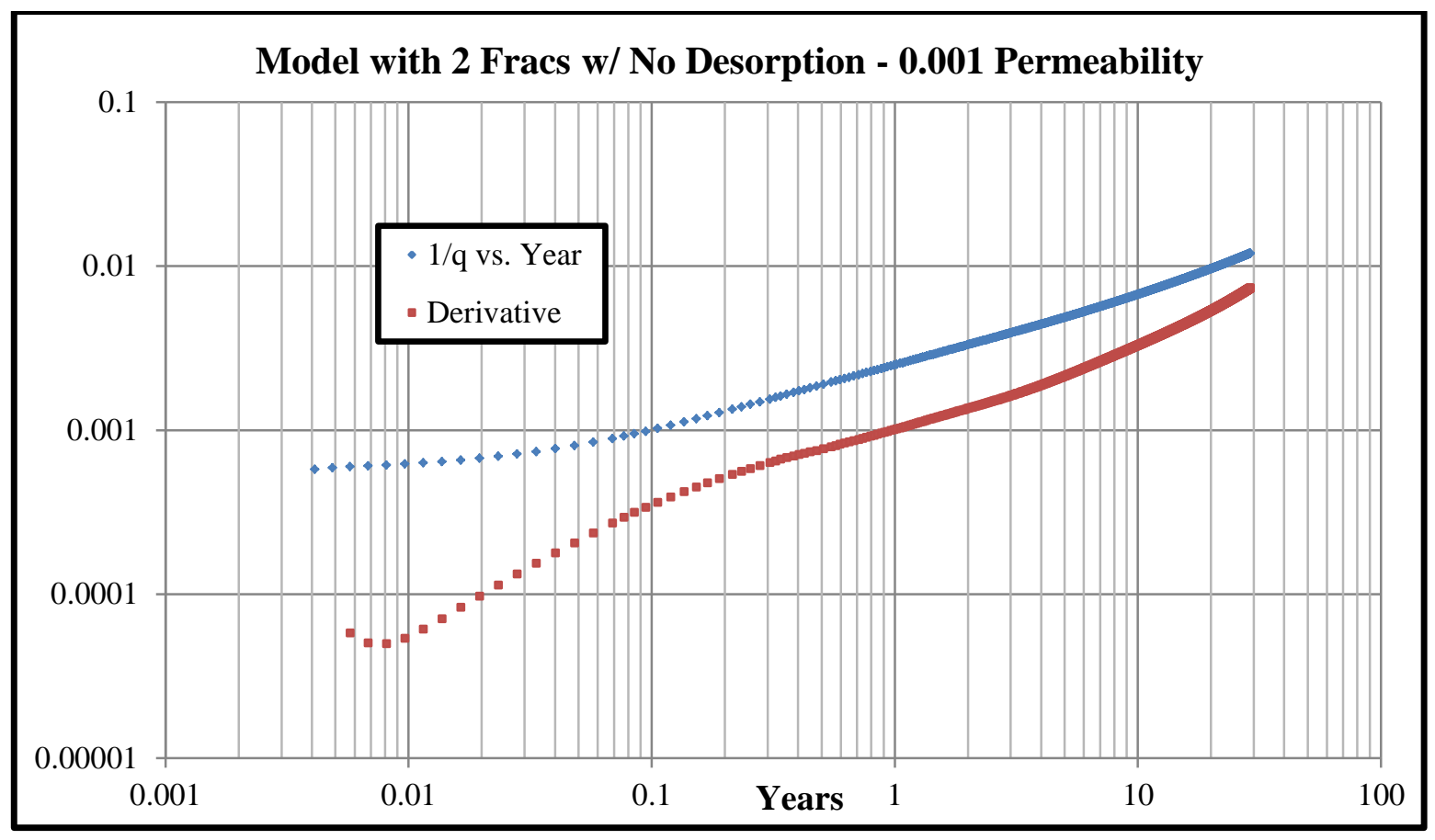

Figure 44 - Appendix C-5: Diagnostic plot for model for 2 hydraulic fractures w/ 0.001 permeability

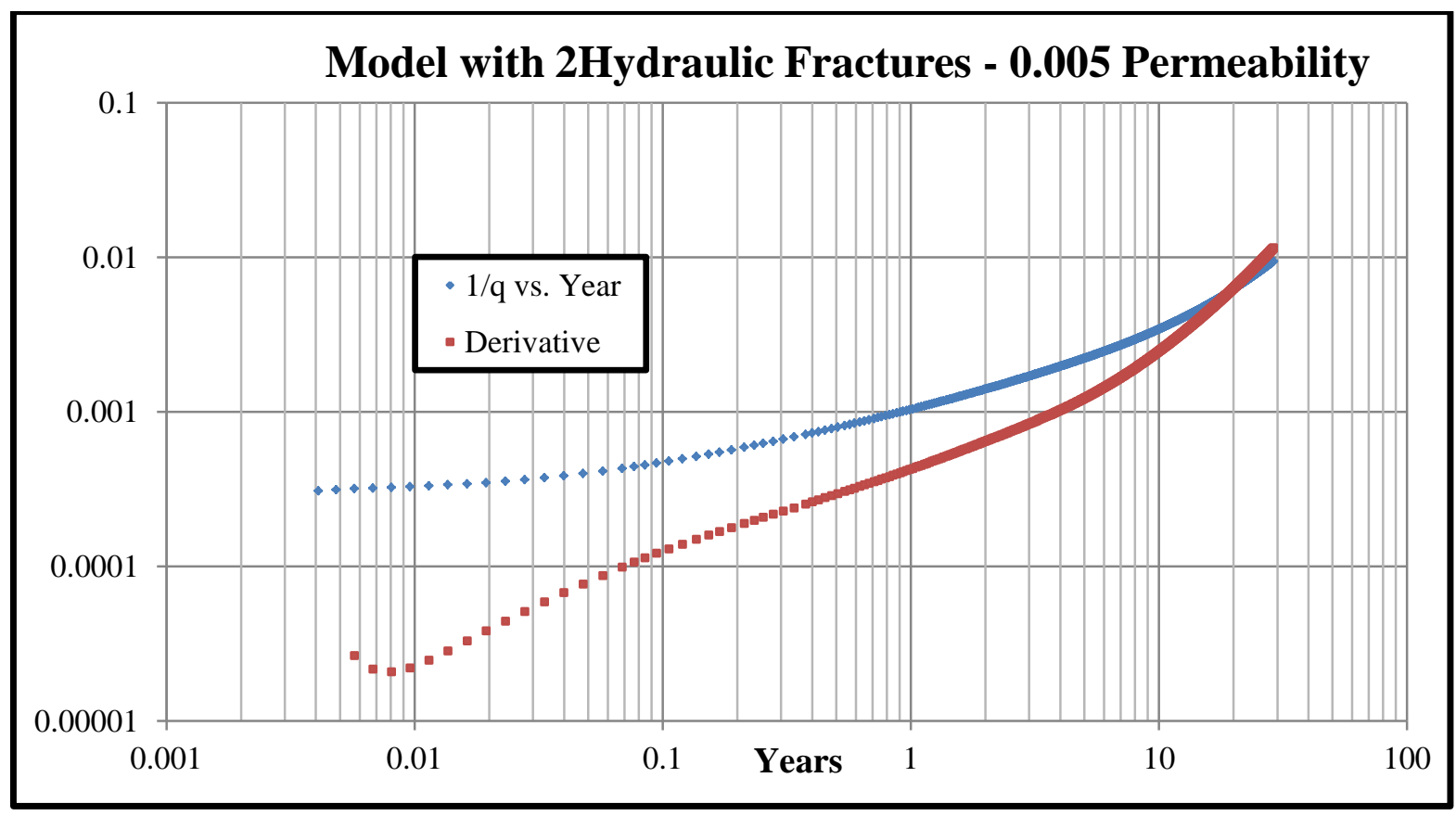

Figure 45 - Appendix C-6: Diagnostic plot for model for 2 hydraulic fractures w/ 0.005 permeability 


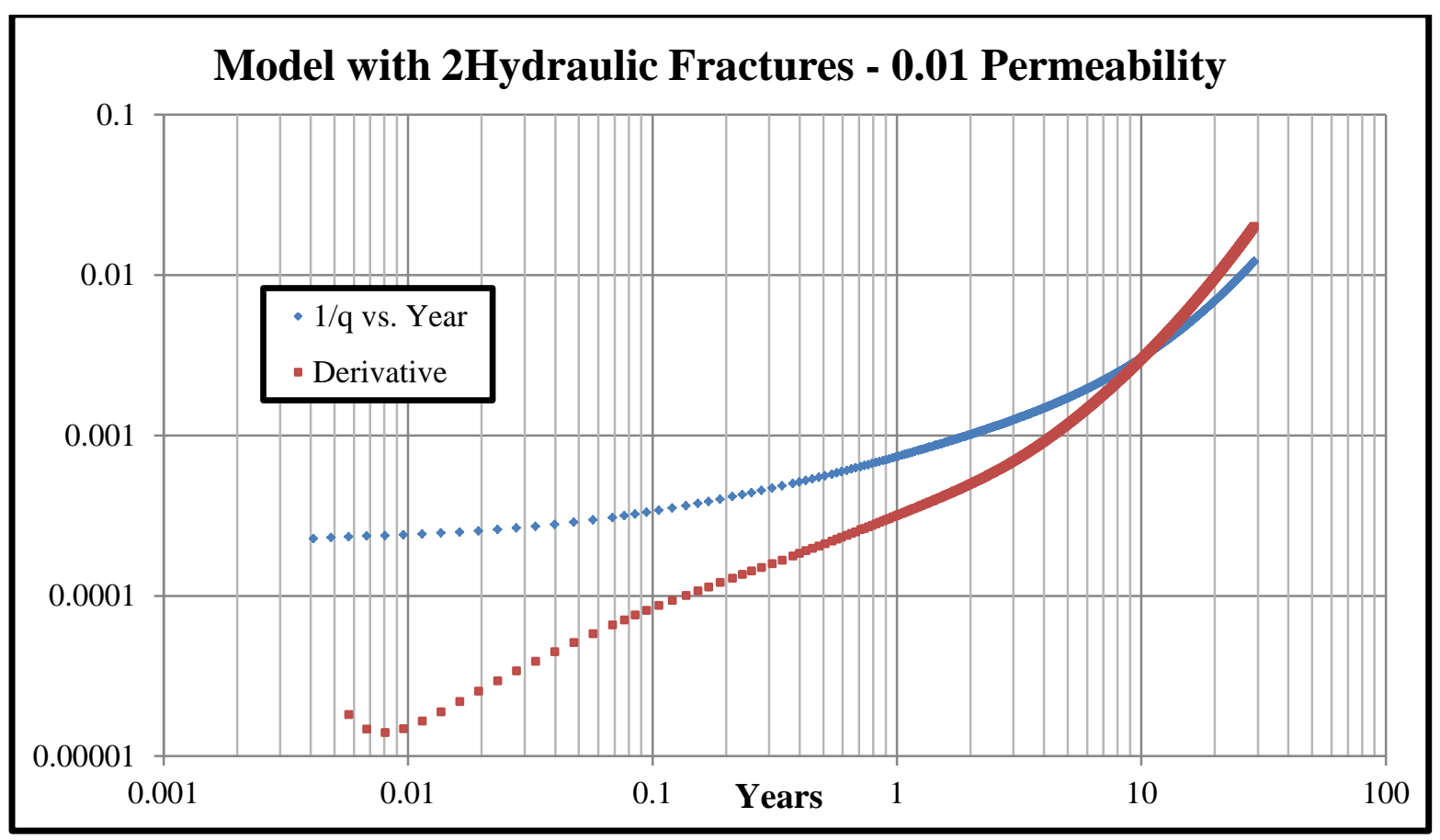

Figure 46 - Appendix C-7: Diagnostic plot for model for 2 hydraulic fractures w/ 0.01 permeability

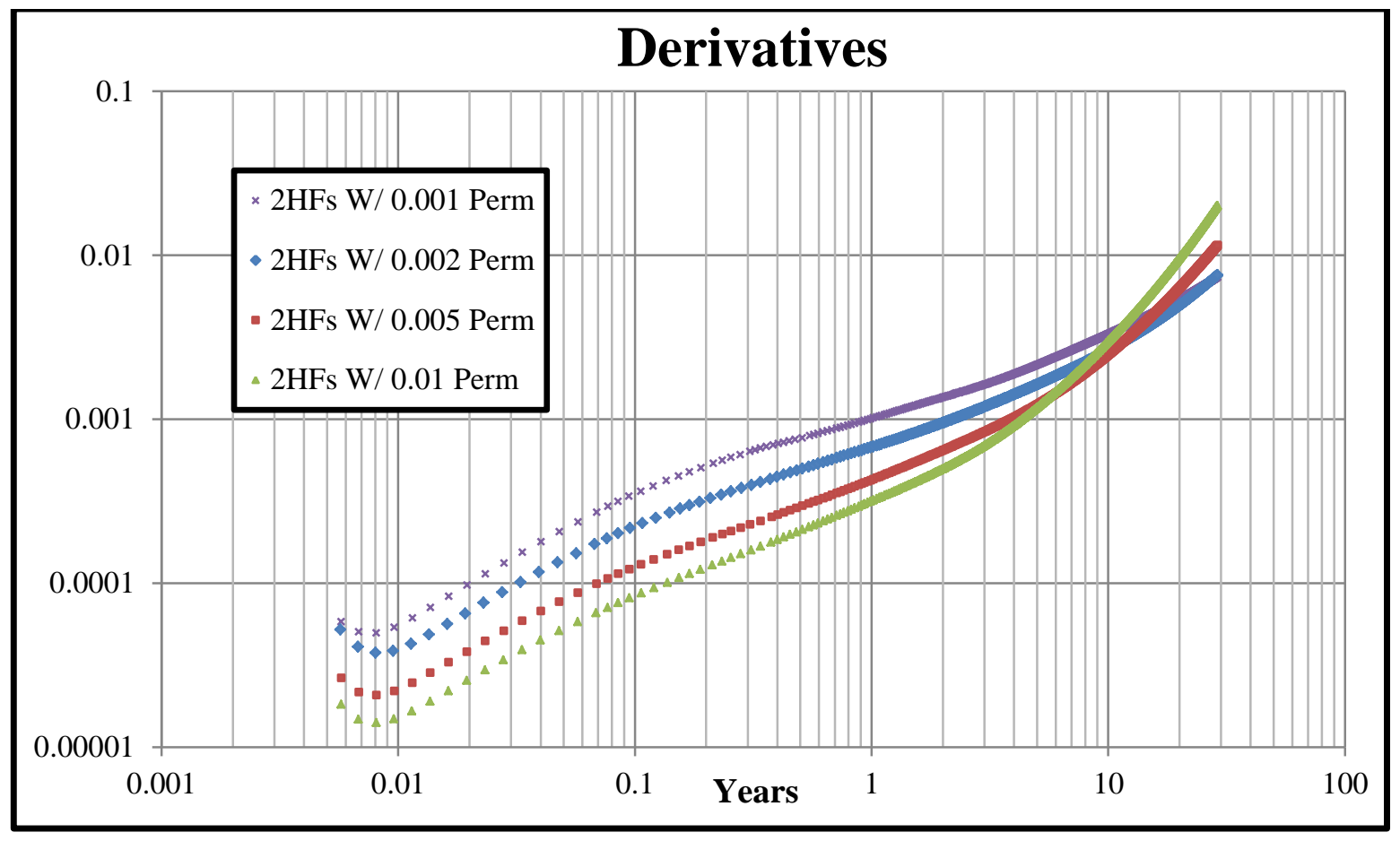

Figure 47 - Appendix C-8: Diagnostic plots for all scenarios for model with 2 hydraulic fractures 


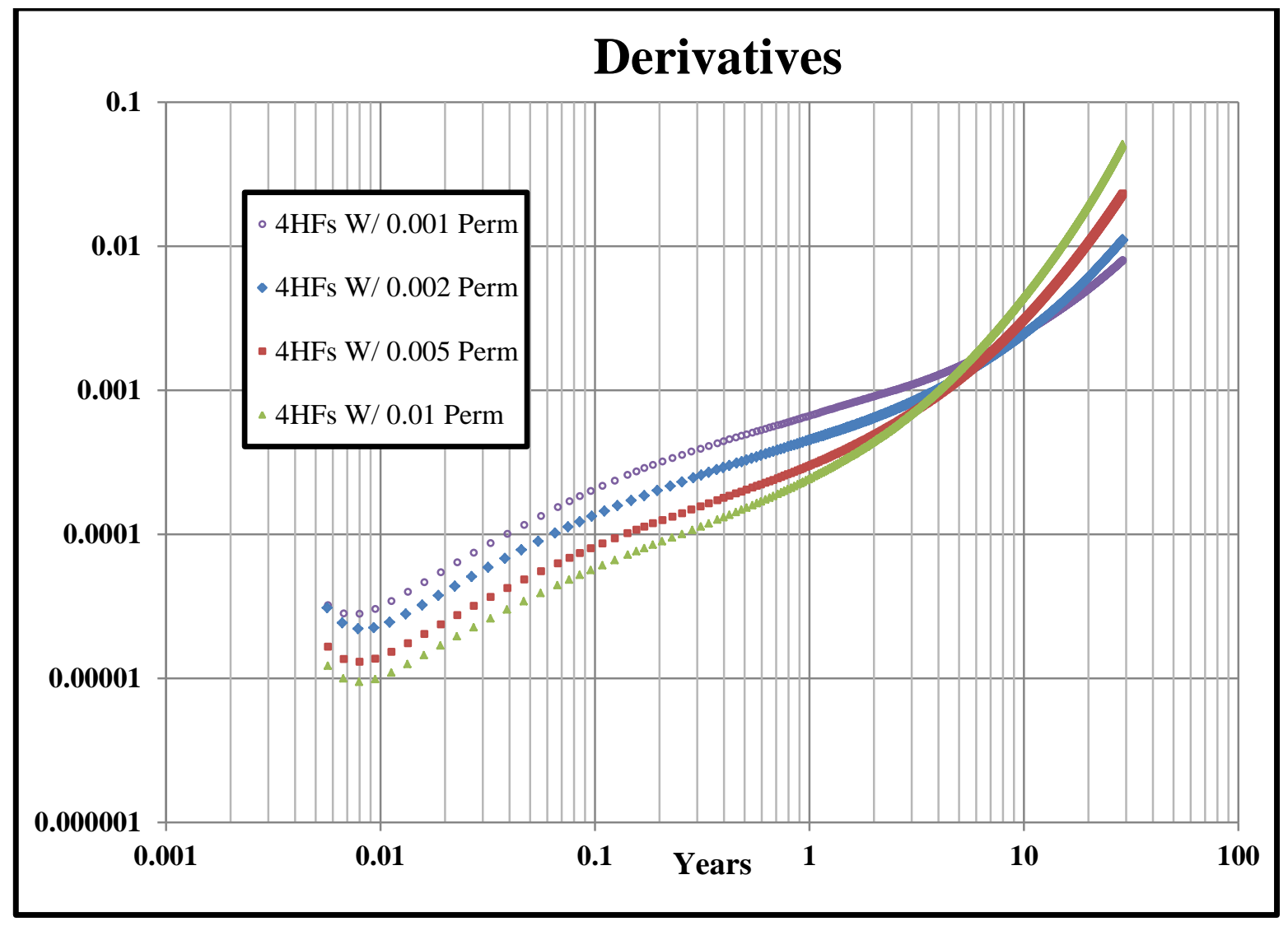

Figure 48 - Appendix C-9: Diagnostic plots for all scenarios for model with 4 hydraulic fractures 